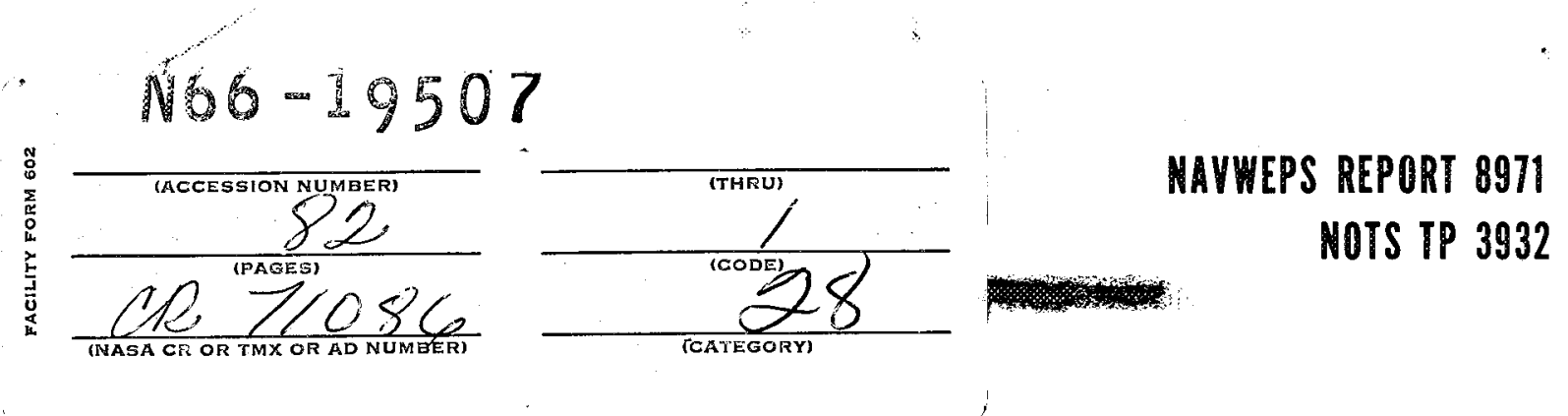

\title{
ACOUSTIC LOSSES OF A SUBSCALE, COLD-FLOW ROCKET MOTOR FOR VARIOUS "J" VALUES
}

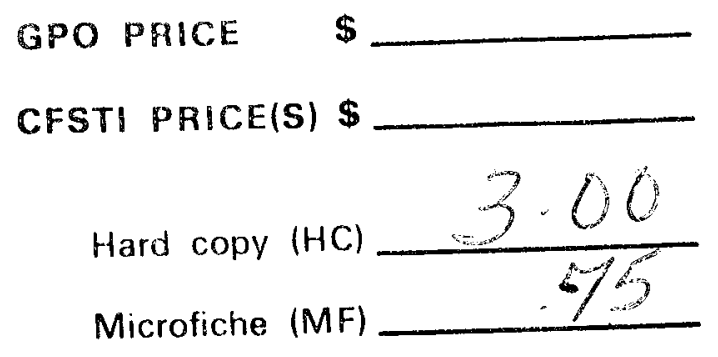

ff 653 July 65 by NASA CR71086.

F. G. Buffum

G. L. Dehority

R. O. Slates

E. W. Price

Research Department

ABSTRACT. Acoustic dissipation studies were undertaken using a subscale, cold-flow rocket motor model to determine the effect of purely geometric variables on the acoustic performance leading to axial mode combustion instability. Cold air served as the working fluid to simulate the internal flow and to obtain a critical nozzle throat condition. Using interchangeable metal parts, it was possible to simulate the geometry of a cylindrical-bore grain at various real motor burn times and also to vary the nozzle throat diameter. The results confirmed the speculation that, for practical motor designs, the radiation of acoustic energy through the nozzle is the largest source of loss for the axial mode and increases with the $J$ of the motor. In view of the change in $J$ with time during burning, this loss can vary conspicuously during the motor burn time.

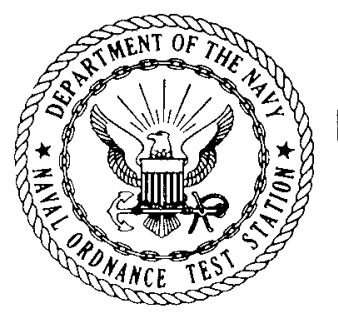

U.S. NAVAL ORDNANCE TEST STATION China Lake, California February 1966 


\title{
U. S. NAVAL ORDNANCE TEST STATION
}

AN ACTIVITY OF THE BUREAU OF NAYAL WEAPONS

\author{
J. I. HARDY, CAPT., USN \\ Commander \\ WM. B. McLean, Ph.D. \\ Technical Director
}

FOREWORD

This report describes the results of the second of a series of experiments studying the effect of geometrical variables on solid rocket combustion instability. Specifically, the present work was undertaken to obtain acoustic loss data for $J$ changes in a cylindrical geometry, subscale, cold-flow rocket motor and to provide the design criteria for an improved measurement system.

The results of the first experiments are reported in NAVWEPS Report 8643, "Attenuation of Axial Acoustic Modes in a Model Missile Motor."

The present work was performed by the Aerothermochemistry Group of the Research Department during the period of October 1964 - July 1965. The research work and the report were done under sponsorship of NASA Work Order WO-3034.

This report is released at the working level for information purposes and does not represent the final judgment of the Station.

Released by

HUGH W. HUNTER, Head, Research Department 27 January 1966
Under authority of WM. B. McLEAN

Technical Director

NOTS Technical Publication 3932 NAVWEPS Report 8971

Published by. . . . . . . . . . . . Research Department Collation... . . Cover, 37 leaves, DD Form 1473 , abstract cards First printing. . . . . . . . . . . 215 unnumbered copies Security classification............... . . . UNCLASSIFIED 
CONTENTS

Nomenclature .. . . . . . . . . . . . . . v

Introduction ....................... 1

Theory of the Experiment . . . . . . . . . . . . . 2

Apparatus. . . . . . . . . . . . . . . . . 3

Instrumentation. . . . . . . . . . . . . . . . 7

Model Chamber Pressure . . . . . . . . . . . . 13

Prechamber Pressure Osciliations . . . . . . . . . 17

Frequency of Oscillation . . . . . . . . . . . . 17

Temperature. . . . . . . . . . . . . . . 17

Calibration and Sensitivity Data........... . . 17

Other Instrumentation. . . . . . . . . . . . 18

Test Procedure . . . . . . . . . . . . . . . 19

Data Reduction . . . . . . . . . . . . . 20

Results and Discussion ................... 23

Test Results..................... 23

Loss Analysis. . . . . . . . . . . . . . . . . 36

Comparison of Present Results with Theory. . . . . . . . 40

Resonant Frequency . . . . . . . . . . . . . 43

Conclusions. . . . . . . . . . . . . . . . 44

Appendixes :

A. Evaluation of Model and Instrument System. . . . . . . 46

B. Comparison of Loss Measurement Using Various Decay

Techniques ................. 54

References .................. . 70 
NOMEN CLATURE

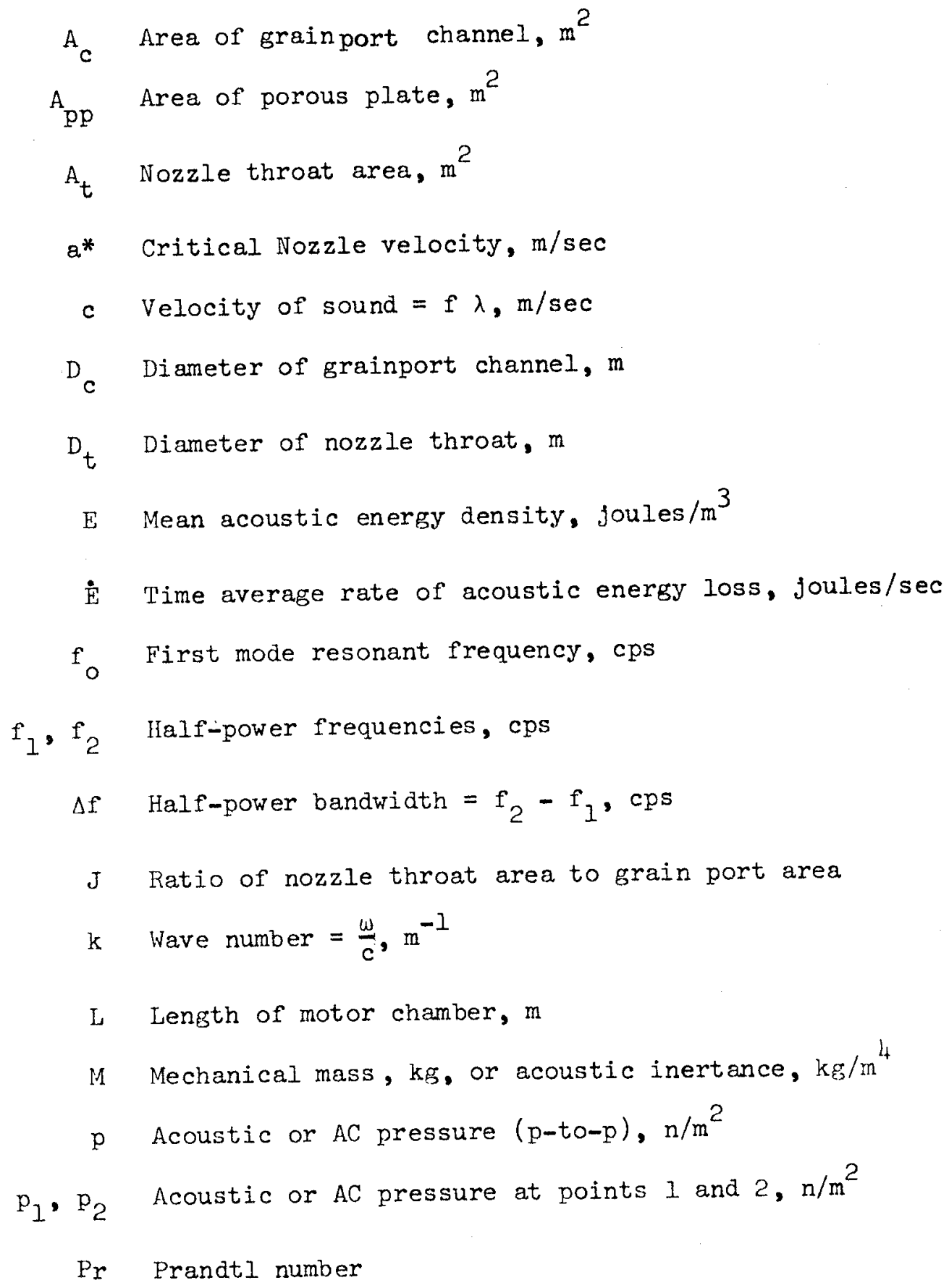




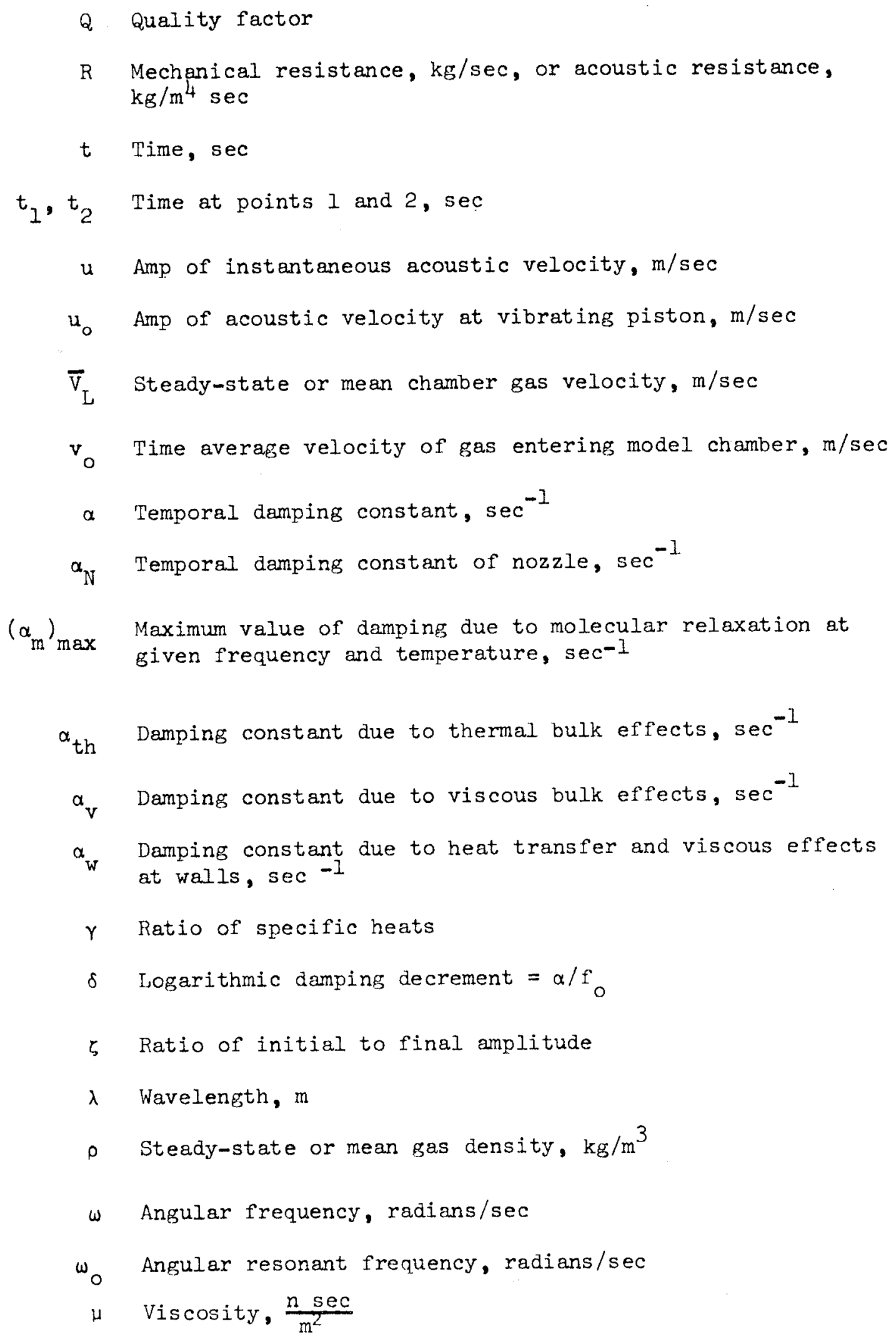




\section{INTRODUCTION}

The most prevalent form of unstable combustion in rocket motors, aptly termed acoustic instability, involves gas oscillations having the frequencies and other physical characteristics associated with one or several of the acoustic modes of the motor cavity. Experimental research has shown that pressure variations in the rocket motor are amplified by the combustion zone near the propellant surface (Ref. 1). Control of acoustic instability may be achieved by lowering the "amplification factor" of the combustion zone (i.e., changing the propellant) or by increasing the acoustic losses of the motor cavity (i.e., changing the internal geometry of the motor). The present work reports the results of an experimental program to determine the effect of motor geometry and operating conditions on these acoustic losses.

In a previous experiment, equipment and techniques were developed for experimentally determining the acoustic characteristics of model motor cavities having a number of internal area changes, cavities, projections, and other geometrical complexities (Ref. 2). In the present case, the primary concern is with the geometrically simpler problem of determining the relation between the acoustic losses in axial modes and the $J$ value of the cavity (the ratio of the nozzle throat area to the propellant grain port area). Other things being equal, a geometry having high acoustic losses in the natural acoustic modes of the combustion chamber should result in relatively stable combustion.

The experimental method used consisted of introducing an acoustic source into a model motor and observing the sound levels of the axial mode resonances during a "firing." Cold, high pressure air was used to simulate the propellant gas flow in the model. This flow was maintained so as to bring the model chamber to a pressure sufficient to obtain sonic flow at the nozzle, thereby assuring a downstream acoustic boundary condition similar to that found in an actual rocket motor. The oscillatory behavior was induced at the forward end of the model chamber by using an oscillating pressure in the inlet air. During a test, the frequency of this oscillation was changed slowly through the range of interest.

The resonant frequencies of a given chamber configuration were determined by noting the frequencies of maximum chamber amplitude as detected by a pressure transducer mounted at the head of the chamber. Using a selection of aluminum sleeves and detachable nozzle end plates, 
the effect of changes in $J$ (corresponding to a progression of burning and to a change in the nozzle size) could be examined. Motor size effects could be studied for the same J geometries by simultaneously changing the aluminum grain and the nozzle end plate.

The experimental results confirmed the speculation that, for practical motor designs, the radiation of energy through the nozzle is the largest source of acoustic loss for the axial mode and that this loss increases approximately linearly with the $J$ of the motor.

In the following sections, the equipment, instrumentation and test procedures, as developed for these tests, are first considered. The means of characterizing the acoustic behavior of the motor cavity, together with a discussion of the variables measured is considered under the section on Data Reduction. The experimental data are presented and interpreted under Results and Discussions. The results are summarized in the Conclusions. Appendix $A$ is an evaluation of the capabilities of the present test equipment. Appendix $B$ discusses various decay rate measurement techniques which were developed during these tests and compares the results with the present work.

The preliminary results of this work were reported at the Interagency Chemical Rocket Propulsion Group Combustion Instability Conference, Orlando Air Force Base, Florida, 16-20 November 1964 (Ref. 3) together with a summary of past work using more complicated internal motor geometries (Ref. 2) and a discussion of more recent decay measurement techniques that have been developed in conjunction with the axial mode instability program. How the present work fits into the general instability picture together with references to other theoretical and experimental studies on the effect of internal geometry on losses and stability is presented in a survey paper on experimental solid rocket combustion instability (Ref. 1 ).

\section{THEORY OF THE EXPERIMENT}

The principles applied in the measurement technique are essentially those applicable to a lumped parameter system under forced vibration (Ref. 4, p. 319). That is, if there is an acoustic excitation of constant strength, of a single frequency, and if this frequency is the same as one of the normal modes of the chamber, resonance will occur. At this resonance frequency, the driving system will supply maximum power to the oscillator. When the driving frequency is not at one of the natural frequencies of the system, the acoustic pressure in the model chamber builas up to a lesser degree. If the acoustic pressure in the chamber is then plotted as a function of the driving frequency, a resonance curve is obtained. As is described below, the driving frequency was very slowly increased through the region of interest so as to maintain essentially steady-state oscillations in the chamber. 
More precisely, this might be termed quasi-steady-state operation. From the shape or sharpness of the resulting acoustic pressure response curve, it is possible to deduce certain properties of the system. The sharpness of this curve can be quantitatively assessed using a quality or $Q$ factor. For simple systems, $Q$ is related to the acoustic attenuation constant. By determining the $Q$ for various simple geometries, the variation of the attenuation constant as a function of motor configuration could be determined.

\section{APPARATUS}

The experimental apparatus used in making these tests consisted of a model motor chamber; a steady air supply capable of maintaining sonic flow in the nozzle of the model; a variable-frequency, oscillating air supply to drive the chamber; and instrumentation to detect and record the resulting chamber behavior.

The model was pressurized by flow through a high impedance porous metal plate at the forward end of the model. Flow through the plate was maintained by a prechamber connected to a high pressure air storage system. The pressure was controlled by regulating valves. A schematic diagram of the air feed system is given in Fig. 1 .

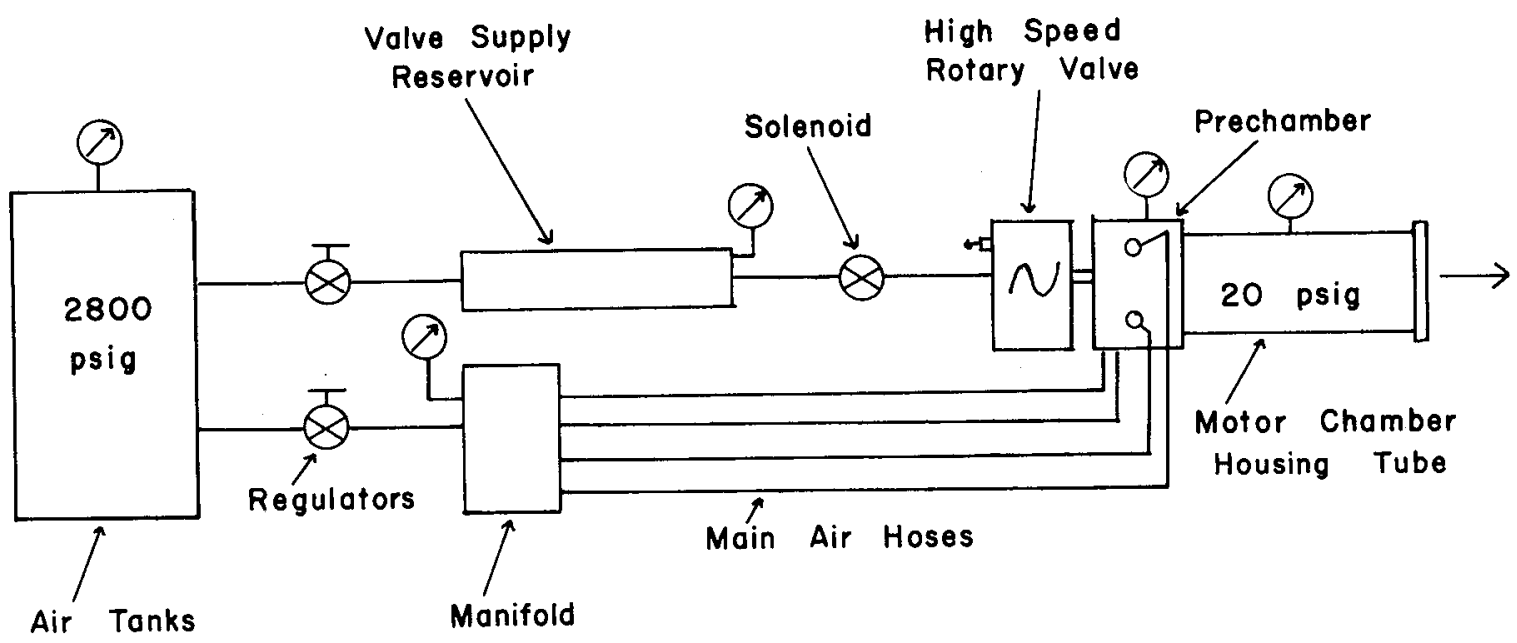

FIG. 1. Schematic of the Air Flow Feed System Used for Steady-State Loss Measurements.

The main air flow was regulated from the 2,800 psi storage tanks and manifolded to the motor prechamber through four lengths of No. 1509 0.375 -inch Aeroquip hose. The hose was acoustically isolated from the 
prechamber by a porous plate at the prechamber inlet. The smaller volume of air for the modulated air supply was fed through a pressure regulator and a 35 -foot section of 0.375 -inch steel tubing to a 1.5 -inch ID section of flexible hose, through the rotary valve, and into the prechamber.

The U. S. Naval Ordnance Test Station (NOTS) designed rotary valve was used to produce a sinusoidal pressure forcing function in the prechamber. The valve consisted of a rotating cylinder with a balanced slot arrangement driven by a 5-hp, variable speed (Varidrive) motor. The valve was designed to provide six cycles of alternate inflow and exhaust (to the atmosphere) per cycle of valve rotation, Fig. 2. The output waveform depended on the outlet and inlet pressure ratios and the orientation and shape of the rotor slots. Using this system, the prechamber driving frequency could be varied from approximately 180 to $1300 \mathrm{cps}$ with a nearly sinusoidal wave form. The valve output was introduced at one end of the prechamber.

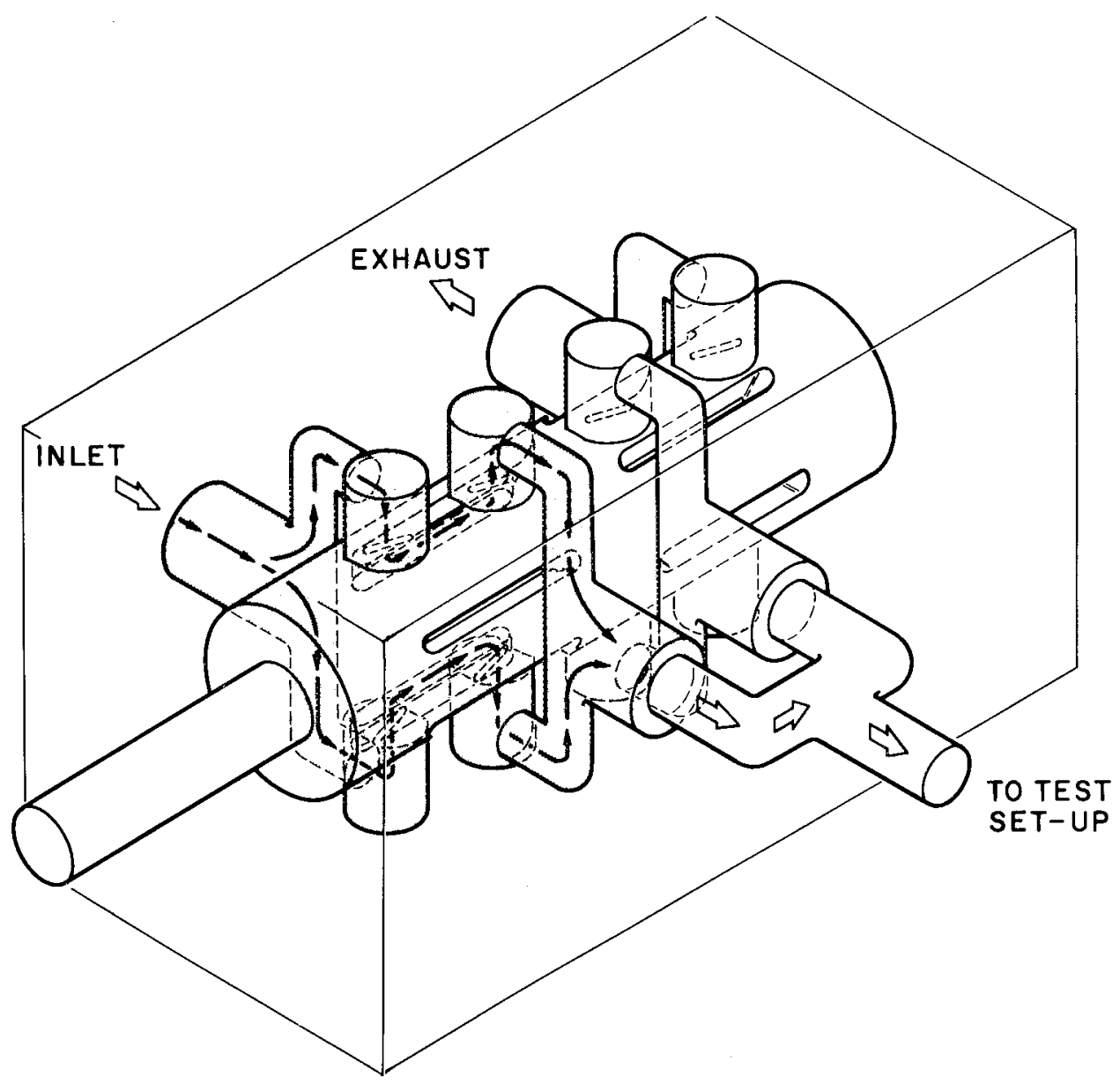

FIG. 2. The NOTS Designed Rotary Valve for Oscillating a Portion of the Incoming Air Flow. 
The prechamber was used to unite the steady and pulsating supply flows. A detailed drawing of the prechamber is given in Fig. 3, and a sketch showing the relation of the prechamber housing to the motor tube is given in Fig. 4. The oscillating flow from the rotating valve entered the prechamber cavity directly from an axial port at the head end. Four side ports located concentrically around the head of the prechamber were used to provide the main air supply. This steady air flow entered the prechamber by passing through an annular disk of 0.125 -inch thick, 40-micron, porous, sintered stainless steel reinforced on the downstream side by an annulus of screening material and a 0.125 -inch thick sheet of perforated stainless steel plate. This was done to acoustically isolate the prechamber from the main air-feed system and thereby minimize acoustic losses and supply line resonances.

The inside dimensions of the prechamber cavity formed a cylindrical cavity approximately 2 inches in diameter and 2 inches in length. The natural frequency of this cavity was about $3,000 \mathrm{cps}$, several times any frequencies of interest during the tests.

The prechamber was separated from the test chamber by a second porous plate sandwiched between annular rings of screening and a perforated steel plate. This high impedance barrier was introduced in hopes that the model chamber could be driven by the large amplitude oscillations in the prechamber without any appreciable feedback or reverse coupling from the chamber.

A 100 psia, Model 4-312, Consolidated Electrodynamics Corporation (CEC) pressure transducer was mounted at the head of the test chamber so that its sensing face was flush with the outer face of the last perforated plate of the prechamber, thereby forming an integral part of the chamber head (Fig. 3). The body of the transducer passed through a close-fitting hole in the perforated steel-porous plate-perforated steel sandwich.

Figure 5 shows the Varidrive motor shaft and disassembled prechamber which shows the rotating valve port and main supply line baffle plate, the transducer, and the porous plate. Figure 6 shows the assembled and instrumented prechamber with connecting air hoses.

The simulated rocket motor consisted of an external housing into which cylinders with various internal diameters could be fitted to simulate a cylindrical bore propellant grain at various burn times. The chamber housing itself consisted of a 12-inch-long piece of flanged aluminum tubing, 3.5-inch internal diameter and 4.5-inch external diameter, bolted onto the exit face of the prechamber.

The grain pieces were aluminum circular cylinders, 12 inches long, with an $O D$ of 3.5 inches, and with various internal diameters. Work reported in Ref. 2 showed that there was little or no difference when 


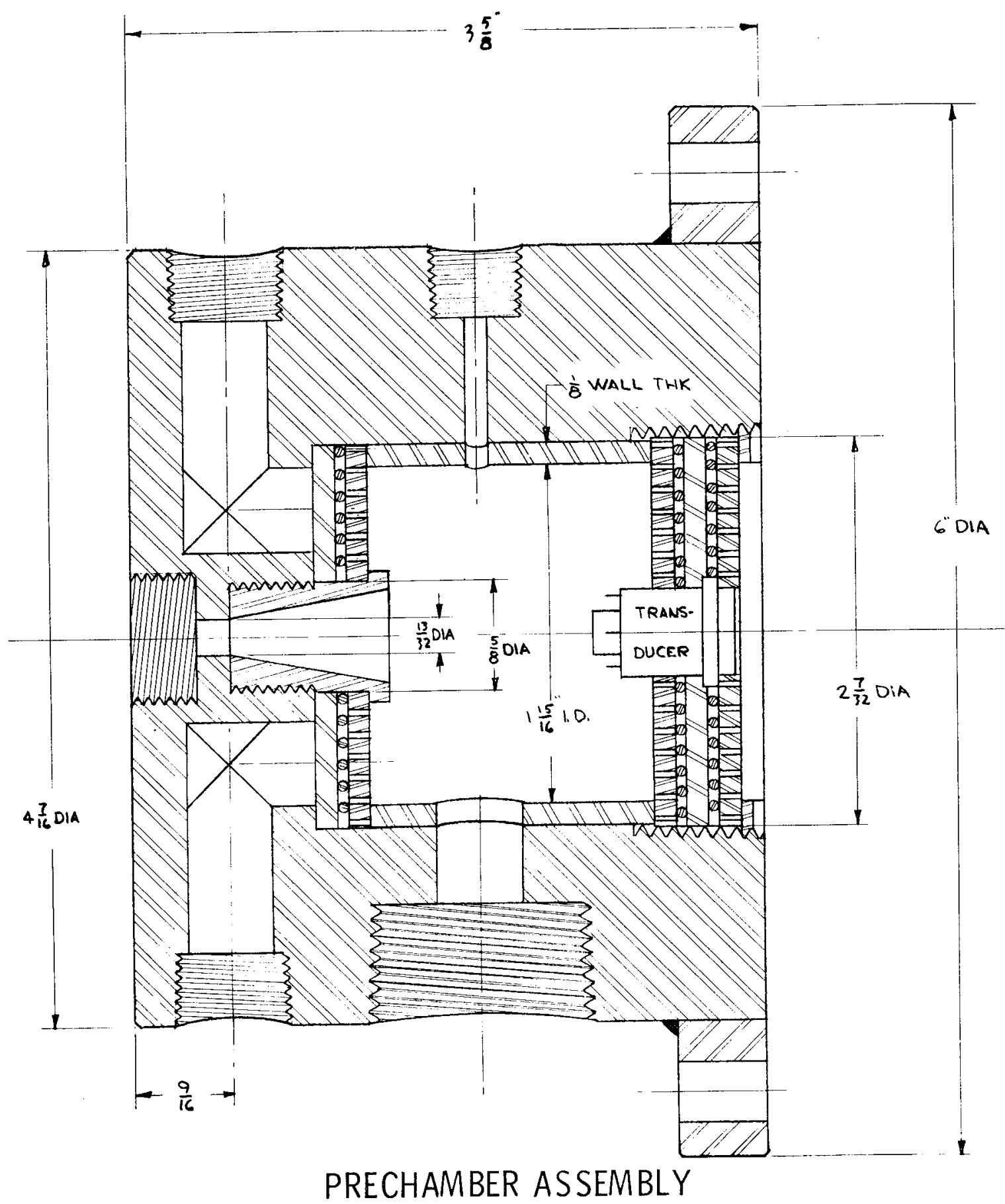

FIG. 3. Cross-Sectional View of the Prechamber Assembly used to Unite the Steady and Pulsing Flows Prior to Entering the Model Chamber. 


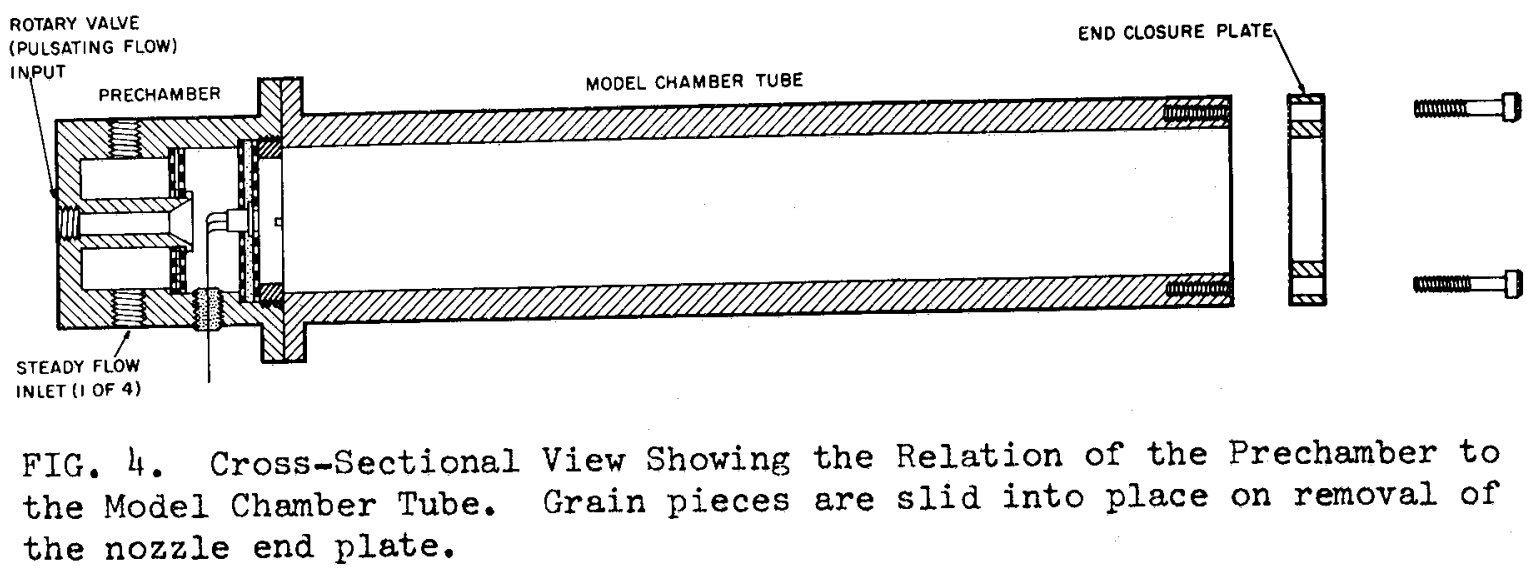

these grain pieces were made of metal rather than an extruded cellulose acetate such as would be used for the binder material in an actual propellant. The internal diameters tested in the present work were 1.0 , $1.5,2.0,2.5,3.0$ and 3.5 inches.

The nozzle blocks were of 0.5 -inch aluminum plate bolted onto the end of the motor housing tube. The nozzle throat diameters were of different sizes so that the J (nozzle throat area/grain port area) could be altered in this way as well as with the grain pieces. The total range of $J$ values that could be covered using both means was from 0.390 to 0.00127 . Table 1 gives the code used to identify the test configurations as well as the nozzle throat diameter, the grain port diameter, and the $J$ calculated from these data. The variable nozzle blocks also allowed for changing the mass flow rates down the grain axis. The inlet radius of the nozzle was 0.125 inch in all cases. This was followed by a straight throat section, approximately 1/32-inch long. The nozzle throats were $0.125,0.250,0.375,0.500$ and 0.625 inches in diameter. The nozzle exit cone was cut at $45^{\circ}$ from the flat throat section. A drawing listing the specifications for these nozzles is given in Fig. 7 .

A photograph of the assembled test equipment is shown in Fig. 8 .

\section{INSTRUMENTATION}

A combination of mechanical and electrical instruments was necessary for controlling and recording the air flow and acoustic behavior. Bourdon tube gages provided visual readout of the steady or DC air pressure at points in the flow system where visual monitoring was needed to manually control the air pressure. These pressure gages are indicated by dials in Fig. 1 . 


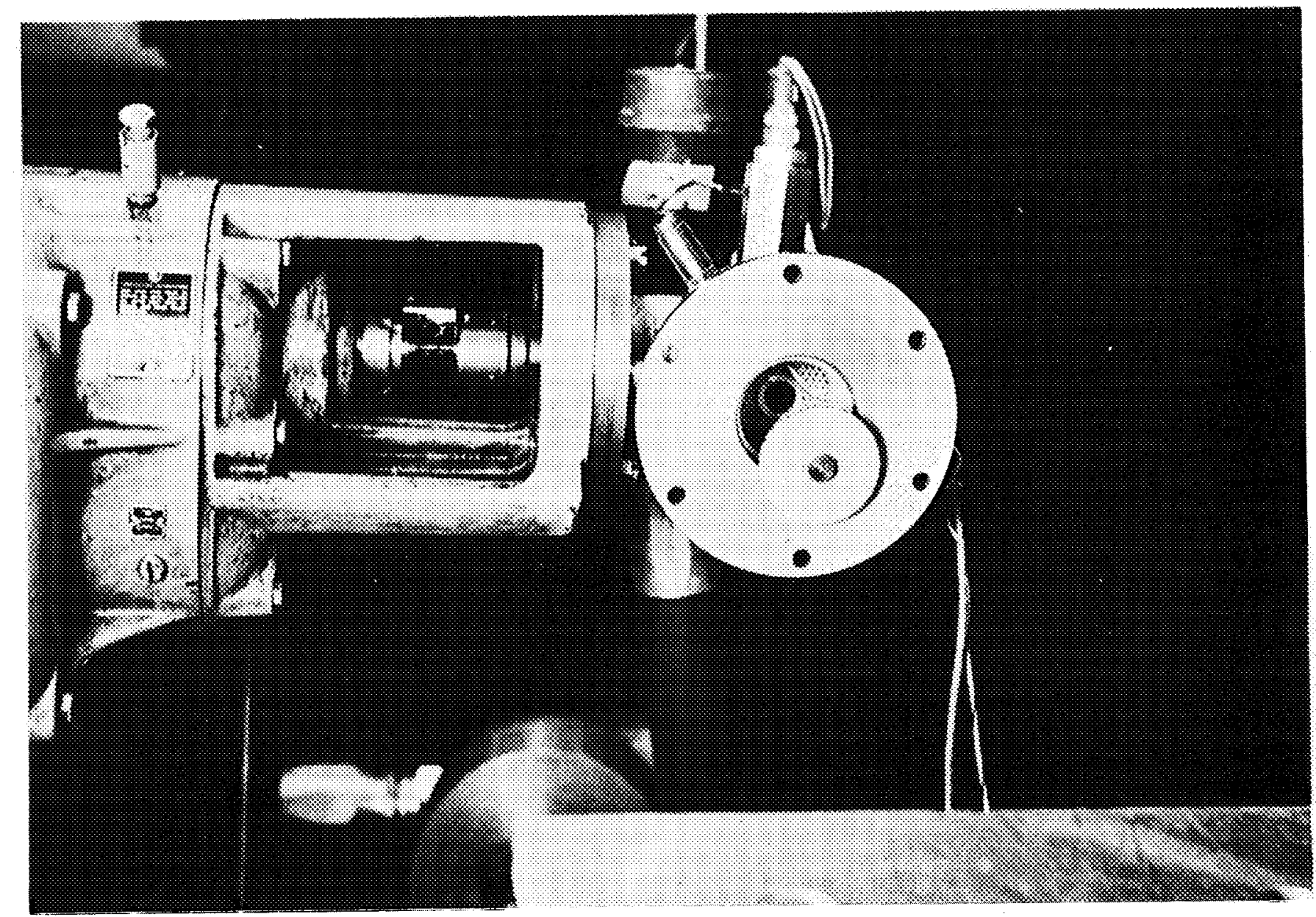

FIG. 5. Disassembled Prechamber Unit Showing Shaft of Varidrive Unit Used to Turn the Rotary Valve, the Interior Face Through Which Main Air Passed, the Entrance Hole for the Pulsed Flow, and the Sintered Steel Plate Used to Separate Prechamber and Chamber With a Transducer at Its Center. 


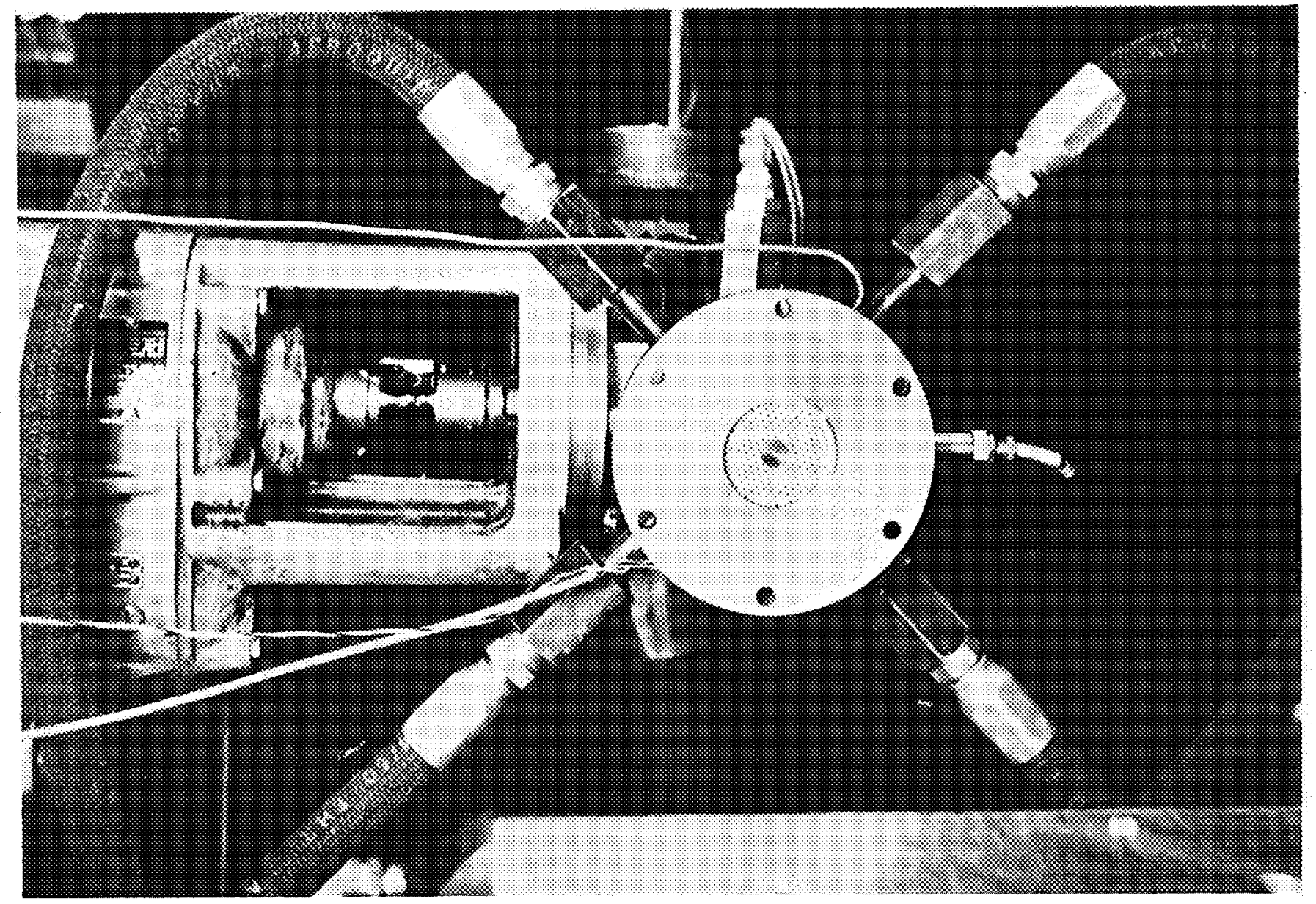

FIG. 6. Assembled Prechamber Unit Showing Four Hoses Used to Bring Main Air to the Prechamber, the Valve Supply Reservoir Hose, the Perforated Steel Disks Used to Support the Sintered Steel, and the Flush Mounted Transducer Face. The chamber tube was bolted directly to this face. 
TABLE 1. Geometry Data for Model Configurations

\begin{tabular}{|c|c|c|c|}
\hline $\begin{array}{l}\text { Configuration } \\
\text { number }\end{array}$ & $\begin{array}{c}\text { Grain port } \\
\text { diameter, } \\
\text { inch }\end{array}$ & $\begin{array}{l}\text { Throat } \\
\text { diameter, } \\
\text { inch }\end{array}$ & $J=\frac{D_{t}^{2}}{D_{c}^{2}}$ \\
\hline $\begin{array}{l}1-1 \\
2-1 \\
3-1 \\
4-1 \\
5-1 \\
6-1\end{array}$ & $\begin{array}{l}1.0 \\
1.5 \\
2.0 \\
2.5 \\
3.0 \\
3.5\end{array}$ & $\begin{array}{l}0.625 \\
0.625 \\
0.625 \\
0.625 \\
0.625 \\
0.625\end{array}$ & $\begin{array}{l}0.3906 \\
0.1736 \\
0.0976 \\
0.0625 \\
0.0434 \\
0.0319\end{array}$ \\
\hline $\begin{array}{l}1-2 \\
2-2 \\
3-2 \\
4-2 \\
5-2 \\
6-2\end{array}$ & $\begin{array}{l}1.0 \\
1.5 \\
2.0 \\
2.5 \\
3.0 \\
3.5\end{array}$ & $\begin{array}{l}0.500 \\
0.500 \\
0.500 \\
0.500 \\
0.500 \\
0.500\end{array}$ & $\begin{array}{l}0.250 \\
0.111 \\
0.0625 \\
0.0400 \\
0.0278 \\
0.0204\end{array}$ \\
\hline $\begin{array}{l}1-3 \\
2-3 \\
3-3 \\
4-3 \\
5-3 \\
6-3\end{array}$ & $\begin{array}{l}1.0 \\
1.5 \\
2.0 \\
2.5 \\
3.0 \\
3.5\end{array}$ & $\begin{array}{l}0.375 \\
0.375 \\
0.375 \\
0.375 \\
0.375 \\
0.375\end{array}$ & $\begin{array}{l}0.1407 \\
0.0625 \\
0.0351 \\
0.0225 \\
0.0156 \\
0.0115\end{array}$ \\
\hline $\begin{array}{l}1-4 \\
2-4 \\
3-4 \\
4-4 \\
5-4 \\
6-4\end{array}$ & $\begin{array}{l}1.0 \\
1.5 \\
2.0 \\
2.5 \\
3.0 \\
3.5\end{array}$ & $\begin{array}{l}0.250 \\
0.250 \\
0.250 \\
0.250 \\
0.250 \\
0.250\end{array}$ & $\begin{array}{l}0.0625 \\
0.0275 \\
0.0156 \\
0.0100 \\
0.0069 \\
0.0051\end{array}$ \\
\hline $\begin{array}{l}1-5 \\
2-5 \\
3-5 \\
4-5 \\
5-5 \\
6-5\end{array}$ & $\begin{array}{l}1.0 \\
1.5 \\
2.0 \\
2.5 \\
3.0 \\
3.5\end{array}$ & $\begin{array}{l}0.125 \\
0.125 \\
0.125 \\
0.125 \\
0.125 \\
0.125\end{array}$ & $\begin{array}{l}0.0156 \\
0.00695 \\
0.00390 \\
0.00250 \\
0.00173 \\
0.00127\end{array}$ \\
\hline
\end{tabular}



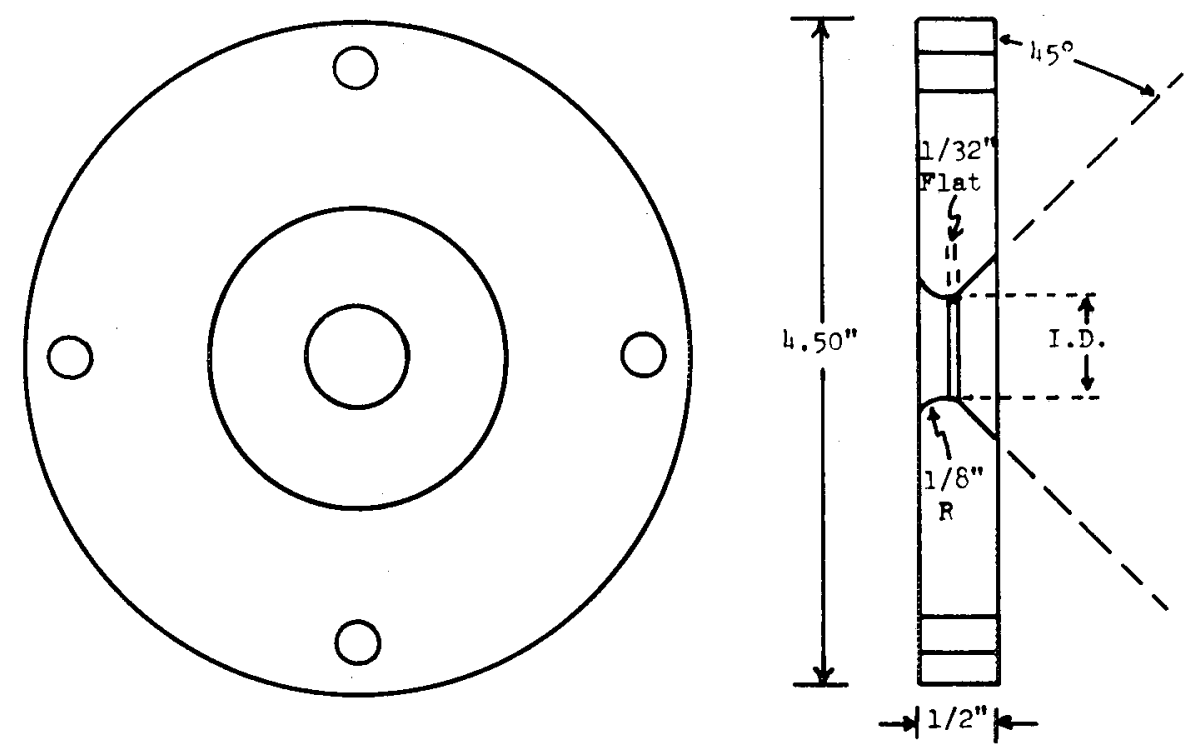

$\left.\begin{array}{l}\text { Make } 5 \text { nozzle plates, } 1 \text { each } \\ \# 1 \text { I.D. }=0.625^{\prime \prime} \\ \# 2 \text { I.D. }=0.500 " \\ \# 3 \quad \text { I.D. }=0.375^{\prime \prime} \\ \# 4 \text { I.D. }=0.250 " \\ \# 5 \text { I.D. }=0.125^{\prime \prime}\end{array}\right\} \begin{aligned} & \text { Tolerance } \\ & \pm 0.0001 "\end{aligned}$

Material:

NI ( $\mathrm{h}^{\mathrm{h}} \mathrm{S}^{\mathrm{m}}$ hardness or similar)

11 holes to be concentric with

4.500" O.D. within 0.00\%" runout

FIG. 7. Prints and Specifications for the Nozzle End Plates. 
- səutT

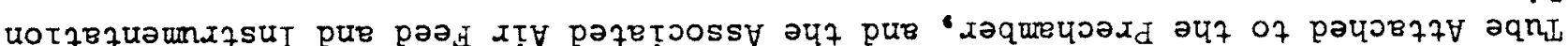

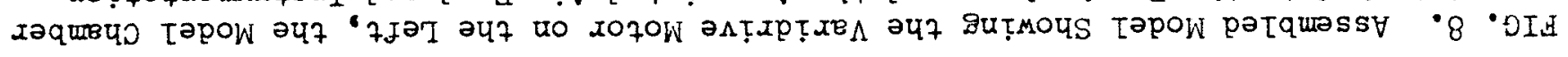

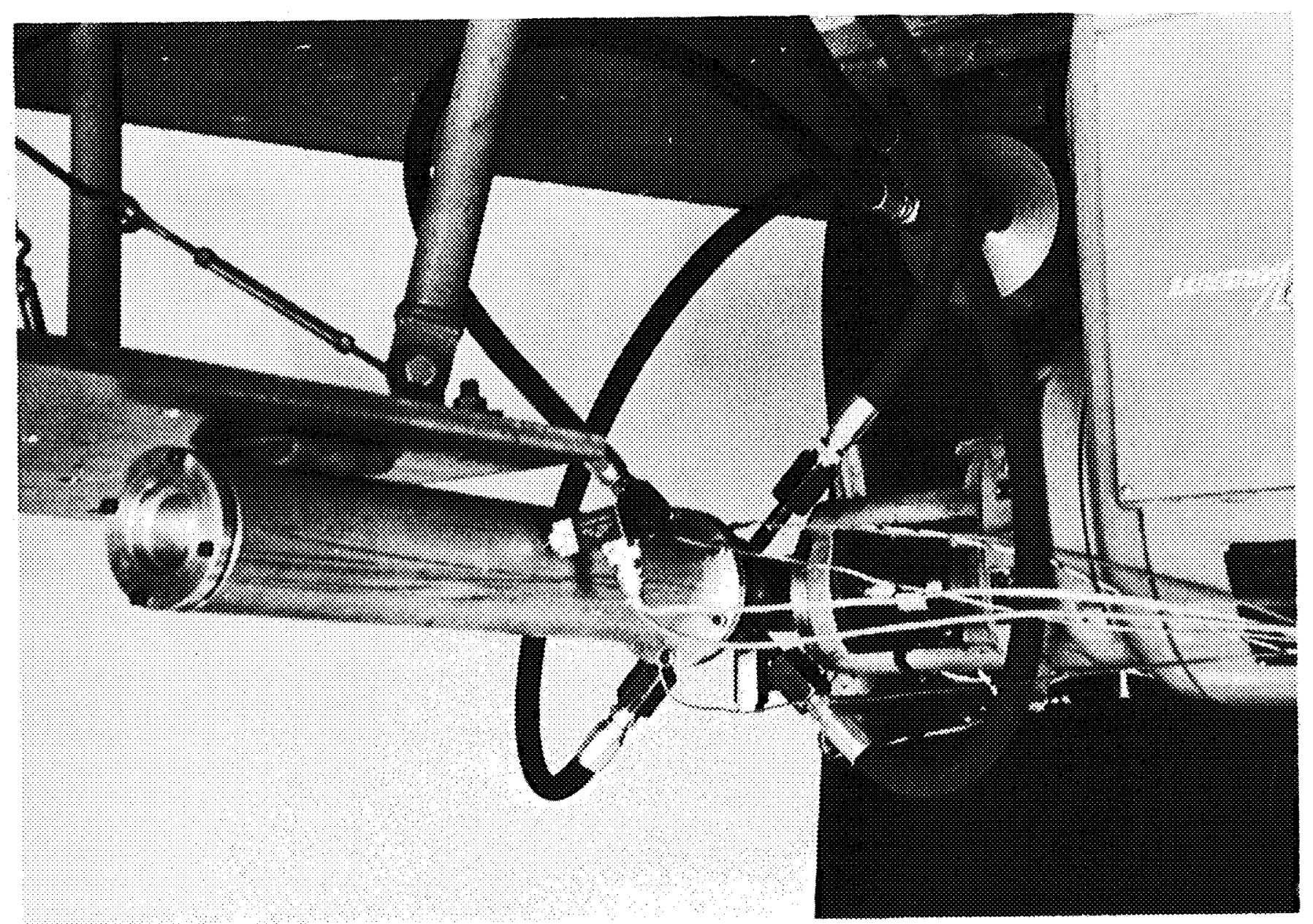


Five electronic transducers provided detection and recording of chamber pressure, acoustic oscillations, and acoustic frequency. The signal from each transducer was suitably conditioned and recorded. A schematic diagram of the signal detection and conditioning that was used is shown in Fig. 9. The various details of this instrumentation are discussed below.

\section{MODEL CHAMBER PRESSURE}

Chamber pressure recordings consisted of two types: (1) steady chamber pressure resulting from net air flow through the model, and (2) oscillating (acoustic) pressure waves superimposed upon the steady pressure by the rotary valve.

The steady chamber pressure was detected by a low frequency, 0 to 40 psig. Statham strain gage transducer and recorded on a CEC recording oscillograph, Type 5-114.

Detection and recording of acoustic pressure oscillations required a more sophisticated approach. Since the oscillation frequencies ranged up to $1,300 \mathrm{cps}$, a transducer with response into the multikilocycle region was needed. Placement of this transducer was critical since every acoustic mode structure contains regions in which no pressure oscillations occur. Two factors suggested that the transducer be located centrally in the porous plate structure at the head end of the model chamber with sensing diaphragm facing into the model chamber. These factors were: (I) only axial acoustic modes were of interest (the air flow and acoustical excitation systems were designed to drive the model in axial modes) and (2) the plate at the head end of the model is in the plane of maximum pressure oscillation for all axial acoustic modes in the chamber, thus making it possible to detect all such modes at this one location. Because of its availability, small size, and high natural frequency, a 0 to 100 psia, CEC, Type 4-312, transducer was used to detect chamber pressure oscillations. Transducer output (maximum output was under $0.15 \mathrm{mv}$ ) was electrically amplified by a factor of 25,000 , filtered by a band-pass filter, then full wave rectified, and the resulting signal recorded on both the CEC oscillograph in Fig. 10 and a Moseley, Model 2 FRA-01-02, two pen, $\mathrm{X}-\mathrm{Y}-\mathrm{Y}$ plotter in Fig. 11. The recorded signal was directly proportional to the amplitude of pressure oscillations in the model chamber. High frequency noise in the transducer output was appreciable in this arrangement, but was at frequencies above the range of interest in this work and was removed by an $80-1,200$ cps band-pass filter.

The amplified $A C$ signal from the CEC pressure transducer was also measured directly by a Bruel \& Kjaer RMS voltmeter. In addition it was used in an analog system along with the signal from the prechamber transducer to produce a signal proportional to the ratio of chamber amplitude to prechamber. 


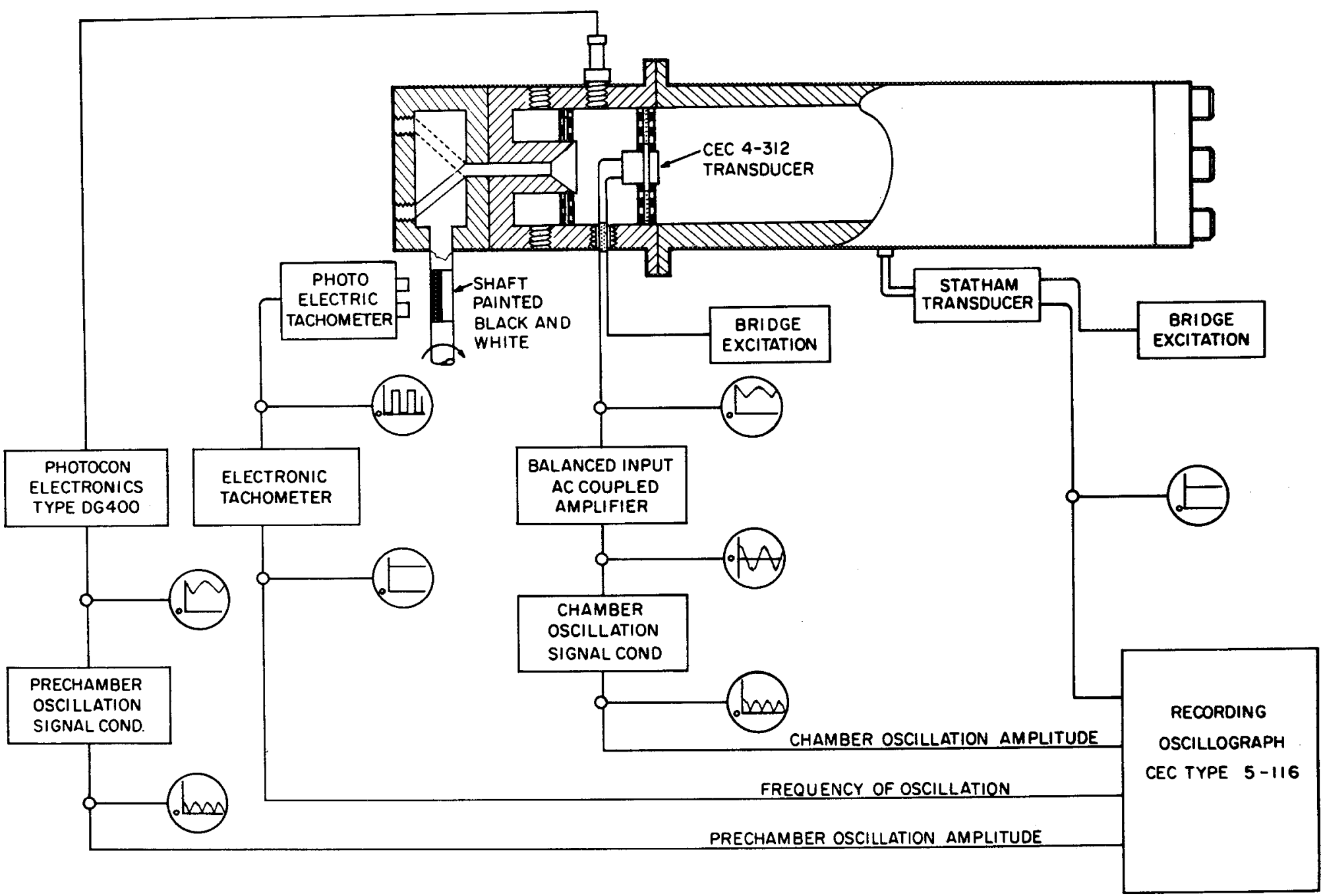

FIG. 9. Schematic of the Signal Detection and Conditioning Done in Conjunction with the Oscillograph Records for the Steady-State Tests. 
Static Reference Trace

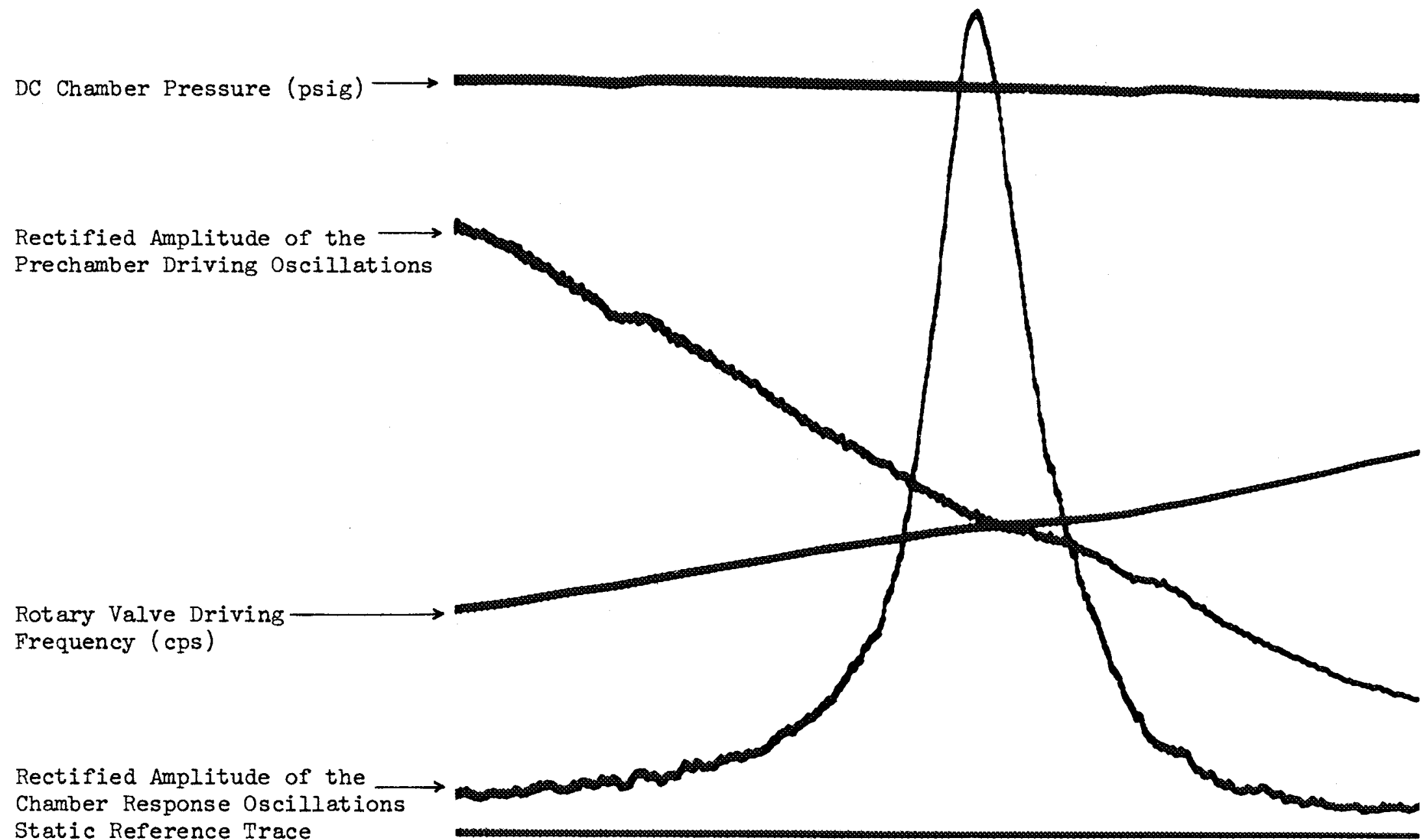

FIG. 10. Annotated Steady-State Oscillograph Test Record. Shows resonant chamber response as driving frequency is increased. Test No. 12513. 


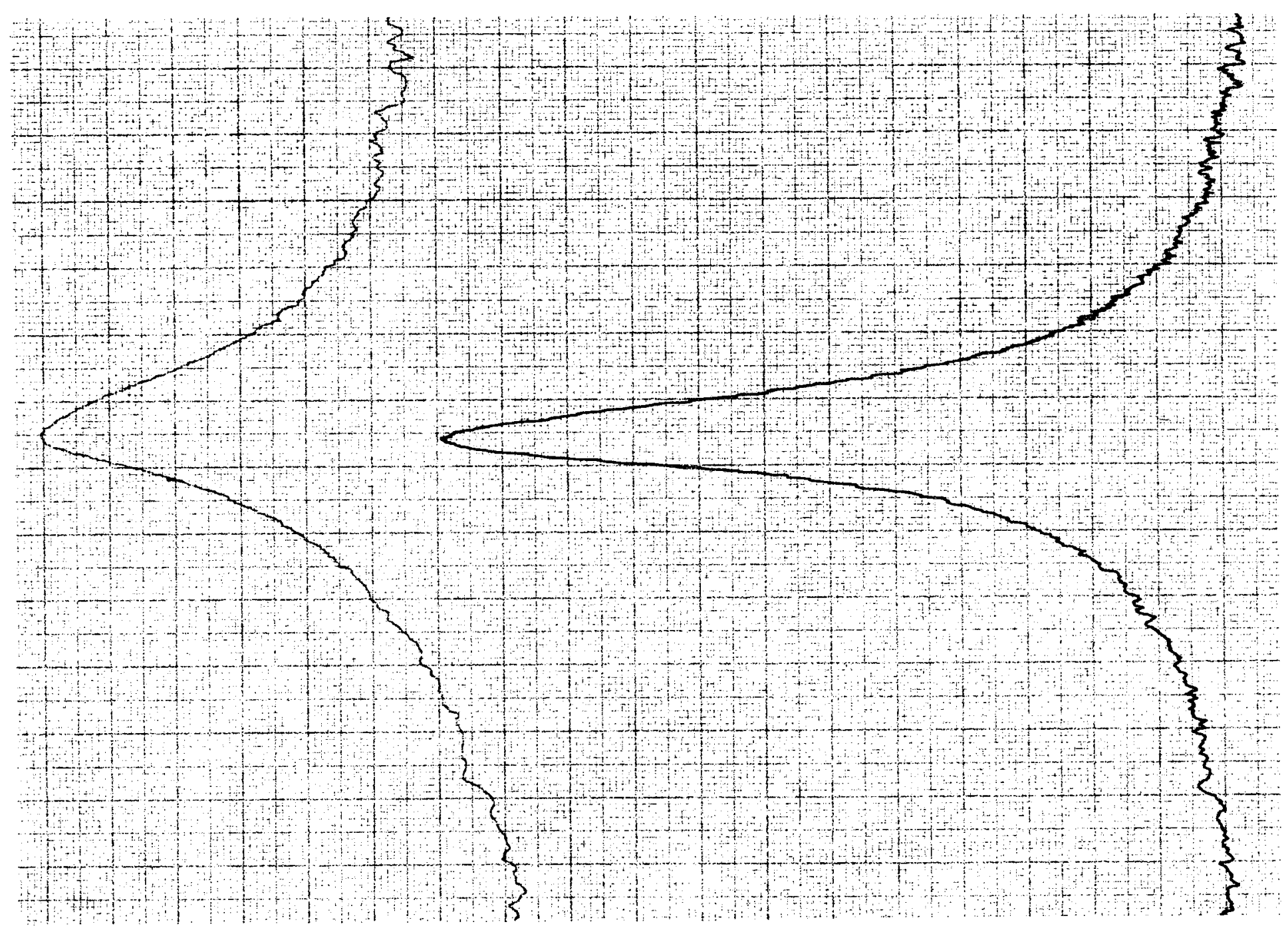

무요

iी \&

要桼

d

os 0

हE

फ्षे क्ष

○ 0 어

형

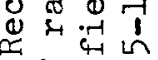

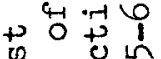
of to ن

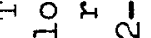
क् † 인 त हैं ठ ते

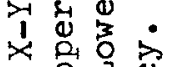
of 政 + in ह यद ब्य . $8 \mathrm{Q}^{\circ}$ 굴 品 ㄷํㅇㄹㄹ

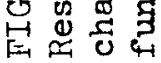




\section{PRECHAMBER PRESSURE OSCILLATIONS}

The amplitude of the acoustic pressure in the prechamber was measured by a variable capacitance, 0 to 500 psig, Photocon Research Products transducer which provided satisfactory frequency response and acceptably high output voltage. This output was under $100 \mathrm{mv}$ so that signal conditioning included amplification by a factor of 1,000 prior to filtering, rectifying, and recording on the oscillograph. This circuitry also provided a signal to the analog circuit, the output of which was plotted against frequency on the two-pen $X-Y-Y$ recorder. Because the acoustic power (i.e., wave amplitude) within the prechamber changed appreciably through the frequency range due to a decreasing air flow per cycle as the rotation rate was increased, it was necessary to measure and record prechamber pressure oscillations. By simultaneously recording chamber and prechamber amplitude as functions of frequency, data were obtained by which the chamber response curve could be normalized.

\section{FREQUENCY OF OSCILLATION}

Measurement of frequency of oscillation was made with a HewlettPackard, Model No. 505-B, electronic tachometer. This unit included a sensing head which contained a focused photoelectric pickup and illuminating lamp. The sensing head was placed to detect the revolutions per minute of the rotary valve driving shaft. This signal was used as the horizontal input to the $X-Y-Y$ plotter, as the input to a digital frequency meter, and was also conditioned and recorded by the oscillograph.

\section{TEMPERATURE}

The temperature of the gas in the chamber was measured intermittently using a bimetallic immersion gage. The gas temperature was essentially steady at $40^{\circ} \mathrm{F}$. This below-ambient temperature was caused by polytropic expansion from the storage tanks.

\section{CALIBRATION AND SENSTTIVITY DATA}

Calibration of gages, transducers, and signal-conditioning channels was varied to suit the requirements of each particular device.

All Bourdon tube pressure gages were checked with an Ashcraft deadweight tester. All gages showed deviations under $2 \%$ full scale. A corrected Bourdon tube gage was used for the steady-state calibration of the pressure transducers. 
The calibration of the oscillograph frequency trace channel consisted of comparing the line deflection to the readout on the digital counter.

The calibration of the other channels using transducers was somewhat more complicated and involved a dual approach using both a static calibration at various DC air pressure levels for a transducer and the use of a calibrated variable frequency oscillator as the input for the rest of the channel. No direct dynamic calibration was used.

The results of these oscillograph system calibrations are shown in Table 2 .

TABLE 2. Calibration and Sensitivity Data

\begin{tabular}{|c|c|c|c|}
\hline Channel & $\begin{array}{l}\text { Transducer } \\
\text { output }^{\mathrm{a}}\end{array}$ & $\begin{array}{l}\text { Electrical } \\
\text { calibration }\end{array}$ & $\begin{array}{l}\text { Oscillograph } \\
\text { deflection } \\
\text { factor }\end{array}$ \\
\hline $\begin{array}{l}\text { Chamber } \\
\text { oscillation } \\
\text { amplitude } \\
\text { CEC 4-312 }\end{array}$ & $159 \mathrm{mv} / \mathrm{psi}$ & $23.4 \mathrm{mv} / \mathrm{in}$ & $0.1473 \mathrm{psi} / \mathrm{in}$. \\
\hline $\begin{array}{l}\text { Prechamber } \\
\text { oscillation } \\
\text { amplitude }\end{array}$ & $21.75 \mathrm{mv} / \mathrm{psi}$ & $175.2 \mathrm{mv} / \mathrm{in}$. & $8.07 \mathrm{psi} / \mathrm{in}$. \\
\hline $\begin{array}{l}\text { Chamber } \\
\text { net pressure }\end{array}$ & $\cdot \cdot \cdot$ & $\cdot \cdot \cdot$ & $10.62 \mathrm{psi} / \mathrm{in}$ \\
\hline $\begin{array}{l}\text { Valve } \\
\text { frequency }\end{array}$ & - $\cdot$ & - $\cdot$ & $171.5 \mathrm{cps} / \mathrm{in}$ \\
\hline
\end{tabular}

These data obtained by a static calibration using variable DC air pressure level.

These data obtained by substituting a calibrated VFO for high frequency transducer within the voltage range determined in a above.

\section{OTHER INSTRUMENTATION}

One of the goals of the test program was to provide design criteria and a trial test setup for a new, automated, loss measurement system to be applied to more complicated geometries. Consequently, 
the data were recorded simultaneously on the system developed in Ref. 2 and recorded and measured on the analog system previously described.

\section{TEST PROCEDURE}

The operation of each test followed a typical pattern: (1) The desired model configuration was assembled in the chamber housing tube, (2) the motor driving the rotary valve was turned on, together with the air which flowed through the valve, (3) the steady air flow was established at the desired pressure level by manual control of the pressure regulators, (4) the recording oscillograph was started and the rotary valve speed of rotation increased slowly by turning the handwheel controlling output speed of the Varidrive unit (output speed was set to minimum prior to beginning of each test), (5) at input frequencies near 1,300 cps the electrical power to the Varidrive motor was cut off and the unit allowed to decelerate to zero revolution per second, (6) the recording oscillograph was shut off, (7) the Varidrive was turned back on and brought to the first resonance peak (the frequency of the peak was determined by using the digital frequency meter and the amplitude using the Bruel \& Kjaer RMS voltmeter), (8) the maximum RMS value was multiplied by 0.707 to determine the RMS voltage of the half-power points of the resonance curve, (9) the Varidrive frequency was changed to the half-power voltage calculated above so as to determine both the upper and then the lower half-power frequency on the digital frequency meter, (10) the Varidrive and the air flow to the system were shut off, and (II) the inserted parts were removed, replaced by a new set of parts and the operations repeated again in a new cycle.

The measurements made during operations (1) through (6) are essentially of the type reported in Ref. 2 to determine the shape of the resonance curve for the system. An annotated oscillograph test record is shown in Fig. 10. Measurements (7) through (9) repeat the test and were made in an effort to improve on the speed and accuracy of the original method as well as to check the instrumentation for the new test facility. A portion of the $X-Y-Y$ plotter record for approximately the same test conditions as above is shown in Fig. 11 .

Three persons carried out the test operations: one operating the air controls, recording the various pressure levels, and operating the prototype instrumentation; one operating the recording oscillograph and visually monitoring the instrument response and gelvanometer deflections on the oscillograph; and one operating the Varidrive controls, making the measurements described in sections (7) through (9) above, and changing the model geometry at the end of each test. 


\section{DATA REDUCTION}

There are several ways of determining the loss characteristics of an oscillating system. The present work reports a steady-state technique using a quality factor, or $Q$, determined from the resonant behavior of the motor cavity. This was done since the test chamber was driven by a continuous source of excitation, the frequency of which could be varied at will. The possibility and the limitations involved in using various decay measurement techniques were also investigated and are reported separately in Appendix $B$.

There are numerous definitions and relations involving Q. Several of these have been brought together both as a convenience to the reader and to show the theory and approximations involved in the present data reduction procedure.

Reference $5, p .25$ defines the $Q$ of a system as the number of cycles for the wave amplitude to decrease to $\left(1 / e^{\pi}\right)$ of its original value. Or slightly rearranged, as in Ref. 6, p. 587, the number of complete oscillations necessary to reach a given ratio, $\zeta$, of initial amplitude to final amplitude is

$$
\frac{\mathrm{Q}}{\pi} \ln \zeta
$$

A more usual and perhaps useful definition is given by Ref. 5, p. 27 and $\operatorname{Ref} .7, \mathrm{pp}, 39,98$ and 146 as

$$
Q=2 \pi \frac{\text { time-average energy stored }}{\text { energy loss per cycle of oscillation }}=2 \pi \text { fo } \frac{E}{\dot{E}}
$$

which for a simple damped oscillator can be expressed in terms of the mechanical constants of the system (Ref. 8, p. 25) by

$$
Q=\frac{\omega_{0} M}{R}
$$

Here $\omega_{0}$ is the resonant angular frequency, $M$ is the mass or inertial term, and $R$ is the mechanical resistance. Stated this way, $Q$ is proportional to the limit of the ratio of frequency to impedance when the reactance component of the complex impedance goes to zero, which occurs at resonance. This formula is valid for systems which behave as a linear, lumped parameter oscillator (Ref. 4, p. 20) in which the stiffness and inertial terms can be considered as either in series or parallel (Ref. 7, p. $40 \& 47$ ). 
In actuality, most oscillators behave to varving degrees as systems having distributed elements. For the present work, the degree of departure from an ideal lumped parameter system was assumed small based on an analysis which showed that the wall and bulk losses were small conpared to the energy transmitted through the ends. It was, therefore, decided to use the simple, lumped parameter $Q$ defined by Eq. 3. For such a Iumped parameter system, $Q$ can also be expressed in terms of the half-power bandwidth formula (Ref. 8, p. 25) for small damping (Ref. 4, p. 2l):

$$
Q=\frac{f_{0}}{f_{2}-f_{1}}=\frac{f_{0}}{\Delta f}
$$

where $f$ represents the resonant frequency, and $f^{\prime}$ and $f_{2}$ are the frequencies at the half-power levels on either side of the resonance peak. In the present work, the frequency could be measured within approximately $1 \mathrm{cps}$, and Eq. 4 was used to obtain the $Q$ of each system as a function of internal geometry.

Once $Q$ has been determined, it can be used to find the temporal damping constant, $\alpha,(\operatorname{Ref}, 4, \mathrm{p} .321$ ) and its relation to the energy decay:

$$
\alpha=\frac{\pi f_{0}}{Q}=1 / 2 \frac{\dot{E}}{E}
$$

The damping constant appears in the exponent of the expression describing the transient decay of amplitude of free oscillations (i.e., when the forcing function is suddenly stopped) as a function of time:

$$
p=p_{0} e^{-\alpha t}
$$

Since there is perhaps more physical feeling for this parameter than for $Q$, it has also been included in the tables of reduced data and used to prepare the final graphs. Note that large attenuation constants are associated with small $Q^{\prime}$ 's and that large $\alpha$ 's imply highly stable geometries.

Using the above discussion as a basis for the data reduction procedure, a few comments are made regarding the actual techniques used in preparing the final graphs. As discussed in the instrument section, 
three systems were used in this steady-state resonance technique to record the chamber response: the oscillograph recordings, the meter readings, and the $X-Y-Y$ plotter graphs. Each is discussed briefly below in terms of the $Q$ values obtained. From these data, the temporal damping constant $\alpha$ was later calculated by Eq. 5 and used for the final plots.

Figure 10 is a typical oscillograph test record showing the driving frequency and rectified chamber response as a function of time. In the data reduction, this chamber response curve was normalized to account for variations in the strength of the driving prechamber oscillations by taking the ratio between the chamber amplitude and the prechamber amplitude. The normalized amplitude curve was then plotted against the driving frequency. This resulted in the intermediate graph shown in Fig. 12. Q was then obtained graphically from this curve using the half-power bandwidth formula of Eq. 4 . $Q$ or $\alpha$ plots could then be obtained as a function of motor geometry.

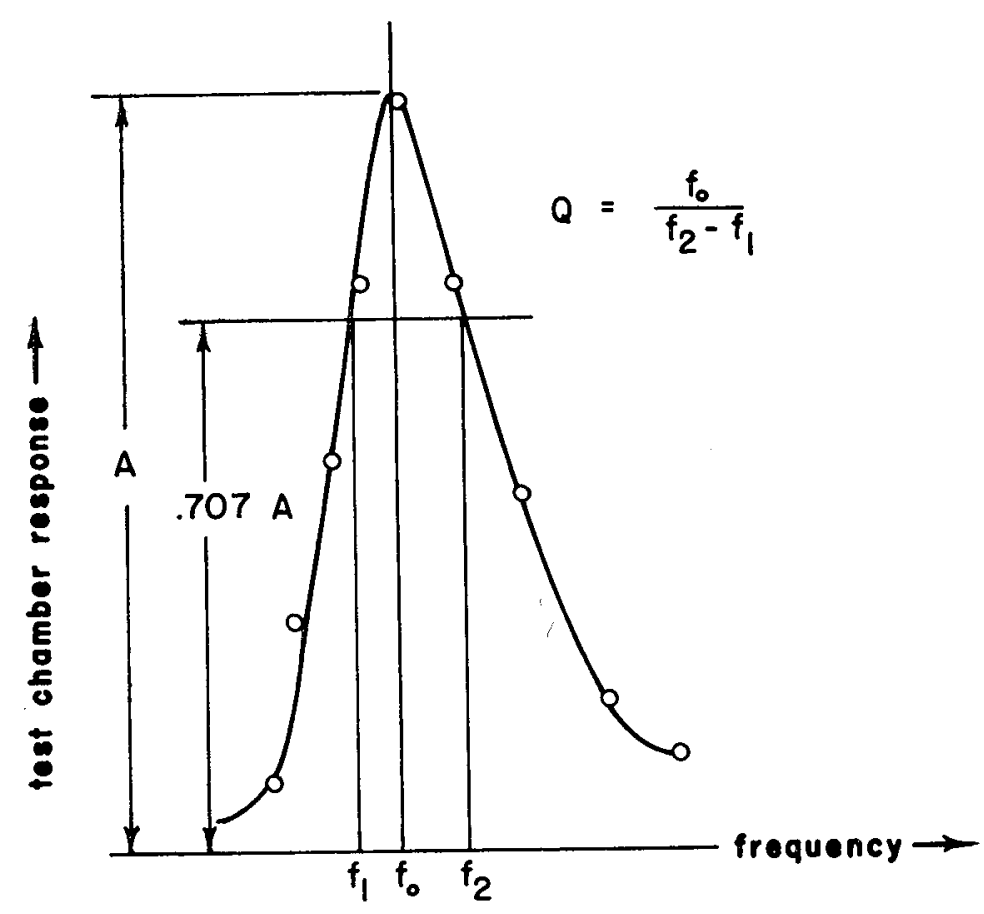

FIG, 12. Ratio of the Chamber to the Prechamber Oscillation Amplitude Measured From the Oscillograph Test Record Versus Frequency. Such intermediate graphs as this were prepared for each test using the oscillograph method and used to obtain a half-power bandwidth $Q$. 
The resonant and half-power frequencies were also measured using a digital frequency meter and a RMS voltmeter to monitor the $A C$ chamber response. Since $Q$ is sensitive to an accurate frequency determination (e.g., a difference in the half-power frequency width of I cps would alter a typical $Q$ from $Q=550 / 10=55.0$ to $Q=550 / 9=61.1$ ), this measuring technique was considerably more accurate as well as much faster than the determinations from the oscillograph records. The frequencies required to determine $Q$ were recorded during the test, and the resulting Q's (or $\alpha^{\prime} s$ ) could be plotted immediately at the end of each run. This permitted immediate reruns if necessary to confirm any unusual test results.

The X-Y-Y plotter recorded two functions (Fig. 1I): the rectified $A C$ chamber response versus driving frequency and the logarithmic ratio of the $A C$ chamber to prechamber pressure versus frequency. From the former curve, a half-power bandwiath $Q$ could be obtained by calculation and measurement. This was done for various tests to see if it corresponded with the $Q$ determinations obtained using the other two techniques.

The $Q$ determinations made using the RMS voltmeter and the digital frequency meter were the most accurate and convenient of the three techniques used. Once the validity of the meter data results had been established, all tests were run this way. Meter data are tabulated in the tables and were used to prepare the final graphs. Because the frequency deflection factor (i.e., cps/inch) was greater using the X-Y-Y plotter than for the oscillograph records, this was the next most accurate method for determining $Q$. The plotter was also quite useful in evaluating the system behavior under different operating conditions which are reported in Appendix A. The oscillograph technique, which had been used previously (Ref. 2), was completely superseded in the present work and was used primarily as a back-up system while setting up the new measuring methods.

\section{RESULTS AND DISCUSSION}

\section{TEST RESULTS}

The test conditions, steady-state-resonance-meter data and calculated acoustic attenuation constant for each of the test runs are presented in tabular form in Table 3.

1. Figure 13 shows the variation of the temporal damping constant versus $J$ for constant nozzle size.

2. Figure 14 shows the variation of the temporal damping constant versus $J$ for constant grain port area. 
3. Figure 15 shows the variation of the first mode resonant frequency versus $\mathrm{J}$ for constant nozzle size.

These results are brought together in Fig. 16 and analyzed in the following sections. The final data for the variation of the dampins constant with $J$ are summarized in Fig. $I 7$ and the resonant frequency response as a function of $\mathrm{J}$ is shown in Fig. 18 .

TABLE 3. Steady-State Resonance Data

\begin{tabular}{|c|c|c|c|c|c|c|}
\hline $\begin{array}{c}\text { Test } \\
\text { number }\end{array}$ & Geometry & $\mathrm{J}$ & $\begin{array}{c}\text { Chamber } \\
\text { pressure, } \\
\text { psig }\end{array}$ & $\begin{array}{l}f_{0} \\
\text { eps }\end{array}$ & $Q=\frac{f_{0}}{\Delta f}$ & $\alpha=\frac{\pi f_{0}}{Q}$, \\
\hline \multicolumn{7}{|c|}{ A. Sonic Nozzle \#I, Throat Diam. $=0.627 \mathrm{in}$. } \\
\hline $\begin{array}{l}2-24-7 \\
2-24-6 \\
2-25-7 \\
2-24-3 \\
2-24-8 \\
2-9-4 \\
2-24-10 \\
2-9-3 \\
2-24-2 \\
2-24-13 \\
2-9-2\end{array}$ & $\begin{array}{l}1-1 \\
2-1 \\
3-1 \\
3-1 \\
4-1 \\
4-1 \\
5-1 \\
5-1 \\
6-1 \\
6-1 \\
6-1\end{array}$ & $\begin{array}{l}0.3906 \\
0.1736 \\
0.0976 \\
0.0976 \\
0.0625 \\
0.0625 \\
0.0434 \\
0.0434 \\
0.0319 \\
0.0319 \\
0.0319\end{array}$ & $\begin{array}{l}20.5 \\
21-0 \\
21.0 \\
26.2 \\
21.8 \\
20.5 \\
20.5 \\
20.0 \\
23.0 \\
19.5 \\
20.0\end{array}$ & $\begin{array}{l}442 \\
501 \\
532 \\
517 \\
530 \\
530 \\
534 \\
532 \\
535 \\
548 \\
543\end{array}$ & $\begin{array}{c}2.33 \\
5.63 \\
7.94 \\
7.07 \\
15.6 \\
13.6 \\
22.2 \\
19.0 \\
16.0 \\
32.3 \\
22.6\end{array}$ & $\begin{array}{r}597 \\
279 \\
210 \\
230 \\
107 \\
122 \\
75 \\
88 \\
105 \\
53 \\
75\end{array}$ \\
\hline \multicolumn{7}{|c|}{ B. Sonic Nozzle \#2, Throat Diam. $=0.500$ in. } \\
\hline $\begin{array}{l}2-24-16 \\
2-24-18 \\
2-4-35 \\
2-25-1 \\
2-25-3 \\
2-9-19 \\
2-4-31 \\
2-9-20 \\
2-4-29 \\
2-9-22 \\
\cdots \cdots \\
2-4-27\end{array}$ & $\begin{array}{l}1-2 \\
2-2 \\
2-2 \\
3-2 \\
3-2 \\
4-2 \\
4-2 \\
5-2 \\
5-2 \\
6-2 \\
6-2 \\
6-2\end{array}$ & $\begin{array}{l}0.2500 \\
0.1110 \\
0.1110 \\
0.0625 \\
0.0625 \\
0.0400 \\
0.0400 \\
0.0278 \\
0.0278 \\
0.0204 \\
0.0204 \\
0.0204\end{array}$ & $\begin{array}{l}20.3 \\
23.0 \\
20.5 \\
19.4 \\
20.2 \\
21.7 \\
21.0 \\
20.0 \\
20.4 \\
19.8 \\
19.8 \\
20.5\end{array}$ & $\begin{array}{l}476 \\
514 \\
520 \\
539 \\
535 \\
539 \\
548 \\
541 \\
550 \\
541 \\
540 \\
554\end{array}$ & $\begin{array}{r}4.6 \\
10.5 \\
9.0 \\
14.6 \\
16.2 \\
25.6 \\
27.4 \\
33.8 \\
30.5 \\
45.0 \\
49.2 \\
55.4\end{array}$ & $\begin{array}{r}323 \\
154 \\
185 \\
116 \\
104 \\
66 \\
63 \\
50 \\
57 \\
38 \\
35 \\
31\end{array}$ \\
\hline
\end{tabular}


TABIE 3. (Contd.)

\begin{tabular}{l|l|l|c|c|c|c}
\hline $\begin{array}{c}\text { Test } \\
\text { number }\end{array}$ & Geometry & $J$ & $\begin{array}{c}\text { Chamber } \\
\text { pressure, } \\
\text { psig }\end{array}$ & $\begin{array}{c}f_{0} \\
\operatorname{cps}\end{array}$ & $Q=\frac{f_{0}}{\Delta f}$ & $\alpha=\frac{\pi f_{0}}{Q}$, \\
$\sec ^{-1}$
\end{tabular}

C. Sonic Nozzle \#3, Throat Diam. $=0.375$ in.

\begin{tabular}{l|r|r|r|r|r|r}
\hline $2-4-25$ & $1-3$ & 0.1407 & 20.4 & 475 & 5.2 & 287 \\
$2-9-1$ & $2-3$ & 0.0625 & 21.0 & 517 & 12.8 & 127 \\
$2-4-23$ & $2-3$ & 0.0625 & 20.5 & 523 & 13.4 & 122 \\
$2-4-21$ & $3-3$ & 0.0351 & 20.0 & 544 & 20.9 & 82 \\
$2-25-9$ & $4-3$ & 0.0225 & 20.8 & 540 & 33.7 & 51 \\
$2-4-19$ & $4-3$ & 0.0225 & 20.5 & 551 & 42.5 & 41 \\
$2-25-8$ & $5-3$ & 0.0156 & 20.8 & 542 & 41.7 & 41 \\
$2-4-17$ & $5-3$ & 0.0156 & 20.8 & 555 & 32.7 & 53 \\
$2-9-23$ & $6-3$ & 0.0115 & 20.5 & 544 & 60.0 & 29 \\
$2-4-15$ & $6-3$ & 0.0115 & 20.5 & 559 & 70.0 & 25 \\
\hline
\end{tabular}

D. Sonic Nozzle \#4, Throat Diam. $=0.250$ in.

\begin{tabular}{l|l|l|l|l|l|l}
\hline $2-25-13$ & $1-4$ & 0.0625 & 20.7 & 476 & 7.4 & 202 \\
$2-4-10$ & $1-4$ & 0.0625 & 20.5 & 492 & 9.1 & 170 \\
$2-4-13$ & $2-4$ & 0.0275 & 20.5 & 533 & 16.2 & 103 \\
$2-4-8$ & $3-4$ & 0.0156 & 20.6 & 551 & 27.6 & 63 \\
$2-25-11$ & $4-4$ & 0.0100 & 19.9 & 547 & 45.6 & 38 \\
$2-4-6$ & $4-4$ & 0.0100 & 20.0 & 558 & 55.8 & 31 \\
$2-25-10$ & $5-4$ & 0.0069 & 20.2 & 550 & 50.0 & 35 \\
$2-4-3$ & $5-4$ & 0.0069 & 20.5 & 561 & 56.1 & 31 \\
$2-4-1$ & $6-4$ & 0.0051 & 25.0 & 564 & 94.0 & 19 \\
\hline
\end{tabular}

E. Sonic Nozzle \#5, Throat Diam. $=0.125$ in.

\begin{tabular}{l|l|l|l|l|l|l}
\hline $2-25-15$ & $1-5$ & 0.01560 & 21.0 & 477 & 5.3 & 283 \\
$2-9-17$ & $1-5$ & 0.01560 & 21.5 & 476 & 5.7 & 262 \\
$2-9-16$ & $2-5$ & 0.00695 & 19.0 & 521 & 11.3 & 145 \\
$2-25-17$ & $3-5$ & 0.00390 & 21.2 & 545 & 18.1 & 95 \\
$2-9-12$ & $4-5$ & 0.00250 & 18.5 & 545 & 25.9 & 66 \\
$2-9-11$ & $5-5$ & 0.00173 & 22.0 & 547 & 34.2 & 50 \\
$2-25-16$ & $6-5$ & 0.00127 & 22.0 & 555 & 39.6 & 44 \\
$2-9-9$ & $6-5$ & 0.00127 & 22.0 & 545 & 49.5 & 35 \\
\hline
\end{tabular}



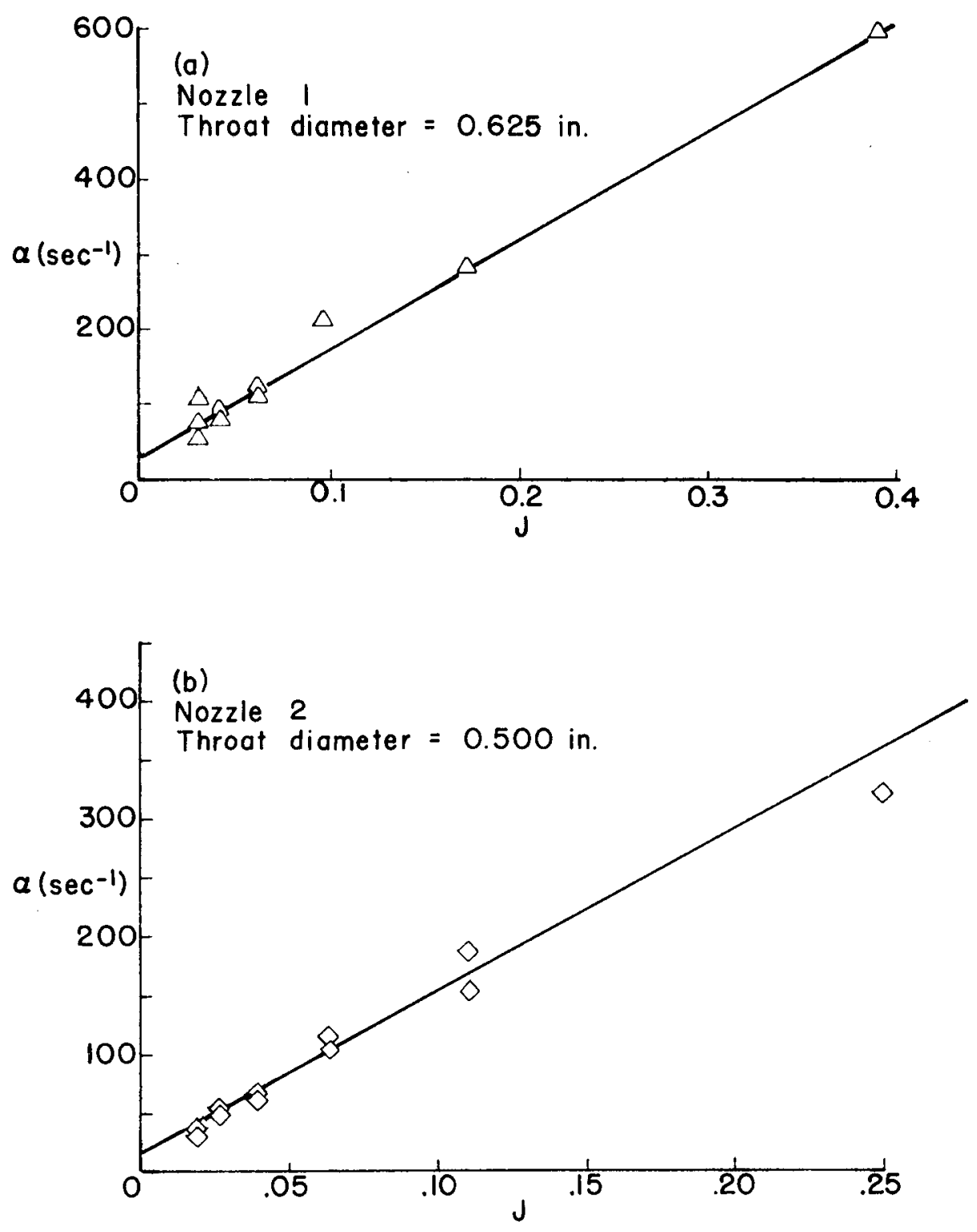

FIG. 13. Linear Plots of Temporal Damping Constant Versus $J$ for Constant Nozzle Diameter. Sonic nozzle throat. Steady-state meter data. 

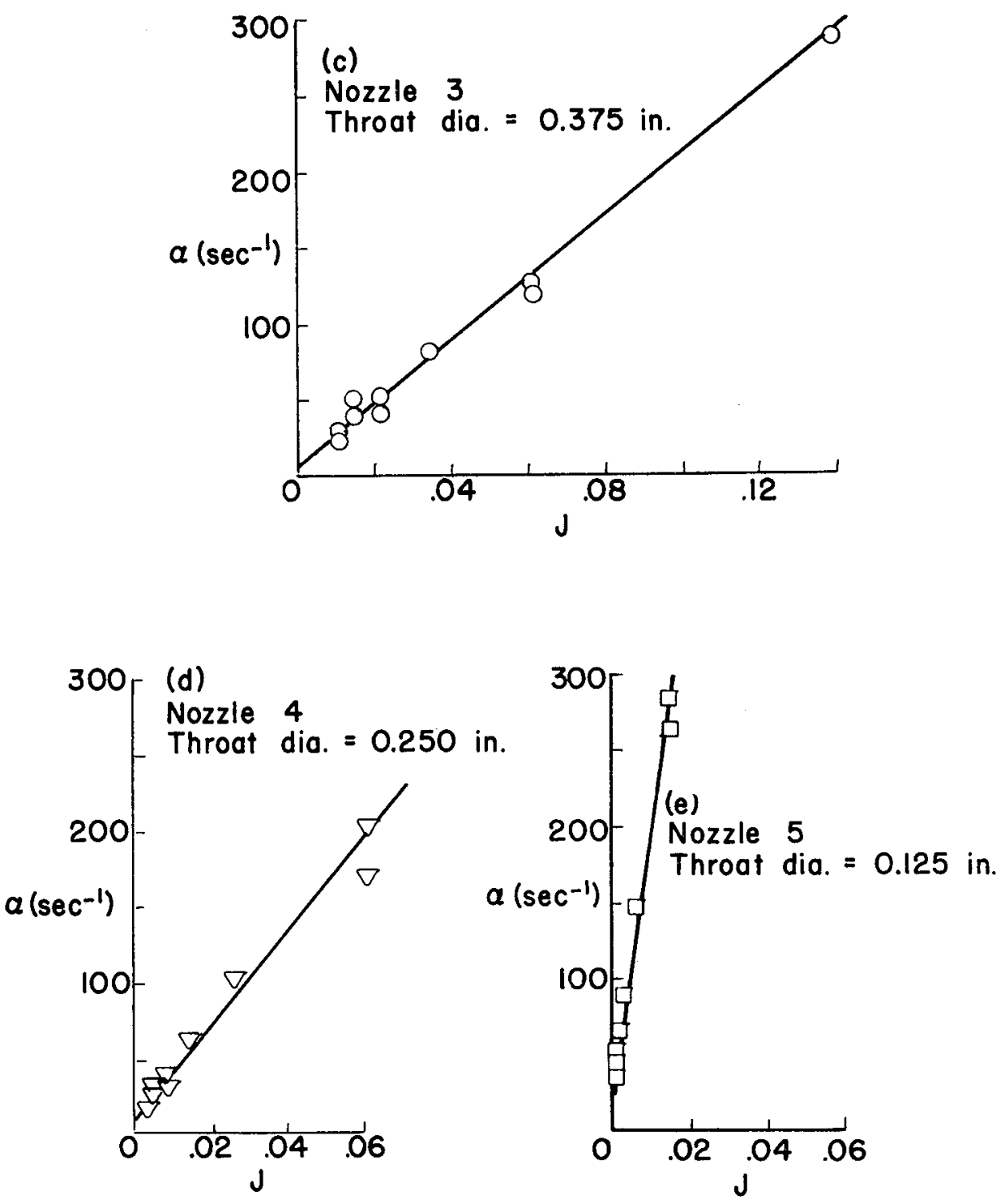

FIG. 13. (Contd.) 


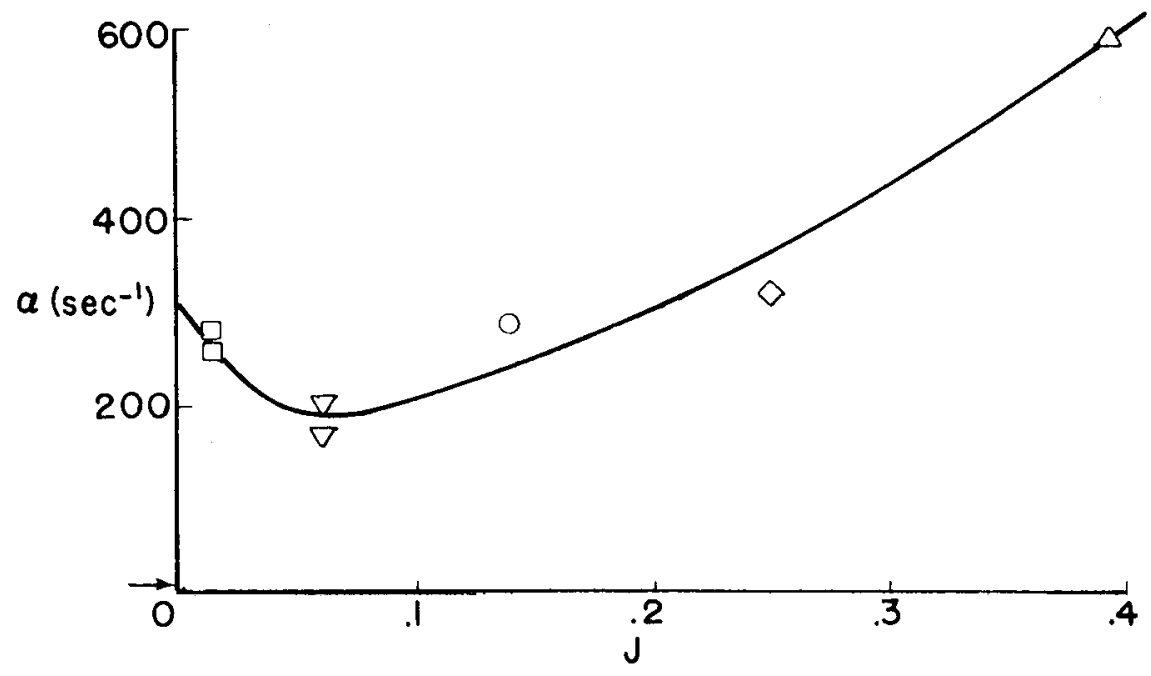

(a) Grain I, Grain port diameter $=1.0$ in.

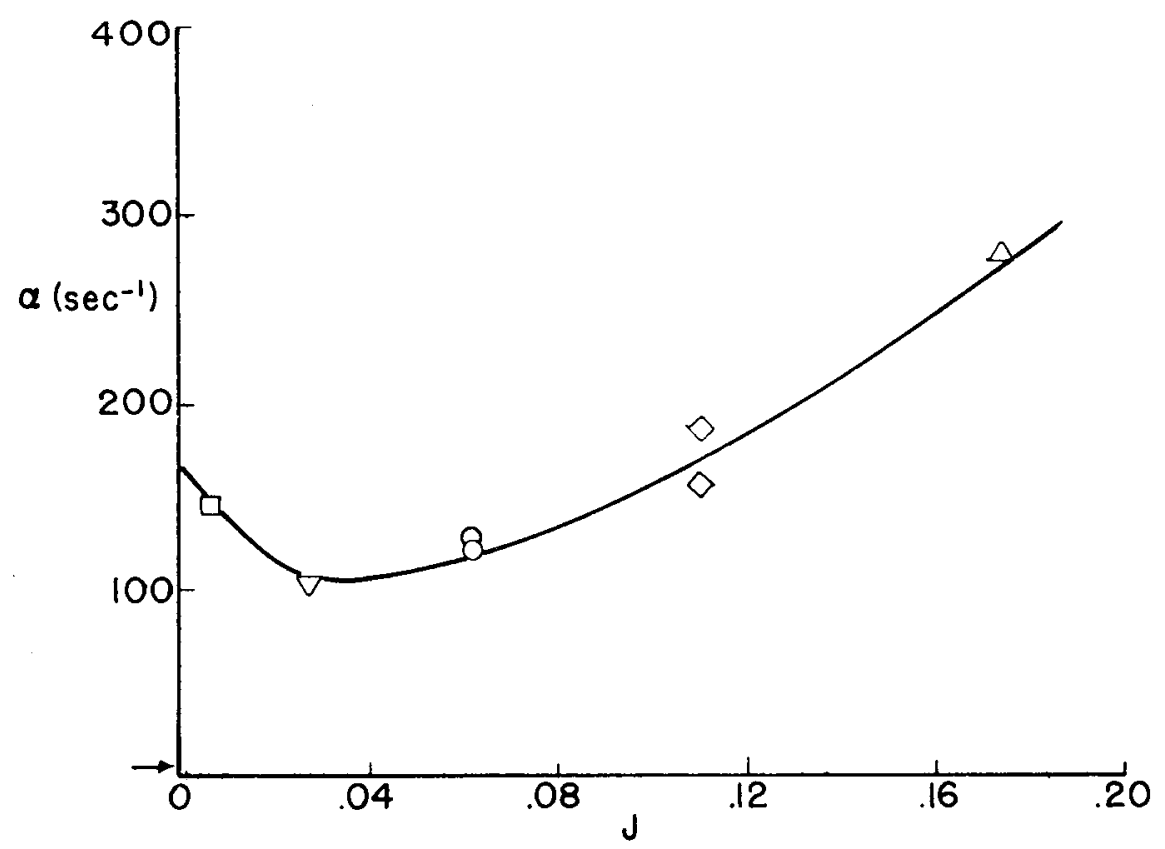

(b) Grain 2, Grain port diameter $=1.5$ in.

FIG. 14. Linear Plots of Temporal Damping Constant Versus $J$ for Constant Grain Port Diameter. Arrow indicates classical wall losses for $J=0$. Sonic nozzle throat. Steady-state meter data. 


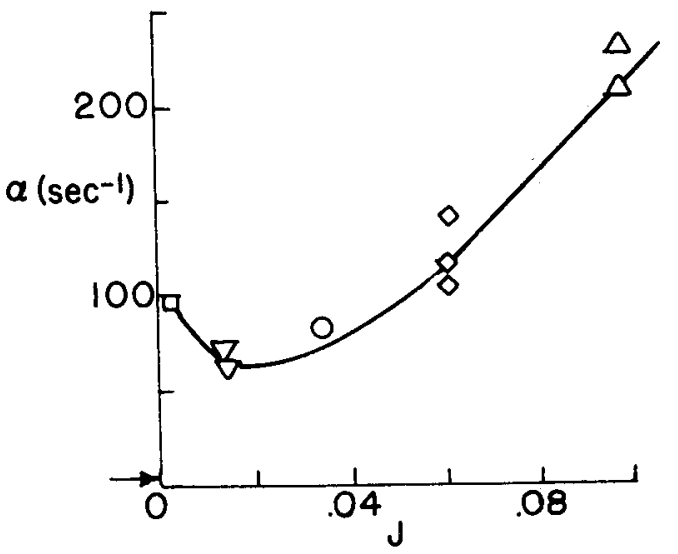

(c) Grain 3

Grain port diameter $=2.0 \mathrm{in}$.

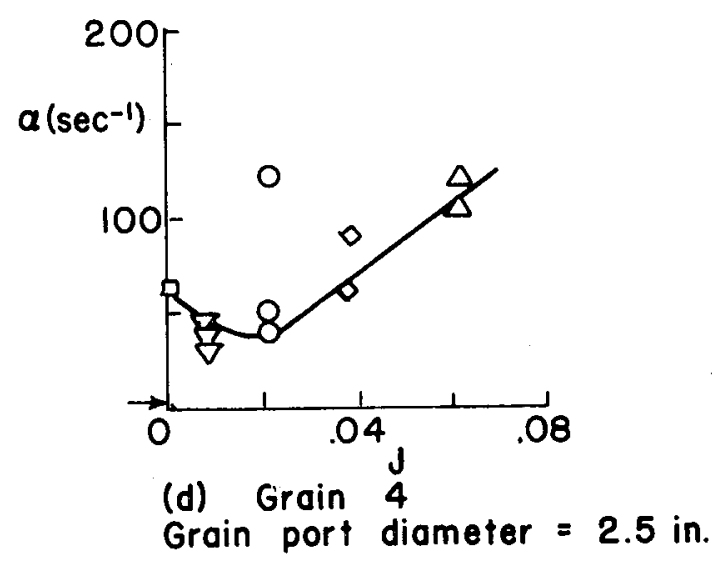

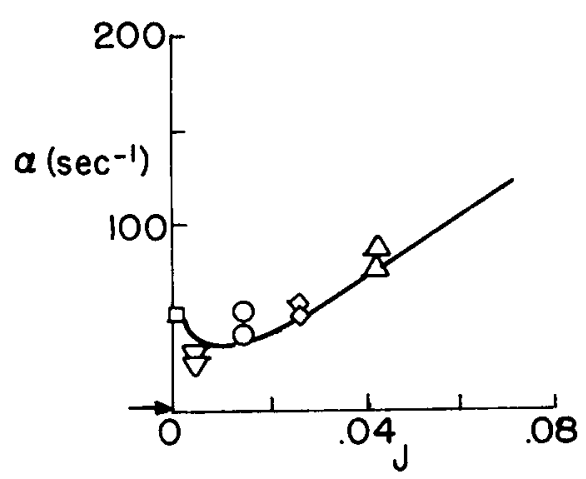

(e) Grain 5

Grain port diameter $=3.0$ in.

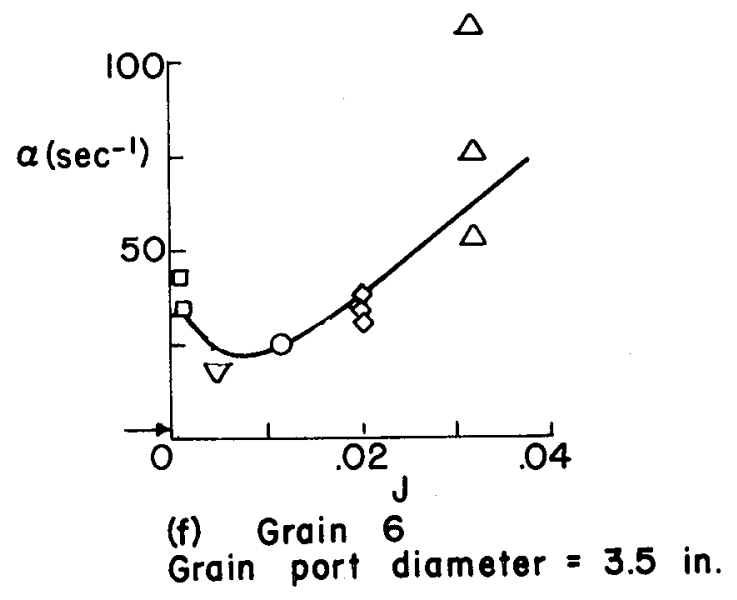

Grain port diameter $=3.5$ in.

FIG. 14. (Contd.) 


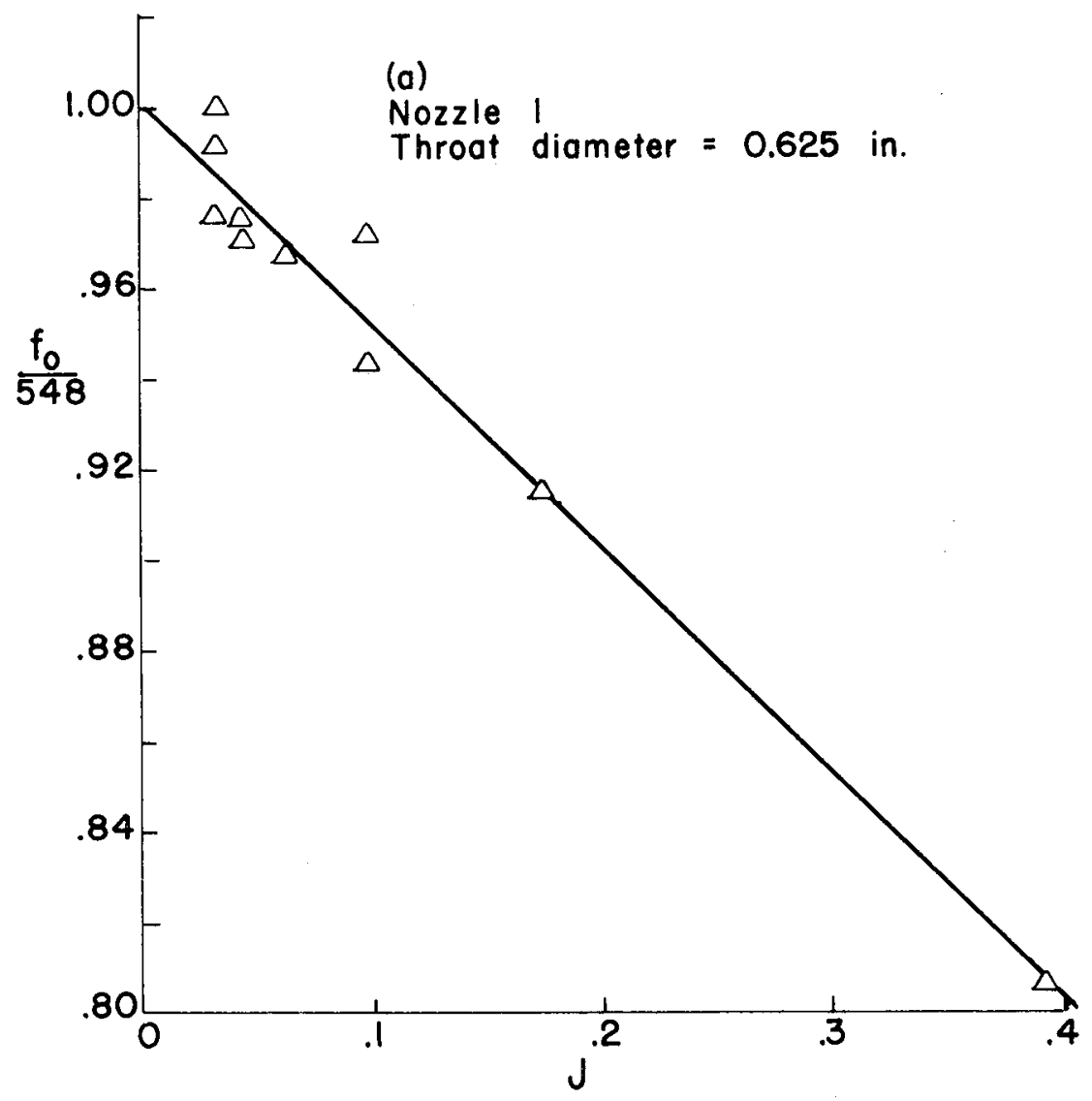

FIG. 15. First Mode Resonant Frequency Versus $J$ for Constant Nozzle Diameter. Sonic nozzle throat. Steady-state meter data. 

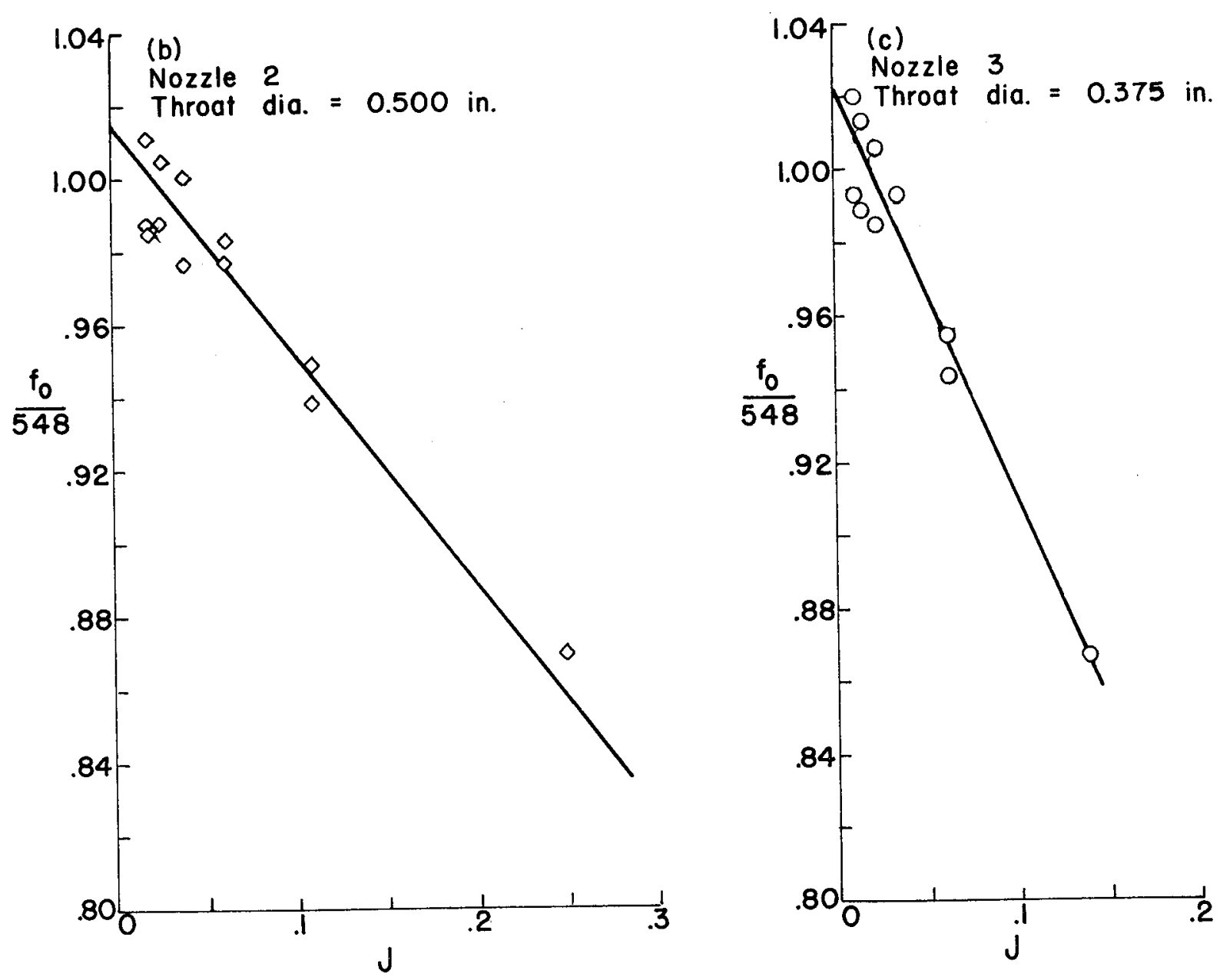

FIG. 15. (Contd.) 

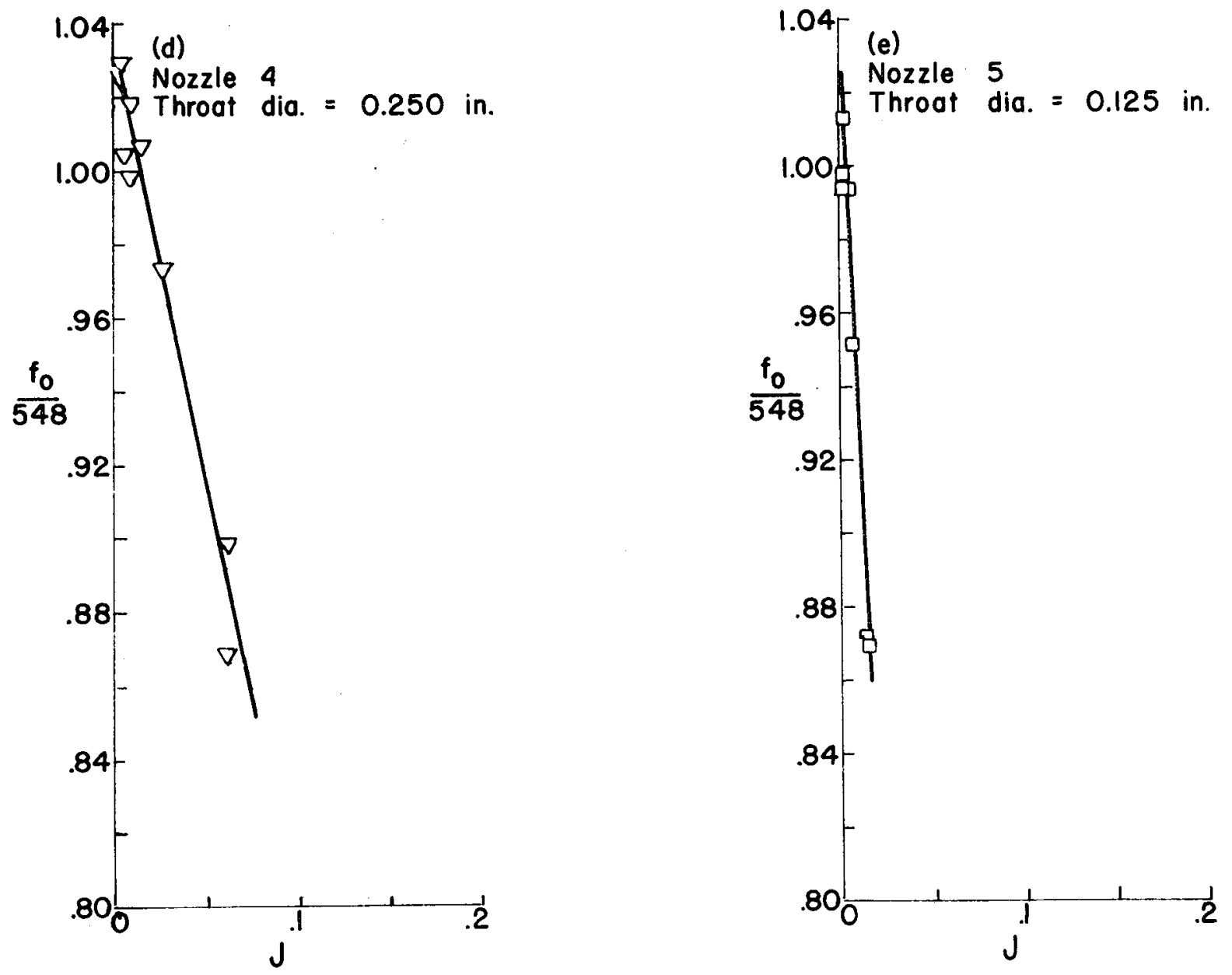

FIG. 15. (Contd.) 


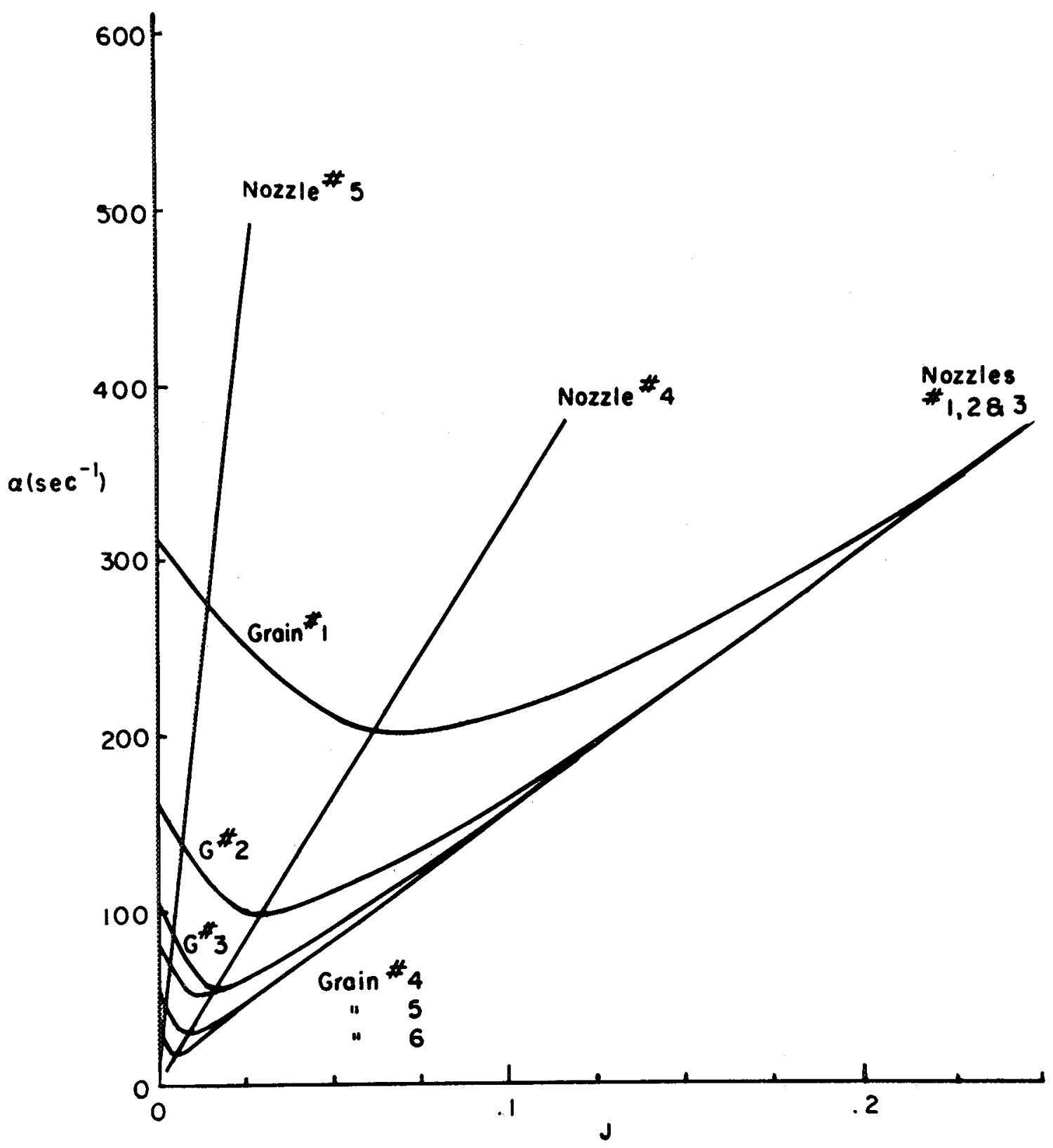

FIG. 16. Composite Linear Plot of Temporal Damping Constant Versus J for Constant Nozzle Diameter and Constant Grain Port Area. Sonic nozzle throat. Steady-state meter data. 


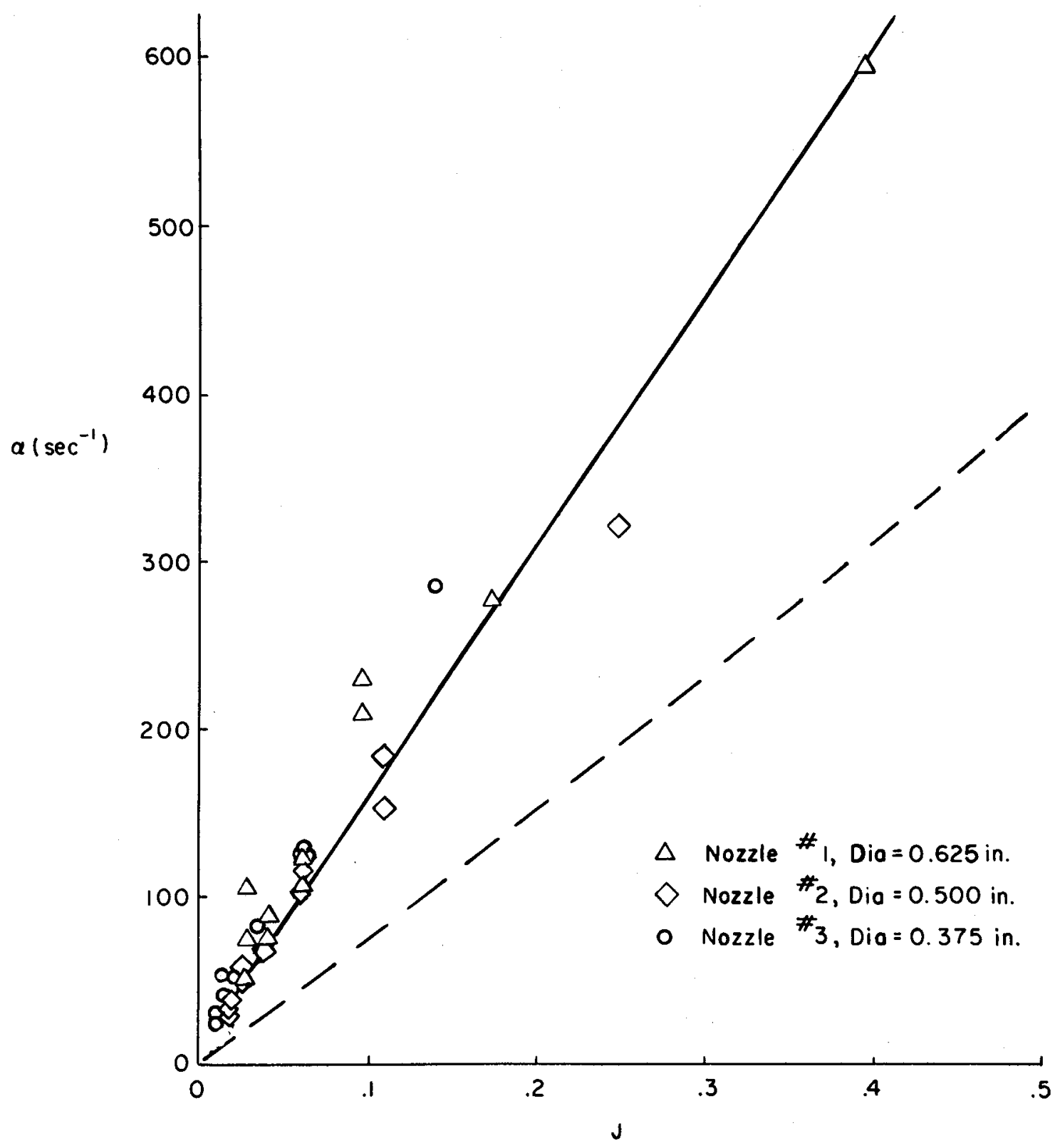

FIG. 17. Temporal Damping Constant Versus $J$ Data for Which the Ratio of Chamber Pressure to Prechamber Pressure was Greater than 0.42 (Quasi-Sonic Porous Plate Condition). Sonic nozzle throat. Steadystate meter data. Dashed line as computed from theory of Ref. 11. 


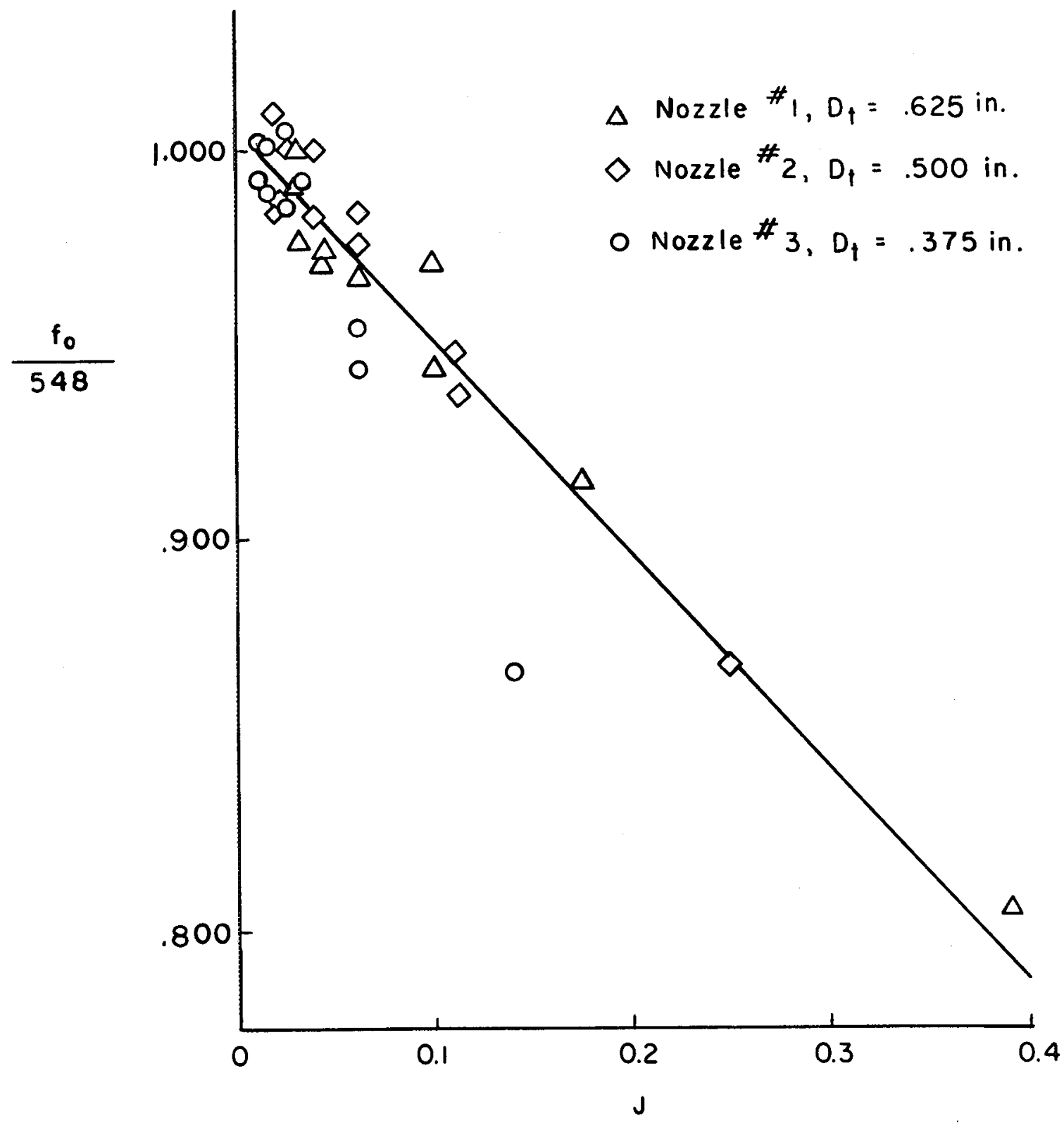

FIG. 18. Actual to Theoretical Resonant Frequency as Function of $J$ for Nozzles 1, 2, and 3. Chamber pressure $=20$ psig. Steady-state meter data. 


\title{
LOSS ANALYSIS
}

Loss Mechanisms. The decrease of acoustic energy in a system can be ascribed to either losses in the medium or to losses occurring at the system boundaries. The actual loss mechanisms that are associated with these locations can be listed as follows:

\author{
Losses in Medium or Bulk Losses \\ Viscous bulk losses \\ Heat conduction bulk losses \\ Relaxation bulk losses \\ Inhomogeneous media bulk losses \\ Losses at Boundaries or Wall Losses \\ Viscous wall losses \\ Heat conduction wall losses \\ Radiation losses to walls \\ Radiation losses from nozzle \\ Absorption losses to porous plate
}

The losses in the medium or bulk losses should consist of losses caused by viscosity, heat transfer, and thermal relaxation mechanisms. Table 4 lists calculated values for these losses as well as wall lossts which will be considered later. The bulk losses due to effects of viscosity and heat transfer were computed from Ref. 8, p. 226, using Table 9.1 which gives the combined spatial attenuation constant due to these loss mechanisms. To obtain the temporal attenuation constant at $548 \mathrm{cycles} / \mathrm{sec}$ (i.e., the nominal first mode frequency of the chamber), the spatial constant was multiplied by the nominal sonic velocity of $1,095 \mathrm{ft} / \mathrm{sec}$. The data in Table 9.1 of Ref. 8 were obtained at a pressure of 1 atm and $20^{\circ} \mathrm{C}$, but any small correction to adjust the value to test condition would be unimportant since the damping constant was found to be several orders of magnitude smaller than the measured attenuation constants of the test chamber. 
TABLE 4. Wall and Bulk Loss Attenuation Coefficients Computed for Zero Mean Flow Conditions

\begin{tabular}{l|c|c|c}
\hline \multirow{2}{*}{$\begin{array}{c}\text { Motor } \\
\text { chamber } \\
\text { number }\end{array}$} & \multicolumn{3}{|c|}{ Temporal damping coefficients, sec } \\
\cline { 2 - 4 } & $\alpha_{\mathrm{w}} \mathrm{a}^{-1}$ & $\left(\alpha_{\mathrm{v}}+\alpha_{\mathrm{th}}\right)$ & $\left(\alpha_{\mathrm{m}}\right)_{\max }$ \\
\hline 1 & 5.74 & $1.38 \times 10^{-3}$ & 0.6 \\
2 & 3.83 & do & do \\
3 & 2.87 & do & do \\
4 & 2.30 & do & do \\
5 & 1.92 & do & do \\
6 & 1.64 & do & do \\
\hline a. $\mu=1.7 \times 10^{-4}$ dyne sec $/ \mathrm{cm}^{2}, \rho=0.00292 \mathrm{grams} /$ \\
$\mathrm{cm}^{3}, \operatorname{Pr}=0.74, \gamma=1.4, \omega=3.450 \mathrm{sec}-1$.
\end{tabular}

The bulk damping due to molecular relaxation was computed from $20^{\circ} \mathrm{C}$ data listed in Table 9.2 of Ref. 8, p. 233. This type of damping is strongly dependent on the relative humidity. The attenuation constant listed in Table 4 is at a maximum for a frequency of $548 \mathrm{cps}$. This maximum was estimated from the data of Ref. 8 to occur at a relative humidity of approximately $7 \%$. Although the relative humidity was not measured for each test, it was in general lower than $7 \%$. Furthermore, attenuation due to molecular relaxation increases with temperature (Ref. 8, p. 23I) and so the value would be smaller if it were adjusted to actual test conditions.

The maximum possible calculated value for the attenuation constant under no-flow conditions is much smaller than the actual measured attenuation constant and so bulk damping cannot be considered as other than a minor source of acoustic loss. The effect of mean flow on these losses will be discussed in a later section.

Concerning the wall losses, the temporal wall damping constant for the combined effects of viscosity and heat conduction was calculated by the following equation:

$$
\alpha=\frac{2}{D_{c}} \sqrt{\frac{u \omega_{0}}{2 p}}\left[1+\left(\gamma^{\frac{1}{2}}-1 / \gamma^{\frac{1}{2}}\right) /(\operatorname{Pr})^{\frac{1}{2}}\right]
$$

This equation was derived by multiplying Eq. 9.41 of Ref. 8, p. 240, by the velocity of sound to convert from a spatial to a temporal damping coefficient and substituting an effective viscosity 


$$
\mu_{\text {eff }}=\mu\left[I+\left(\gamma^{\frac{1}{2}}-\frac{1}{\gamma^{\frac{1}{2}}}\right) \operatorname{Pr}^{-\frac{1}{2}}\right]
$$

given by Eq. 9.43 of the same reference in place of the actual viscosity. Properties of air at $40^{\circ} \mathrm{F}$ were used in the calculation. The computed values of wall damping attenuation constants listed in Table 4 are also much less than the experimentally measured losses.

Radiation losses to the wall were avoided by the use of heavy motor housing tube which acted as a rigid wall.

The acoustic losses of the experiment, therefore, are assumed to be due to a combination of losses from the nozzle and absorption losses to the porous plate at the head of the chamber. The separation and determination of each of these two mechanisms was one of the main problems of the analysis.

$\mathrm{J}=0$ Losses. In the limit of $\mathrm{J}=0$, the mean flow and nozzle radiation losses go to zero because the mean flow and nozzle size go to zero. Extrapolation of the experimental curves to $J=0$ would thus be expected to give an intercept indicative of the other system losses. Figure 13 presents linear plots of a versus $J$. Each graph is for a fixed nozzle geometry and so the change in $J$ is brought about by changes in the chamber diameter. A value of $\mathrm{J}=0$ for the data plotted this way corresponds to an infinite diameter chamber. A corresponding value of $\alpha$ thus includes only contributions due to bulk losses and losses from the two end plates since the values of nozzle, porous plate, and wall losses relative to bulk and end plate losses go to zero as the chamber diameter goes to infinity (Ref. 8, p. 240). Since the bulk and end plate losses themselves are very small, the intercept of the curves in Fig. 13 on the $\alpha$-axis would be expected to be near zero. A straight line extrapolation of the data does vield such a result.

Figure 14 also presents plots of $\alpha$ versus $J$, but in this case the diameter of the cavity was held constant while the nozzle throat diameter was varied. Plotted this way, the $J=0$ position represents a finite chamber diameter but a zero diameter nozzle throat. Extrapolation to an intercept on the $\alpha$-axis in this case yeilds fairly large values. Since the extrapolation in this case may include rather large porous plate or wall losses as $J$ approaches zero, these sources of loss were examined further. The wall losses were computed as discussed previously. The results of these calculations are presented in Table 4 and indicated by the arrows on Fig. 14 and show that the wall losses alone are far below the observed values. The experimental acoustic losses must then have been due to the presence of the porous plate since all other losses have been shown to be small compared to the measured values. The conclusion is that the zero velocity damping $(J=0)$ is primarily due to the porous plate. 
In summary, extrapolation of the constant-nozzle curves (Fig. 13) to $J=0$ gives losses in reasonable agreement with the calculated bulk losses which should be dominant in this type of limiting argument. On the other hand, extrapolation of the constant-chamber curves (Fig. 14) to $J=0$ gives a residual loss that is much higher than the wall losses. This result suggests that losses from the porous plate are dominant in the limit of small $J$ when the motor diameter is comparable to the plate diameter.

$J \neq 0$ Losses. When $J \neq 0$, the nozzle losses must be considered. Additionally, in the presence of appreciable mean flow, due consideration must also be given to a re-evaluation of the bulk and wall losses.

The various types of bulk losses are in essence a result of the presence of time dependent, localized temperature and pressure gradients created in the body of the gas by the standing wave. A superimposed uniform mean velocity imposed on an oscillating gas column would not be expected to cause any major change in magnitude of this type of bulk damping since it would have little effect on the relative state of adjacent gas particles. The mean flow could however effect the damping by a more gross turbulent effect due to the possibility of conversion of mean flow energy into acoustic energy or by degradation of acoustic energy caused by non-acoustic irregularities in the flow (Ref. 9 and 12). Such effects would be expected to be most important at high mean gas velocities and could be relatively more important for less "clean" geometries than those used in this series of tests.

Results from Ref. 10, p. 502, indicate that the effect of mean flow on viscous and thermal losses at the wall is not large, thus the principal effect of increasing $J$ is expected to be in losses associated with the nozzle and, possibly, with the porous plate.

Examining the contribution of the porous plate to losses for the case of $J \neq 0$, it is hypothesized that the losses are low under conditions where the pressure drop across the plate is high, with losses going to zero when sonic or near sonic flow prevails in the outlet pores of the plate. It may be observed in Fig. 14, 16 and 17 , that the experimental results show the attenuation coefficient varies linearly with J. However, as the nozzle size goes to zero, there is a lower pressure drop across the porous plate and the attenuation constant tends to deviate from this linear relation. The data in Fig. 17 are a replot of data in Fig. 16 having only tests with a pressure ratio across the porous plate greater than 2.3 , a condition interpreted as giving sonic or near-sonic exit flow from the pores of the plate. It is significant that exclusion of the low pressure ratio points leaves data which are well correlated by a single line. 


\section{COMPARISON OF PRESENT RESULTS WITH THEORY}

The previous discussion has indicated that the acoustic losses from the chamber are primarily due to the transmission of acoustic energy through the nozzle. A consideration of the possible mechanisms involved suggest that these losses are due to the radiation of acoustic energy from the nozzle and the convection of additional energy through the nozzle. Mathematically, this means that the attenuation constant, $\alpha$, consists of two terms: one depending on the nozzle admittance and one on the mean flow through the nozzle.

An analysis accounting for both of these terms has been made by Hart and McClure (Ref. 11, p. 1051) and which for an end-burner (the mass addition situation most closely corresponding to the present experiment) gives a nozle attenuation constant of:

$$
\alpha_{N}=\frac{V}{L}+\left(\frac{\gamma-l}{2}\right) \frac{V}{L}
$$

The first term of this equation accounts for the convective effects. The second term accounts for the nozzle radiation losses and is based. on a calculation of the nozzle admittance function made previously by Crocco and Cheng (Ref. 13, p. 180).

To relate $V$, the mean gas flow velocity in the chamber, to $J$, a plot was made of the isentropic data in Shapiro (Ref. 14, p. 614) - this being given in Fig. 19. This shows that for the range of $J$ values encountered in the present work ( $J$ less than 0.4 ) an essentially linear approximation can be used:

$$
\frac{\mathrm{V}}{\mathrm{a}^{*}} \simeq 0.66 \mathrm{~J}
$$

so that

$$
V \simeq 0.66 a^{*} \mathrm{~J}
$$

Using this expression in $\mathrm{Eq}$. 8, the following relation between $\alpha$ and $\mathrm{J}$ results:

$$
\alpha_{N}=0.66 \frac{a^{*} J}{I}\left(1+\frac{\gamma-1}{2}\right)
$$

This curve is compared to the experimental results by the dashed line on Fig. 17. As can be seen, the computed value for the nozzle transmission losses falls much below the "nozzle loss" line of the test data. 


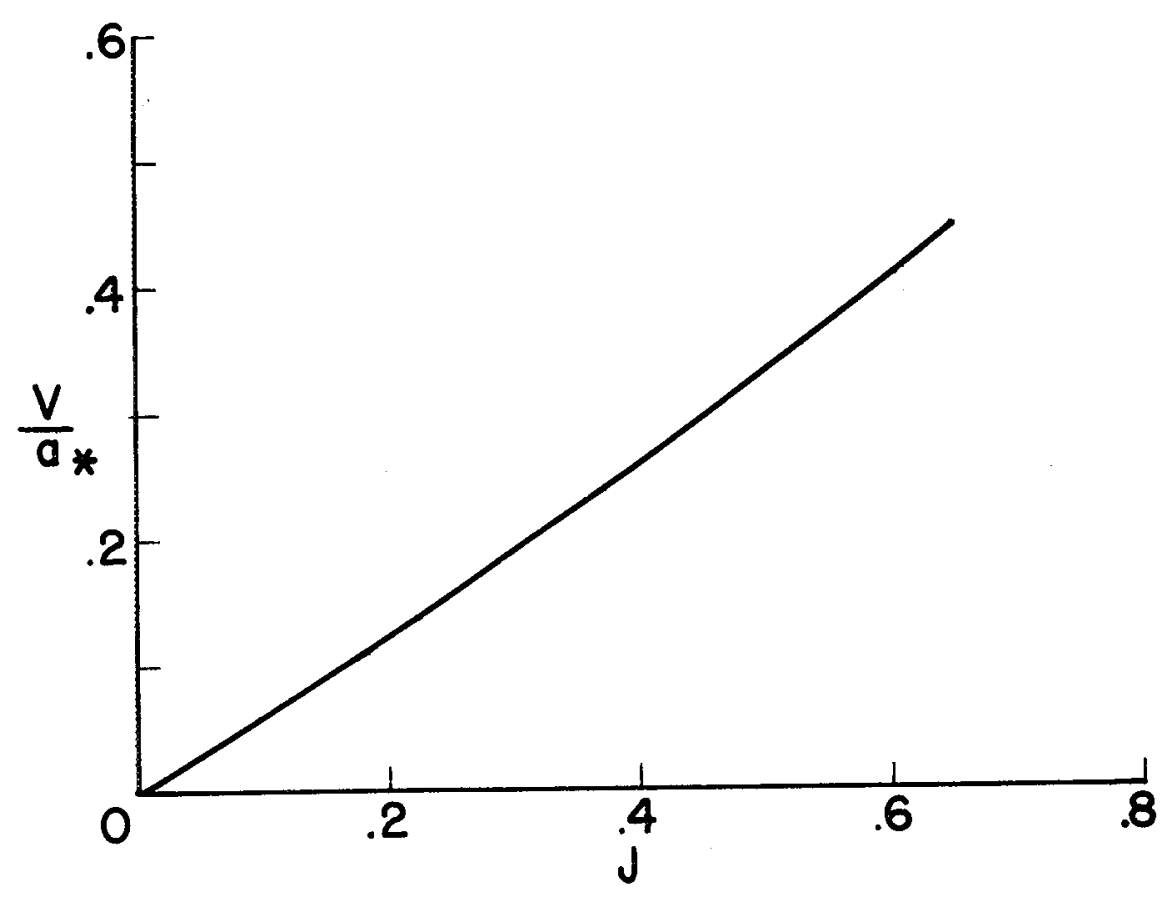

FIG. 19. Nondimensionalized Ratio of Mean Chamber Flow Velocity (V) to Critical Nozzle Velocity ( $a^{*}$ ) Plotted as a Function of $\mathrm{J}$. Used in computation of nozzle losses by Hart and McClure theory. Computed from experimental conditions using isentropic theory.

Crocco and his co-workers later found experimentally that the real part of the nozzle admittance was roughly twice as large as they had predicted theoretically (Ref. 16). It was believed that this was due to a departure from the initially assumed isentropic conditions.

In view of the disagreement of the predicted results with the present experimental data and considering Crocco's results, a relatively simple, one-dimensional analysis for a system with no mean flow was made. This analysis assumed that the driving was done by a vibrating piston at the head end of the chamber with a velocity

$$
u=u_{0} \cos \omega t
$$

The nozzle was approximated by assuming that the aft end of the chamber was coupled to a nonreflecting infinite tube with a diameter corresponding to that of the throat of an actual nozzle. The ratio of the 
area of the tube to the chamber would thus correspond to $\mathrm{J}$. Only damping due to radiation to the smaller tube was considered.

Using the defining relation for $\alpha$

$$
\alpha=\frac{E}{2 E}
$$

the values of $\dot{E}$ and $E$ were computed from the linear analysis as

$$
\frac{\dot{E}}{A_{c}}=\frac{\rho c u_{o}^{2} A_{c} A_{t}}{A_{c}^{2} \sin ^{2} k L+A_{t}^{2} \cos ^{2} k L}
$$

and

$$
\frac{E}{A_{c}}=1 / 4 \rho u_{o}^{2} L\left[I+\left(\frac{A_{c}}{A_{t}}\right)^{2}\right]
$$

If it is assumed that a pressure anti-node exists at the nozzle entrance, the above expressions can be used in Eq. 12 to give:

$$
\alpha=\left(\frac{\mathrm{J}}{\mathrm{J}^{2}+1}\right) \frac{\mathrm{c}}{\mathrm{L}}
$$

It is interesting to note that here $\alpha$ is independent of the upstream boundary condition and depends only on the downstream area ratio.

When this expression is used in conjunction with the Hart-McClure convective term, the following expression for the nozzle attenuation constant results:

$$
\alpha_{N}=\frac{\rho^{*} V^{*}}{\rho L} J+\left(\frac{J}{J^{2}+1}\right) \frac{c}{L}
$$

where the starred quanities refer to conditions at the sonic nozzle throat and the unstarred quanities refer to the nozzle inlet conditions. Assuming $J^{2}<l$, one obtains

$$
\alpha=\frac{\rho^{*}}{\rho} \frac{V^{*}}{c} \frac{c J}{L}+\frac{c J}{L}
$$


Since $I$ is small, the Mach number is small and, therefore,

$$
\frac{\rho^{*}}{\rho} \simeq \frac{\rho^{*}}{\rho_{0}} \equiv\left(\frac{2}{\gamma+1}\right)^{\frac{1}{\gamma-1}}
$$

and

$$
\frac{V *}{c}=\left(\frac{2}{\gamma+1}\right)^{1 / 2}
$$

substituting these relations into $\mathrm{Eq}$. 17 , the expression for a becomes

$$
\alpha=\left(\frac{2}{\gamma+1}\right)^{\frac{\gamma+1}{2(\gamma-I)}} \frac{c J}{L}+\frac{c J}{L}
$$

For $\gamma=1.2$

$$
\alpha \simeq 1.59 \frac{\mathrm{cJ}}{\mathrm{L}}
$$

and for $\gamma=1.4$

$$
\alpha \simeq 1.58 \frac{\mathrm{cJ}}{\mathrm{L}}
$$

The trend predicted by Eq. 20 is indicated by the solid line through the experimental data points in Fig. 17.

Reference 17 gives a detailed derivation of the equations involved in the one-dimensional, no-flow treatment and discusses how they were used to obtain the final loss expression. Although the use of these equations resulted in excellent correlations of the experimental data, it would seem from the assumptions made that the agreement may be fortuitous.

RESONANT FREQUENCY

Plots of the chamber resonant frequency versus $J$ are shown in Fig. 15. The frequency is nondimensionalized by dividing by the first mode frequency of the test chamber treated as a closed-closed tube. 
The difference between the values of the experimental intercepts with the vertical axis and the predicted value of one could be explained by variations of the gas temperature, since the computed frequency was based on a nominal gas temperature of $40^{\circ} \mathrm{F}$, and by experimental scatter of the data.

\section{CONCLUSIONS}

The present work was undertaken because of the difficulty of predicting the stability of rocket motor combustors. The objective was to provide an inexpensive means for determining the acoustic attenuation of axial modes of relatively complicated combustor cavities. The method was proven by using a simple combustor configuration for which losses could be roughly predicted, and the results of this preliminary testing are presented. For the axially symmetrical geometries studied, the results indicate the following:

1. Nozzle radiation losses increase approximately linearly with $\mathrm{J}$.

2. Nozzle losses are independent of the way in which $J$ is changed; either by a change in the grain port area or the nozzle throat area.

3. The nozzle losses determined experimentally are greater than had been previously predicted. However, the present results seem to agree closely with a theory using a linear, no-flow nozzle admittance term and the Hart-McClure convective term. For engineering design purposes, the nozzle attenuation constant including both radiation and convection of acoustic energy for first longitudinal mode oscillation can be approximated by

$$
\alpha \simeq 1.59 \frac{\mathrm{cJ}}{\mathrm{I}}
$$

4. The data and the theoretical analysis show that under the test conditions both the acoustic bulk and wall losses were negligible compared to the nozzle radiation losses for the axial mode of oscillation.

5. The experimental method was found to be a suitable and promising technique. The steady-state resonance method was applicable through the $J$ range of practical interest and can be used for attenuation studies either with or without critical nozzle flow. The use of meters in conjunction with the $X-Y-Y$ plotter in steady-state tests greatly improved the accuracy and the speed of the data reduction formerly done from oscillograph records alone.

In addition to the steady-state resonance method of determining the attenuation constant, the possibilities and limitations involved in using two decay measurement techniques were also investigated and are described in the appendices. The pulse decay technique was not satisfactory due to 
the introduction of hot combustion gases and solid phase matter into the chamber and because of multiple-mode excitation. The steady-state decay technique was found to be limited to rocket chambers with decay constants less than $150 \mathrm{sec}^{-1}$ corresponding to geometries with small nozzle to grain port area ratios ( $J$ less than 0.14 ). The results of these tests were valid, however, and gave an independent confirmation of the attenuation constant in the range where it could be applied. The results of this investigation established the validity of the original concept of the experiment, and provided valuable information towards development of a fully automated test apparatus. When final construction is completed it will be possible to routinely evaluate the acoustic response of various solid or liquid rocket motors having more complex geometries, to test various chamber damping devices, and to carry out systematic investigations for research. Since these tests can be run easily, quickly, and cheaply compared to motor firings, and since geometrical effects can have serious consequences on various motor processes, the use of this system as a design tool is strongly recommended. 
Appendix A

EVALUATION OF MODEL AND INSTRUMENT SYSTEM

A number of investigations were made regarding various aspects of the model and instrument system behavior. These tests were motivated primarily to establish the accuracy of the data and to discover reasons for certain characteristics of the system.

Tests were run to examine the behavior of the chamber oscillations and half-power bandwidth $Q$ as a function of the driving or rotary valve inlet pressure. These tests were run for both a 3-6 and a 6-3 geometry. The results for the latter case are shown in Fig. 20. The conclusions from these tests were: (1) the valve pressure does not alter the basic level of off-resonance chamber response, (2) this suggests that the basic off-resonance response level is due to noise associated with the particular geometry being tested, and ( 3 ) that $Q$ is essentially the same for all rotary valve inlet pressures as long as it can be read above the off-resonance noise level and is read from the no-flow base line.

Tests were run to determine the noise level as a function of nozzle size. For these tests the various nozzle end plates were fastened to an empty chamber. The rotary valve was blocked off from the prechamber and the flow was supplied from the mean or DC flow system only. Since the abscissa of the $X-Y-Y$ plotter was actuated by the frequency signal from the valve, the valve was run through the usual frequency range to obtain a plot analogous to the other test records. The $X-Y-Y$ plotter sheet from this series of tests is shown in Fig. 2l. A graph of the results, where the electric zero values have been subtracted out, is given in Fig. 22. The conclusions from these tests were: (1) the system noise for any particular geometry is primarily aerodynamic, (2) maintaining a chamber pressure level of 20 psig, there is a large increase in the noise level as the nozzle size is increased.

Tests were run to determine whether the above increase in the noise level was due to the larger circumference associated with a larger nozzle. For this test, another nozzle end plate was made which had two nozzles instead of the usual one but which had the same total nozzle throat area as the No. I nozzle (throat diameter $=0.627$-inch). For this arrangement, the total circumference of the two-hole nozzle is 1.414 times the circumference of the single nozzle. The conclusion from this test was that since the amplitude response was essentially identical for the two geometries at frequencies other than at resonance 
$Q=\frac{6}{\Delta f}$ at valve inlet pressure

$Q_{1}=\frac{554}{9}=61.6$ at $183-185$ psig

$Q_{2}=\frac{553}{9}=61.5$ at 102

$Q_{3}=\frac{552}{9}=61.4$ at 76

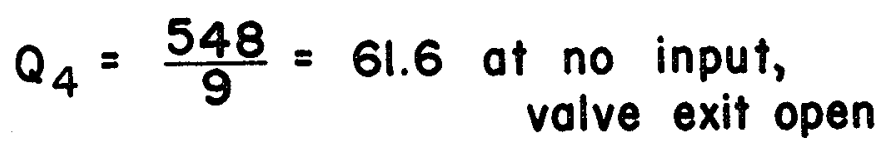

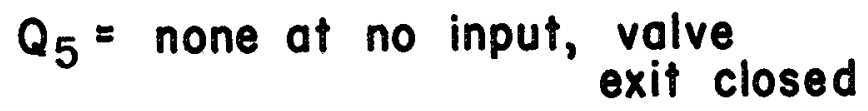

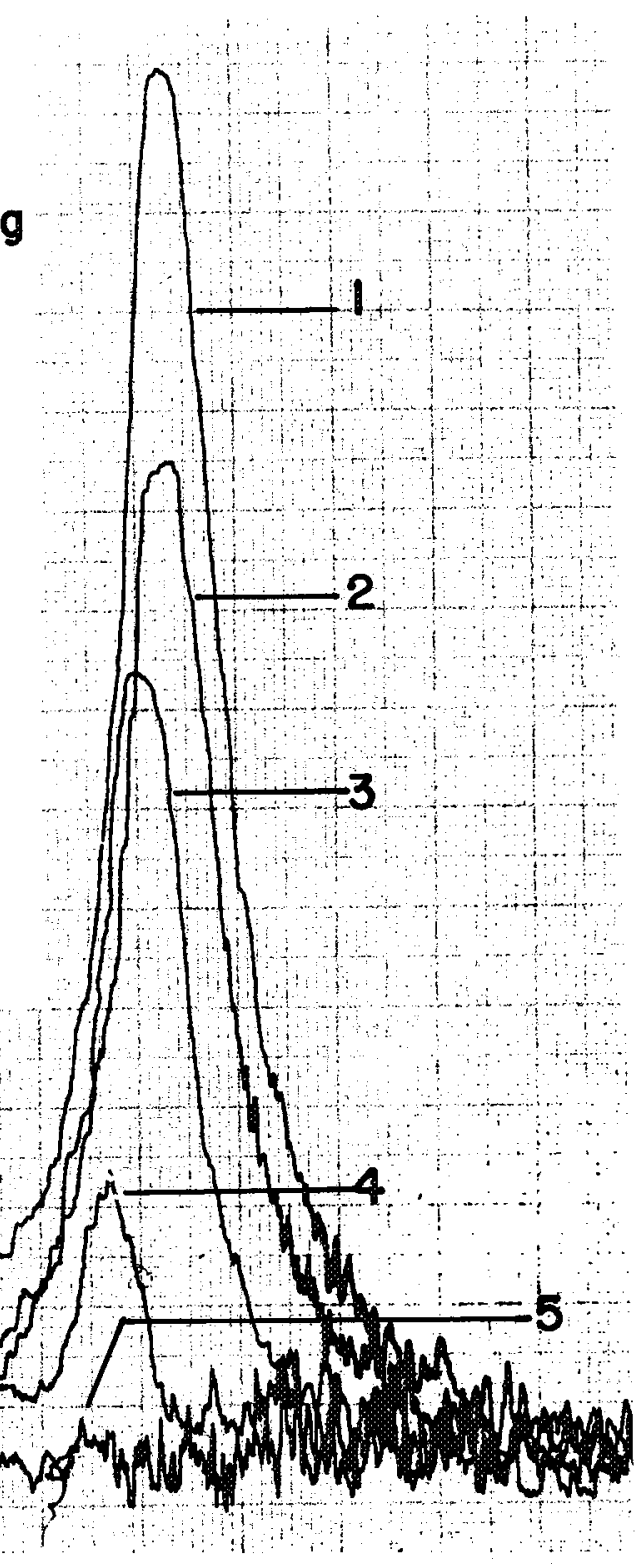

FIG. 20. Chamber Response Versus Frequency. Taken to study effect of upstream rotary valve inlet pressure on chamber oscillation strength and $Q$. Nozzle No. 3 (throat diameter $=.375 \mathrm{inch}$ ). $\mathrm{J}=.0115$. Chamber pressure $=20$ psig. Test No. 2-16-65-3. 
Noise level (RMS Volts)

I. Nozzle I

2. Nozzle 2

3. Nozzle 3

4. Nozzle 4

5. Nozzle 5

6. No nozzle - no flow $0.25-0.35 \mathrm{v}$

$\left.\begin{array}{l}1.5-1.6 v \\ 1.05-1.2 v \\ 0.5-0.6 v \\ 0.29 v \\ 0.29 v \\ 0.25-0.35 v \\ 0.24 v\end{array}\right\}$

No flow through rotary valve

7. Electrical noise level $0.24 \mathrm{v}$

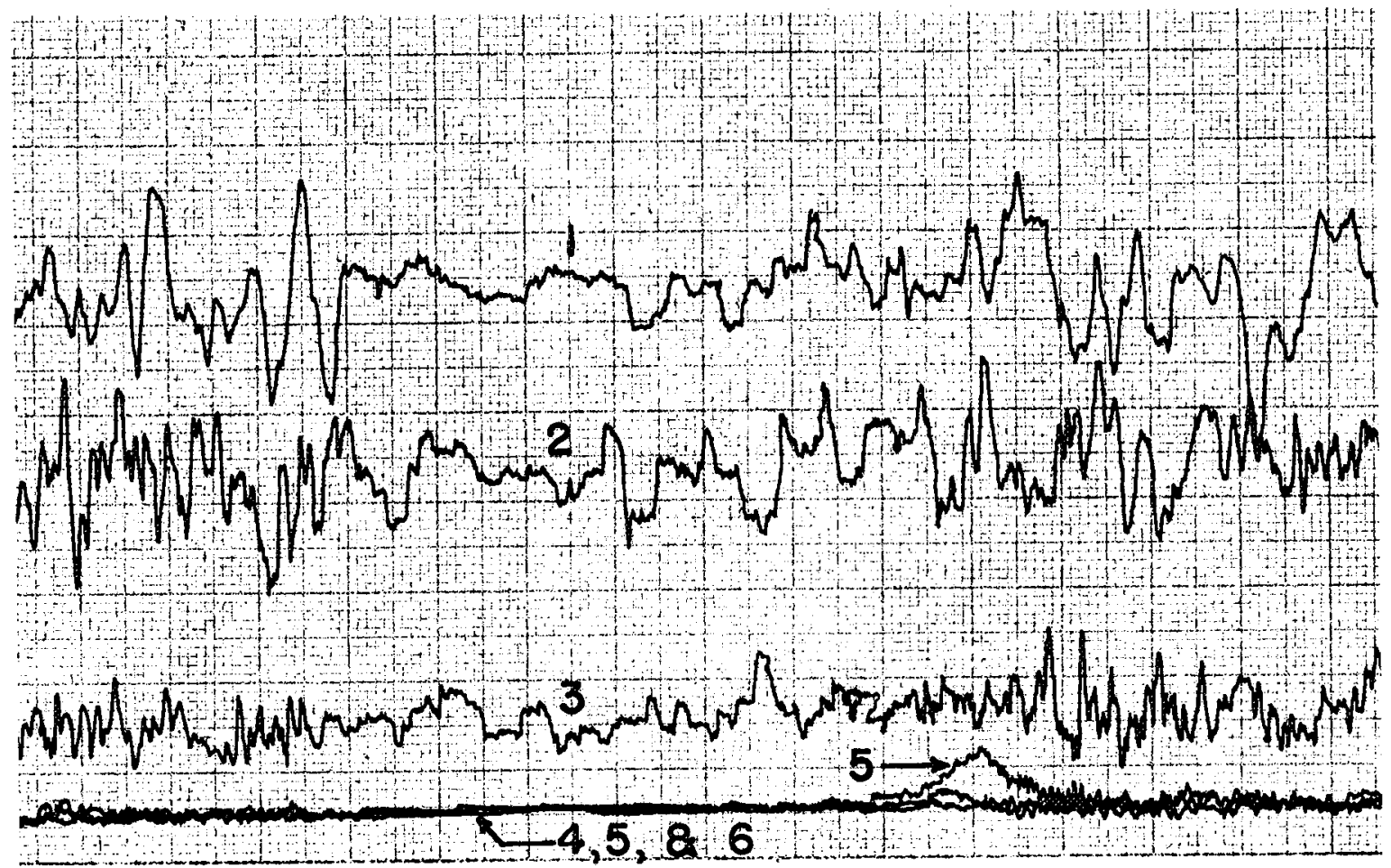

FIG. 21. Chamber Response Without Excitation Versus Frequency. Taken to study effect of nozzle size (mean flow) on chamber noise level. Nozzle throat diameters: No. $1=.625$ inch; No. $2=.500$ inch; No. $3=$ .375 inch; No. $4=.250$ inch; No. $5=.125$ inch. Chamber pressure $=$ 20 psig. 


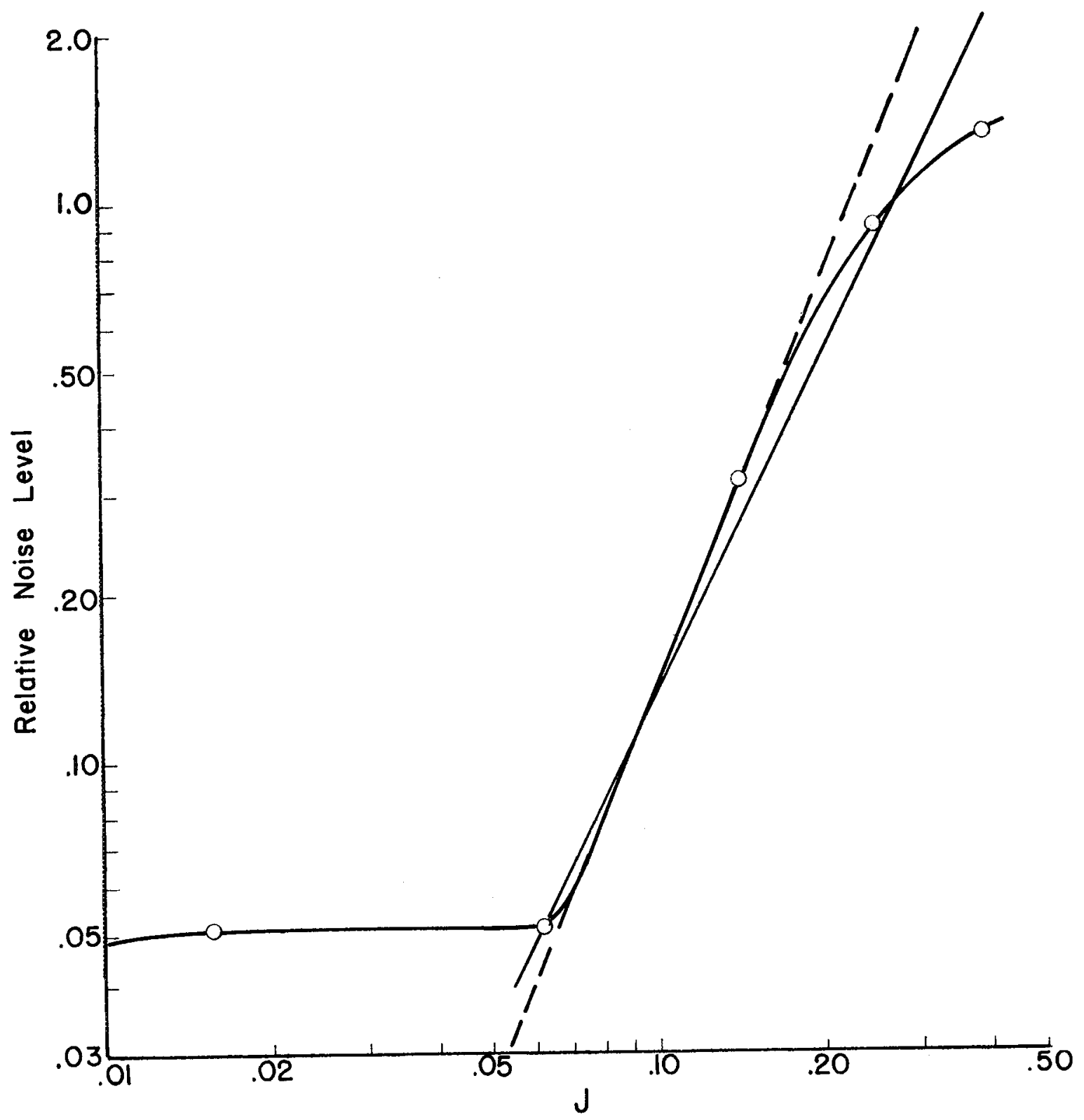

FIG. 22. Increase in the Chamber Acoustic Noise Level With Increasing Nozzle Throat Area (and Hence Flow Rate) for Constant Chamber Pressure of $20 \mathrm{psig}$ and Grain Port Diameter of 3.5 Inches. 
(Fig. 23), the chamber noise was due either to flow through the porous plate at the head of the chamber or to turbuient noise from flow along the inside of the model chamber.

Tests were run to examine the noise level and $Q$ as a function of the chamber pressure. It was believed that a 6-3 geometry would be representative of both the geometry range and $J$ range of the tests in this work and this was used. One test was at a chamber pressure of $40 \mathrm{psig}$, one at $30 \mathrm{psig}$, and one at $20 \mathrm{psig.} \mathrm{The} \mathrm{data} \mathrm{is} \mathrm{presented} \mathrm{in}$ Fig. 24. The conclusions were: (1) a higher chamber pressure, and consequently a higher mass flow rate, results in higher noise levels, (2) higher chamber pressure, and consequently a higher mass flow rate, also results in higher resonant peaks (presumably more random acoustic energy is available to be converted into an orderly resonance response) and ( 3 ) $Q$ of the chamber is essentially unchanged as long as the chamber pressure is high enough to insure a critical nozzle throat condition.

Tests were run to examine the change in level of the chamber oscillation strength as the mean flow is increased (see paragraph above) by increasing chamber pressure. These two parameters are plotted along the ordinate and abscissa respectively of Fig. 25 which shows the test results. The tests were run using a 6-3 geometry. The slope of the acoustic pressure amplitude curve changes slowly in the vicinity of the critical pressure ratio and appears to approach lines of constant slope 


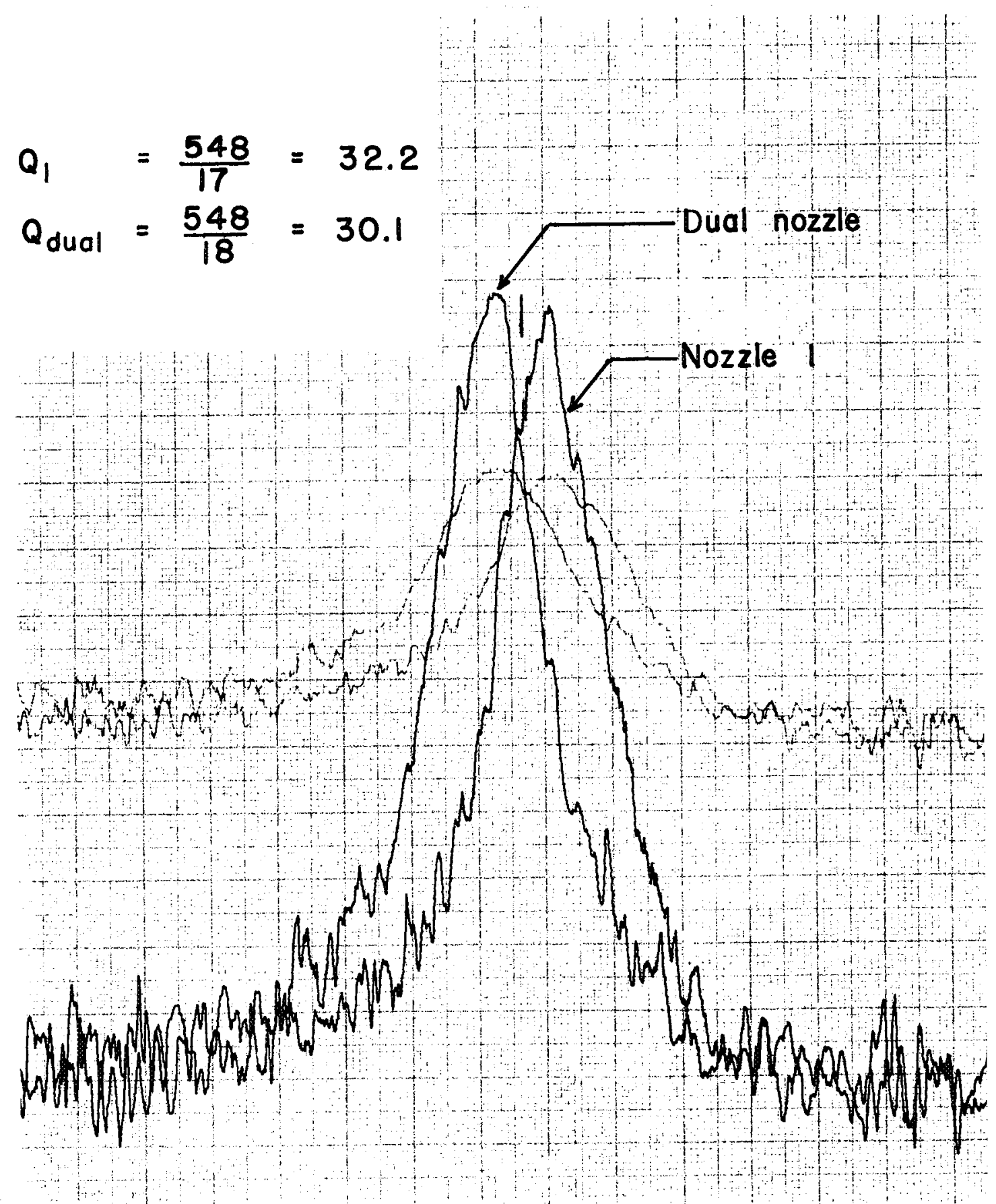

FIG. 23. Behavior of Chamber Noise Level as Function of Nozzle Throat Circumference for Same Nozzle Throat Area: Nozzle No. I Versus Dual Nozzle. Chamber pressure - 20 psig. 


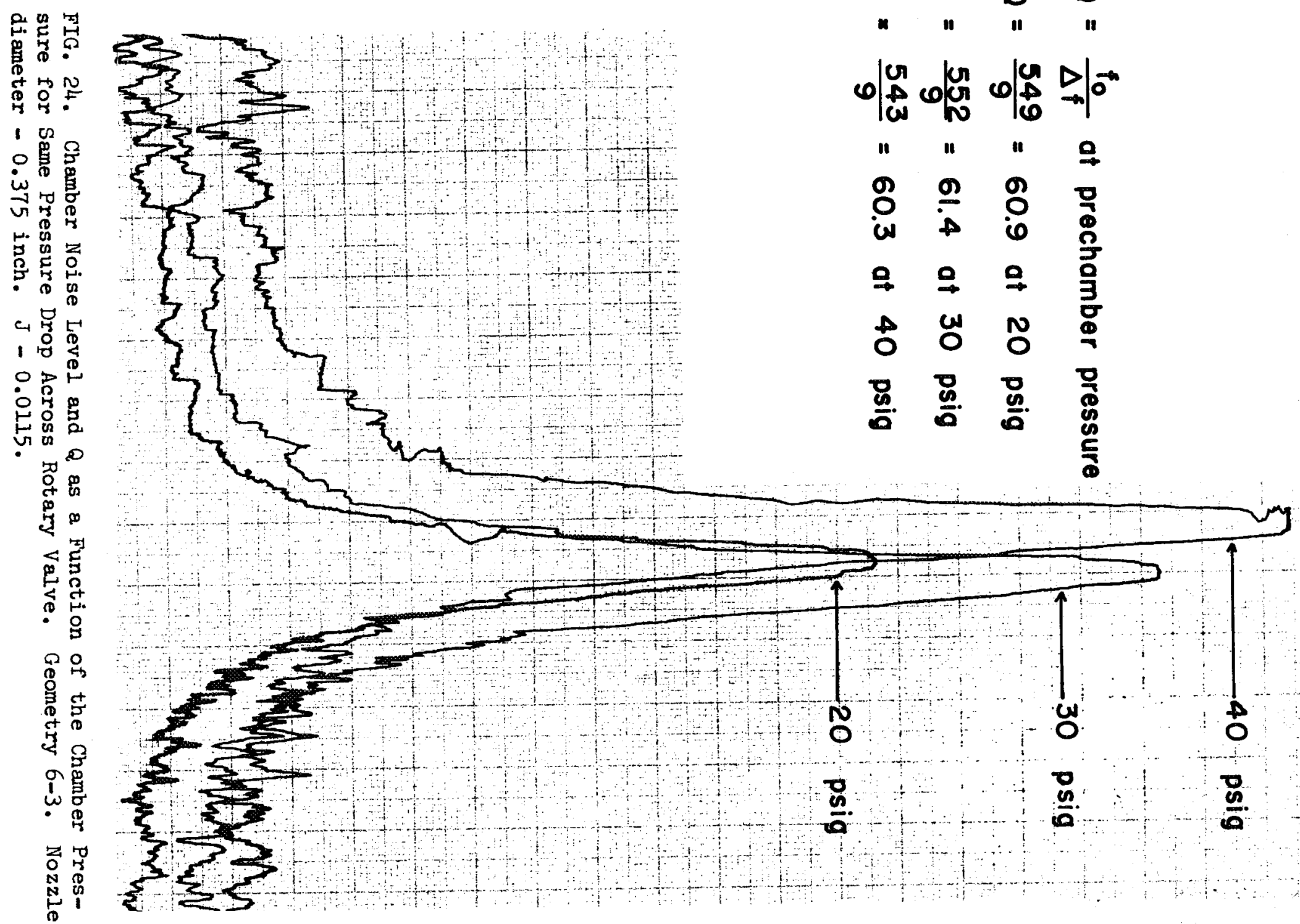


Amplitude of Chamber Response

so

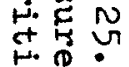

䗆

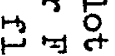

₹

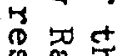

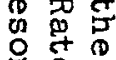

政

$<<$

象

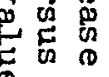

觔

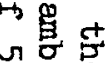

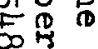

$\circ$ 용

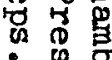

(5)

वृ.

空

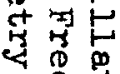

志㤐总

造 施

官窇

竞

8

员空

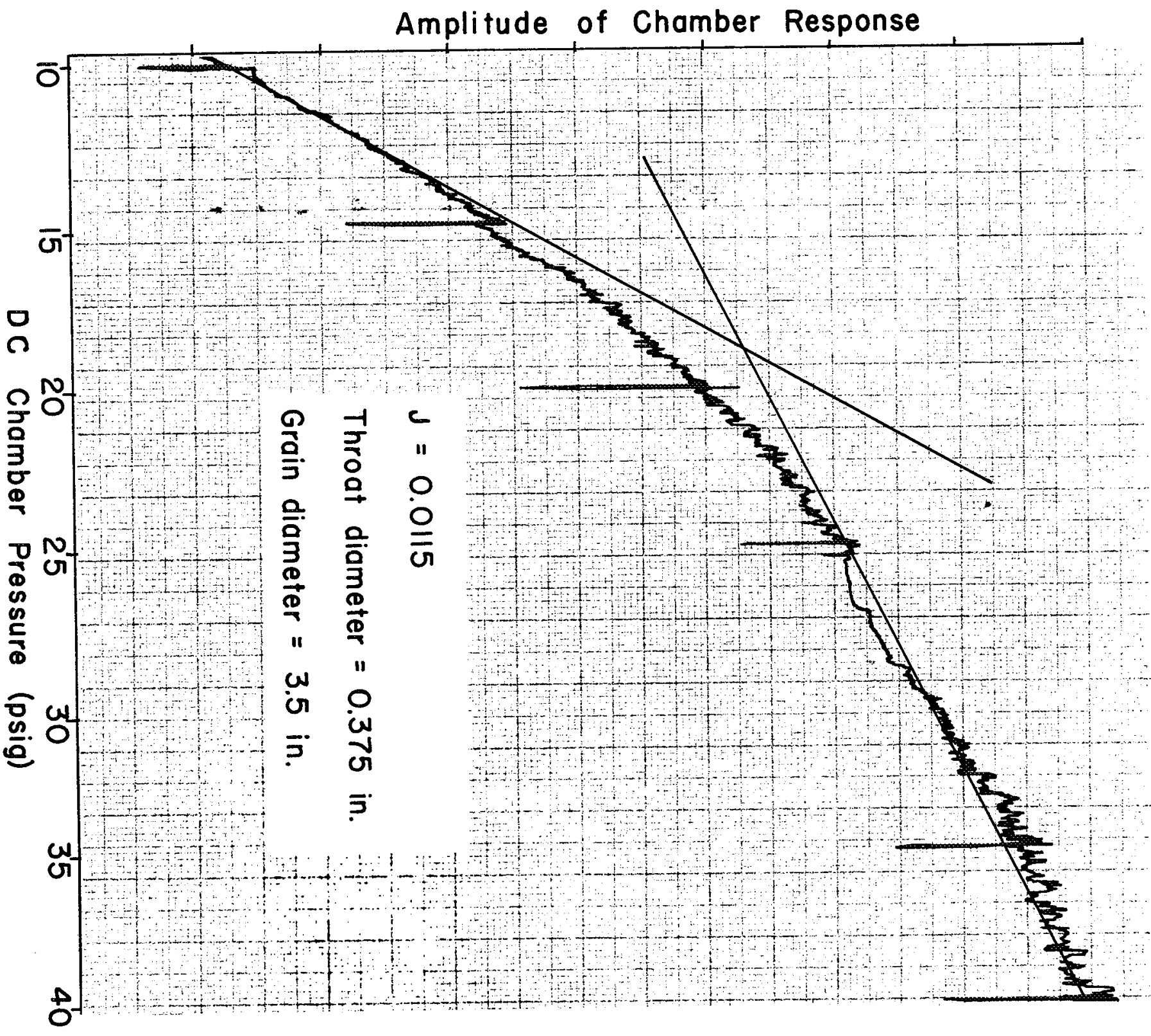


Appendix B

COMPARISON OF LOSS MEASUREMENTS USING VARIOUS DECAY TECHNIQUES

In the main part of the report, the response of the system to a quasi-steady-state driving frequency was analyzed. This gave a resonance curve from which the acoustic attenuation constant was derived. However, the rate of energy loss from a resonant system can also be determined from the decay of its free vibrations. Since there are test situations where it would be inconvenient to use the steady-state equipment, the use of various decay techniques were investigated. These included pulsed driving of the chamber using both blank cartridges and a burst diaphragm and the measurement of the decay of the wave shape from its steady-state performance. The results of this work show that while there is considerable discrepancy between the pulse results and the previous steady-state data, the agreement is quite good using the steadystate decay measurements.

\section{BLANK CARTRIDGE PULSE TESTS}

In this technique a blank cartridge was used to generate a pulse with a sharp front. It was assumed that the acoustic energy of the harmonics making up the pulse shape would drive the various frequencies of the cavity with the fundamental axial mode being predominant. Once excited and the driving source removed, the acoustic pressure for each mode of vibration will decay exponentially at its own frequency and at a rate determined by its particular damping constant. A sound-pressure decay curve obtained from an oscilloscope trace of the chamber response should therefore give the necessary data to determine the acoustic attenuation constant for a given motor geometry.

The model hardware used to conduct these tests was essentially the same as described previously for the steady-state work. Now, however, the Varidrive motor was disconnected from the prechamber, and a pulse generating device referred to as the "gun" was introduced to the chamber cavity.

At first, the excitation pulse was formed by a small black powder charge loaded into a steel tube which passed through the prechamber and into the chamber. The charge was ignited by a shorted bridge wire. Later, in the interest of safety and repeatability, the hardware was redesigned (Fig. 26) to fire either a .32 caliber or a .22 caliber blank cartridge, an adapter being slipped into the receiver end of the tube when using the latter. A cap was screwed onto the end of the tube which received the shell. This cap had a solenoid actuated firing pin suitable to the type of cartridge being fired, i.e., the center-fire .32 's or the rim-fire .22's. 

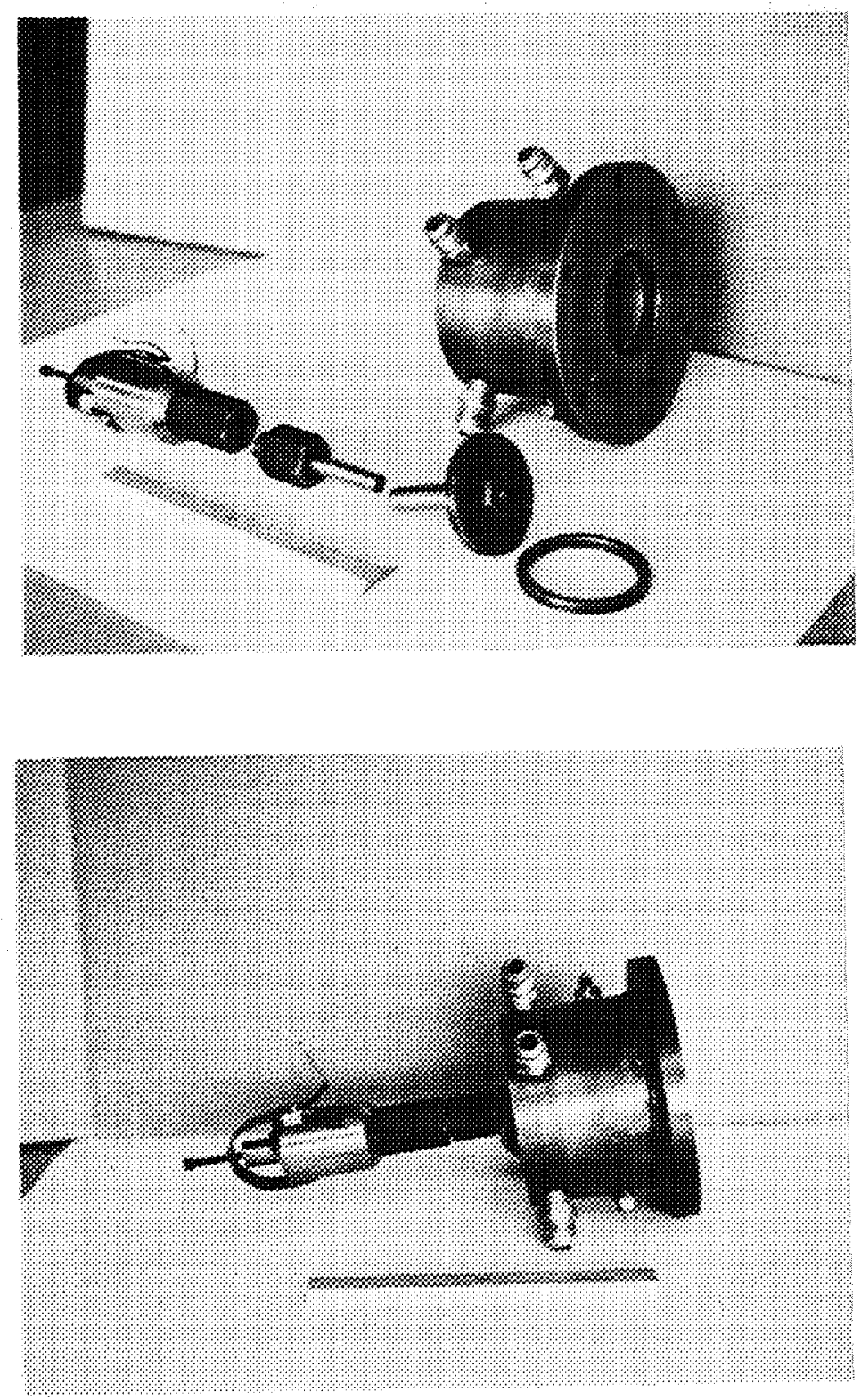

FIG. 26. The Disassembled and Assembled Pulse Gun Hardware Used to Fire Blanks in the Transient Response Tests. 
The central location of the gun muzzle at the head of the chamber precluded the use of this spot in the chamber for a transducer. Thus, transducer mounting holes were placed in each of the nozzle end plates, just off-axis so as not to interfere with the interior nozzle geometry, so that an external transducer could be flush-mounted with the interior end plate. A 0 to 200 psig Photocon transducer was used to monitor the AC chamber response.

As before, the primary air supply entered the model via the prechamber and, hence, through the perforated and porous steel plates separating the prechamber from the chamber.

Figure 27 is typical of the pulse decay oscilloscope traces obtained using this method and shows that as $J$ decreases for a given nozzle size, corresponding to increasing the grain port area, the motor cavity becomes considerably more conservative. The acoustic attenuation constants determined from these records were much higher than those obtained previously using the steady-state resonance technique and are presented in Table 5.

TABLE 5. Blank Cartridge Data, Nozzle No. 3

\begin{tabular}{|c|c|c|c|c|c|}
\hline $\begin{array}{c}\text { Test } \\
\text { number }\end{array}$ & Geometry & $\mathrm{J}$ & $\begin{array}{c}\text { Chamber } \\
\text { pressure, } \\
\text { psig }\end{array}$ & $\begin{array}{l}\text { fo' } \\
\text { cps }\end{array}$ & $\sec ^{\alpha, 1}$ \\
\hline \multicolumn{6}{|c|}{ Commercial } \\
\hline $\begin{array}{l}184 \\
182 \mathrm{~A} \\
181 \mathrm{~A} \\
182 \\
181 \\
180 \\
61\end{array}$ & $\begin{array}{l}1-3 \\
2-3 \\
3-3 \\
4-3 \\
5-3 \\
6-3 \\
6-3\end{array}$ & $\begin{array}{l}0.1407 \\
0.0625 \\
0.0351 \\
0.0225 \\
0.0156 \\
0.0115 \\
0.0115\end{array}$ & $\begin{array}{l}20.0 \\
20.5 \\
20.5 \\
21.0 \\
20.0 \\
19.2 \\
20.0\end{array}$ & $\begin{array}{r}1095 \\
1010 \\
867 \\
766 \\
691 \\
662\end{array}$ & $\begin{array}{r}727 \\
537 \\
276 \\
91 \\
58 \\
92\end{array}$ \\
\hline \multicolumn{6}{|c|}{ B. .32 Blank, Commercial } \\
\hline $\begin{array}{l}216 \\
217 \\
218 \\
219 \\
220 \\
221\end{array}$ & $\begin{array}{l}1-3 \\
2-3 \\
3-3 \\
4-3 \\
5-3 \\
6-3\end{array}$ & $\begin{array}{l}0.1407 \\
0.0625 \\
0.0351 \\
0.0225 \\
0.0156 \\
0.0115\end{array}$ & $\begin{array}{l}20.0 \\
20.0 \\
20.5 \\
20.7 \\
20.9 \\
20.8\end{array}$ & $\begin{array}{r}10 \\
1150 \\
1039 \\
834 \\
662\end{array}$ & $\begin{array}{r}20 \\
266 \\
176 \\
104 \\
96 \\
85\end{array}$ \\
\hline
\end{tabular}



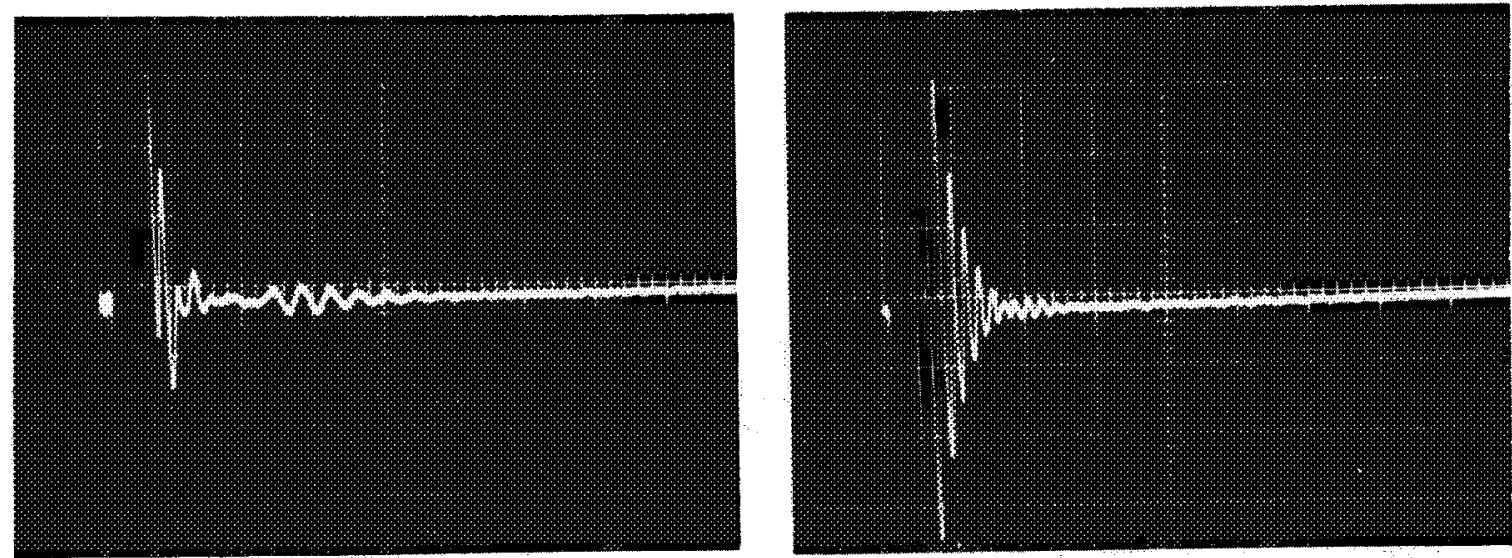

Test 184

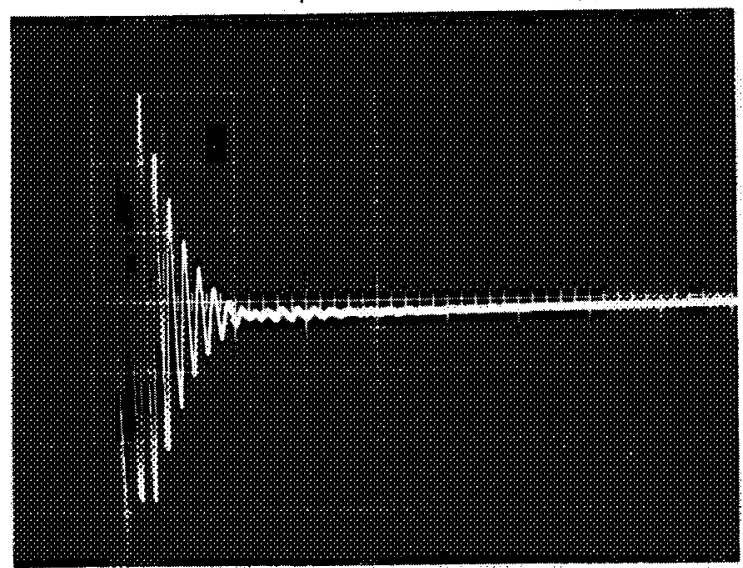

Test $181 \mathrm{~A}$

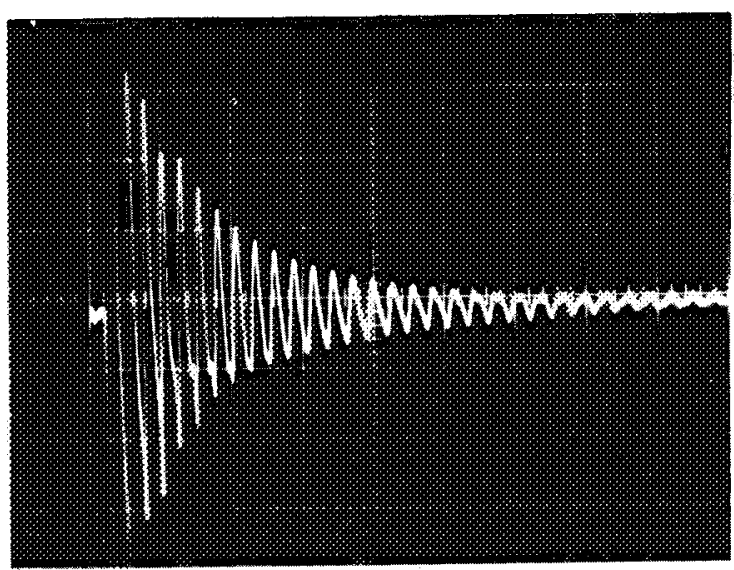

Test 181

$$
J=.0156
$$

Test $182 \mathrm{~A}$

$J=.0625$

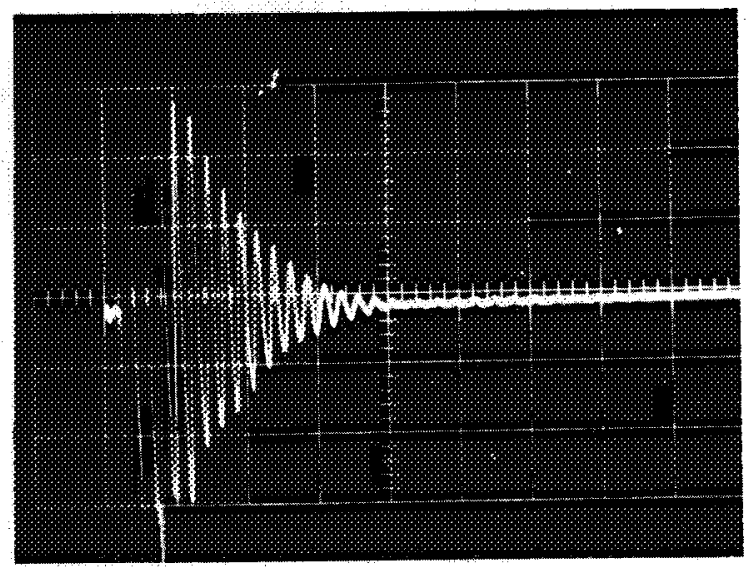

Test 182

$J=.0225$

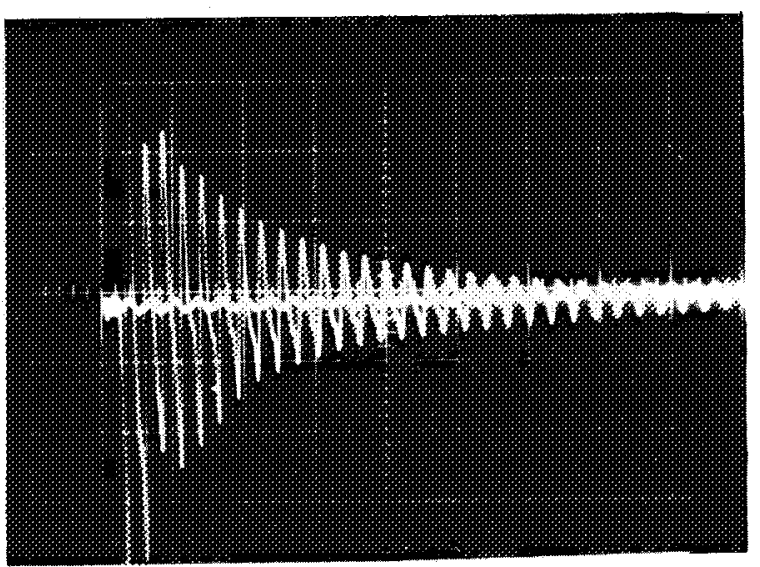

Test 180$$
J=.0115
$$

FIG. 27. Oscilloscope Records for .22 Blank Pulse Tests Using Nozzle No. 3 and Increasing Grain Port Area. Chamber pressure $=20$ psig. Horizontal sweep $=5 \mathrm{millisec} / \mathrm{cm}$. Vertical sweep $=2.77 \mathrm{psi} / \mathrm{cm}$. 
To determine the reason for the difference between the pulse test data and those obtained in the steady-state tests and to further evaluate the pulse concept for possible future use, several additional tests were made. These included test runs to determine the effect of shell caliber; the possibility of "tailoring" the pulse by recrimping the cartridge in various ways around the end wadding, thereby producing a blank with different firing characteristics; and the influence of condensed phase or particle damping both through the use of different powders and special home-loaded cartridges containing a load of 10micron aluminum oxide particles. The physical characteristics of these shells are listed below:

.22 Short, Commercial - Winchester .22 Short Blanks, extra loud report, containing $186 \pm 3$ milligrams of $3 \mathrm{~F}-\mathrm{G}$ black powder.

.32 Commercial - Winchester .32 Blanks, extra loud report, containing 230 milligrams smokeless powder.

.22 Shorts, Uncrimped and Neck Crimped - Home loaded .22 short blanks containing 70 milligrams of Dupont bulk smokeless powder and wadding.

.22 Short, Roll Crimped - Home loaded .22 short blanks containing approximately 80 milligrams of Dupont bulk smokeless powder and wadding.

.22 Long, Neck Crimped - Home loaded .22 long blanks loaded first with 70 milligrams Dupont bulk smokeless powder, no separator, then 60 milligrams of 10 micron aluminum oxide $\left(\mathrm{Al}_{2} \mathrm{O}_{3}\right)$ polishing compound, and finally wadding.

Fig. 28 shows representative oscilloscope traces, and Table 6 gives the resulting attenuation constants and frequencies observed.

TABLE 6. Special Blank Cartridge Data

\begin{tabular}{l|l|l|l|r}
\hline $\begin{array}{c}\text { Test } \\
\text { number }\end{array}$ & Shell type & $\begin{array}{c}\text { Chamber } \\
\text { pressure, } \\
\text { psig }\end{array}$ & $\begin{array}{c}f_{0^{\prime}} \\
\text { cps }\end{array}$ & $\begin{array}{c}\alpha, \\
\text { sec }^{-1}\end{array}$ \\
\hline 223 & .22 Short Uncrimped & 20.0 & 571 & 33.5 \\
224 & .22 Short Roll Crimp & 20.0 & 579 & 61.7 \\
234 & .22 Short Neck Crimp & 21.5 & 590 & 67.0 \\
225 & .22 Short Commercial & 20.0 & 754 & 114.3 \\
232 & .22 Long, Neck Crimp & 20.4 & 609 & 90.7 \\
233 & .22 Long, Neck Crimp & 20.0 & 590 & 64.4 \\
214 & .32 Commercial & 20.0 & 697 & 91.3 \\
215 & .32 Commercial & 21.0 & 697 & 61.8 \\
\hline
\end{tabular}

${ }^{a}$ Pulse Test Data of 30 December 1964, Geometry: 6-4; $J=0.0051$. 


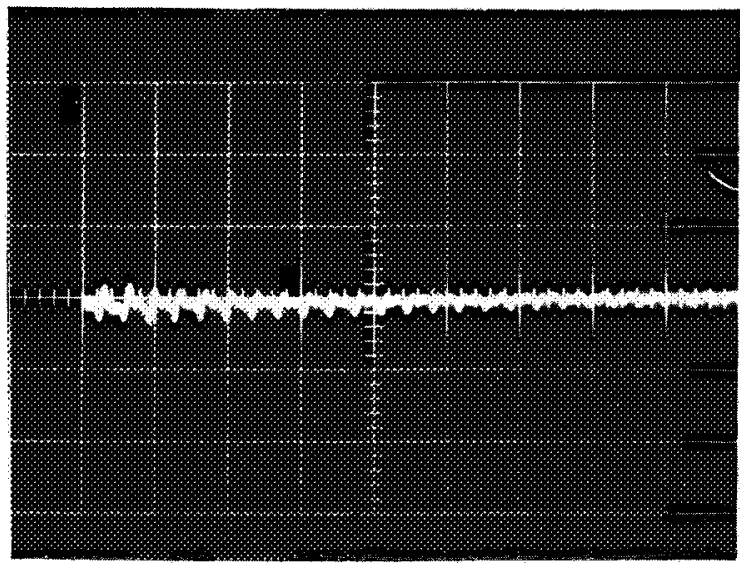

Test 223

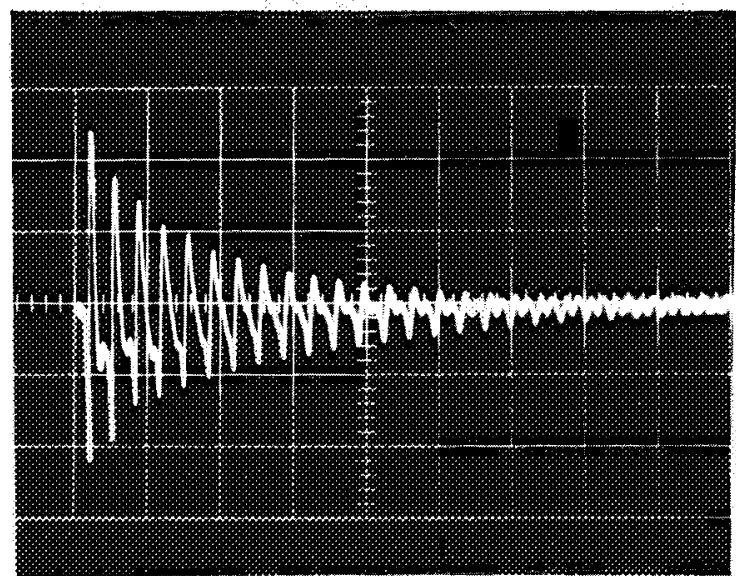

Iest 234 .22 Short, Neck Crimped

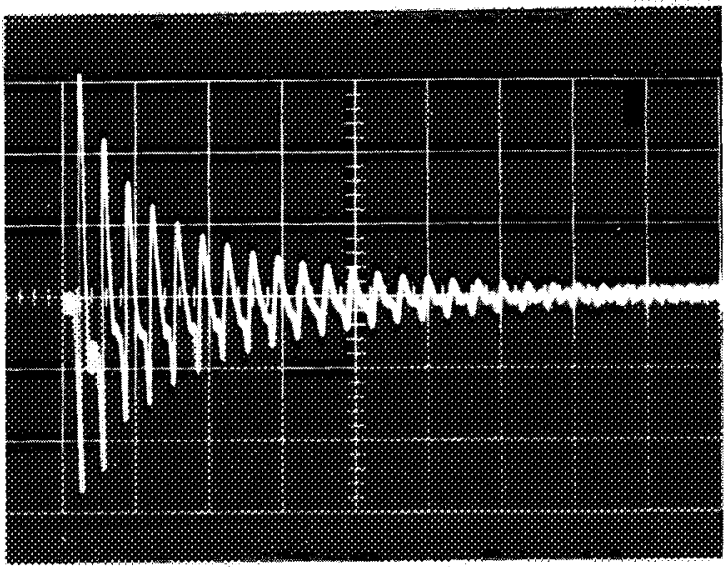

Test $232 \quad .22$ Long, Special

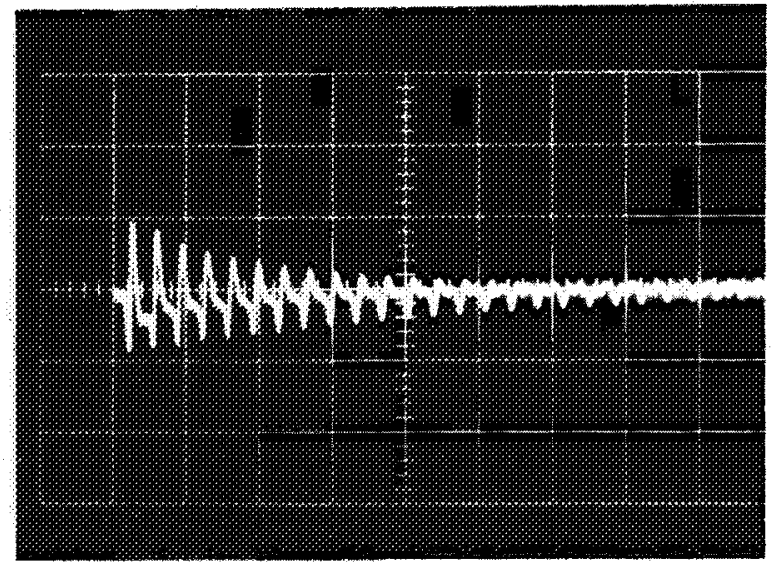

Test $224 \quad .22$ Short, Roll Crimpec

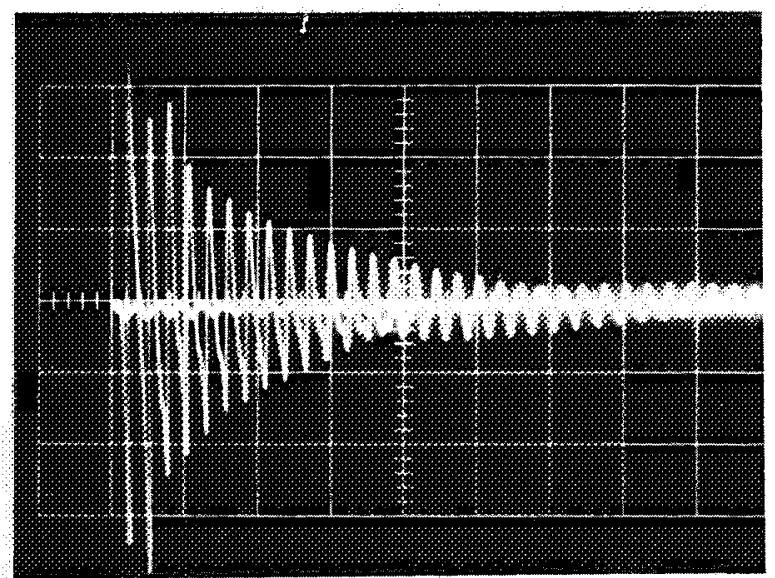

Test $225 \quad .22$ Short, Commercial

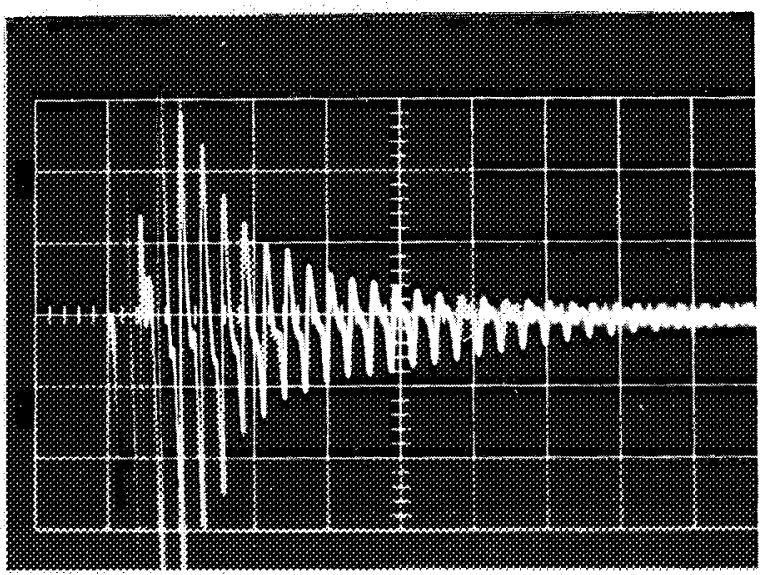

Test $214 \quad .32$ Commercial

FIG. 28. Oscilloscope Records Using Specially Loaded Blank Cartridges to Determine Effects of End Crimping, Condensed Phase Material, and Shell Caliber. Geometry 6-4. Chamber pressure $=20$ psig. Horizontal sweep $=5$ milisec $/ \mathrm{cm}$. Vertical sweep $=2.77 \mathrm{psi} / \mathrm{cm}$. 


\section{BURST DIAPHRAGM PULSE TESTS}

The high frequencies measured in the blank cartridge pulse tests indicated that the pulse cartridge introduced hot combustion gases into the model chamber and so changed the character of the working fluid. Subsequent calculations for two limiting flow cases were able to bracket the frequencies observed. Thus, to (1) remove the temperature change effect, (2) use a working fluid with known properties, and (3) remove any condensed phase material, tests were run using a burst diaphragm to replace the shell.

The same gun barrel arrangement as before was used but with the firing pin assembly replaced by a very short driver chamber. The diaphragm was of .003-inch brass shim stock, scored, and broken by increasing the driver pressure.

Figure 29 is typical of the oscilloscope traces obtained using this technique. The acoustic attenuation constants determined from these records were not as large as those obtained using the blank cartridges but were still higher than the steady-state resonance results. Table 7 gives the decay frequencies and calculated attenuation constants for these tests.

TABLE 7. Burst Diaphragm Data, Nozzle No. 4

\begin{tabular}{|c|c|c|c|c|c|}
\hline $\begin{array}{l}\text { Test } \\
\text { number }\end{array}$ & Geometry & $J$ & $\begin{array}{l}\text { Chamber } \\
\text { pressure, } \\
\text { psig }\end{array}$ & $\begin{array}{l}f_{0} \\
\text { cps }\end{array}$ & $\sec ^{-1}$ \\
\hline \multicolumn{6}{|c|}{ A. Sonic Nozzle } \\
\hline $\begin{array}{l}333 \\
327 \\
324 \\
322 \\
332 \\
331\end{array}$ & $\begin{array}{l}1-4 \\
2-4 \\
3-4 \\
4-4 \\
5-4 \\
6-4\end{array}$ & $\begin{array}{l}0.0625 \\
0.0275 \\
0.0156 \\
0.0100 \\
0.0069 \\
0.0051\end{array}$ & $\begin{array}{l}20 \\
20 \\
20 \\
20 \\
20 \\
20\end{array}$ & $\begin{array}{l}\ddot{566} \\
563 \\
573 \\
569 \\
571\end{array}$ & $\begin{array}{r}1160 \\
114 \\
82 \\
71 \\
48\end{array}$ \\
\hline
\end{tabular}

B. Subsonic Nozzle

\begin{tabular}{l|l|l|l|l|l}
\hline 328 & $1-4$ & 0.0625 & 0 & $\ldots \ddot{1}$ & $\ldots$ \\
326 & $2-4$ & 0.0275 & 0 & 545 & 272 \\
323 & $3-4$ & 0.0156 & 0 & 563 & 190 \\
320 & $4-4$ & 0.0100 & 0 & 572 & 106 \\
319 & $5-4$ & 0.0069 & 0 & 572 & 80 \\
316 & $6-4$ & 0.0051 & 0 & 578 & 66 \\
\hline
\end{tabular}




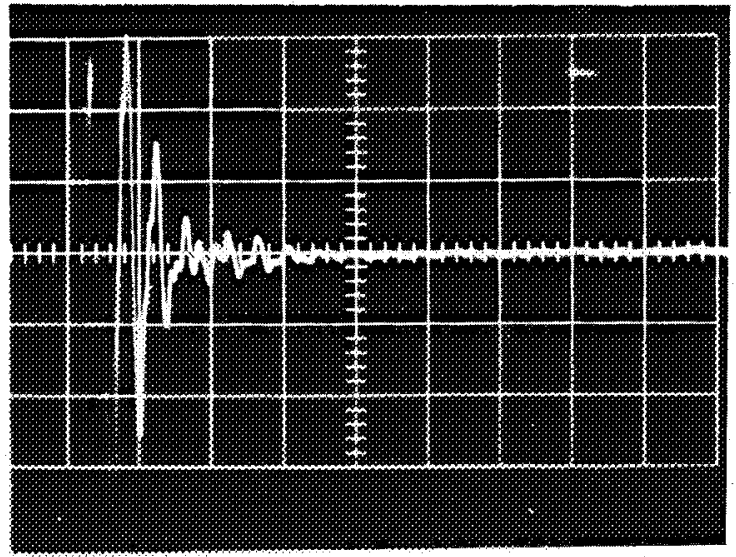

Test 333

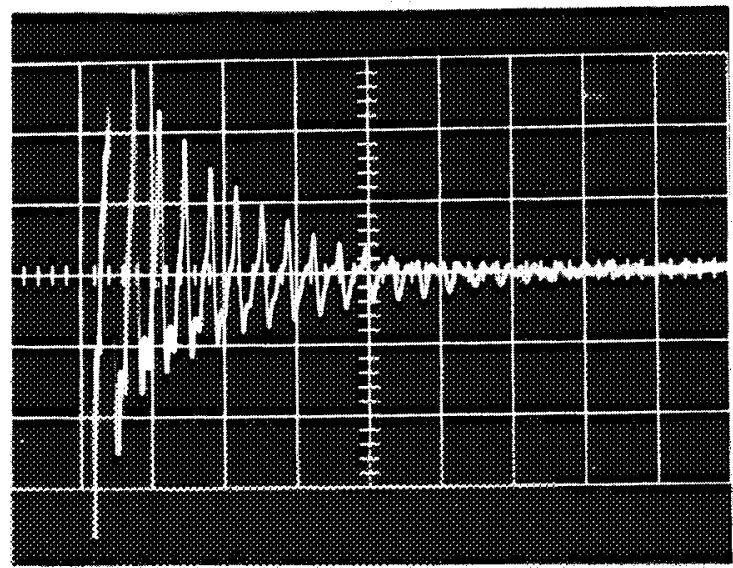

Test 324

$J=.0156$

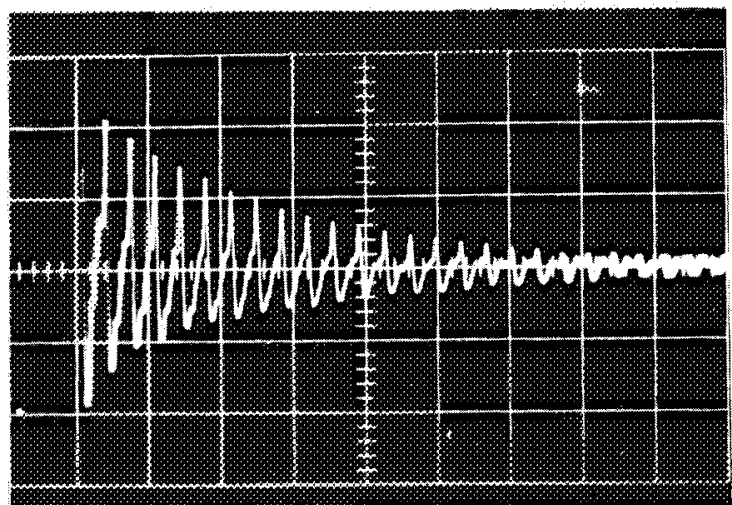

Test 332

$$
J=.0069
$$

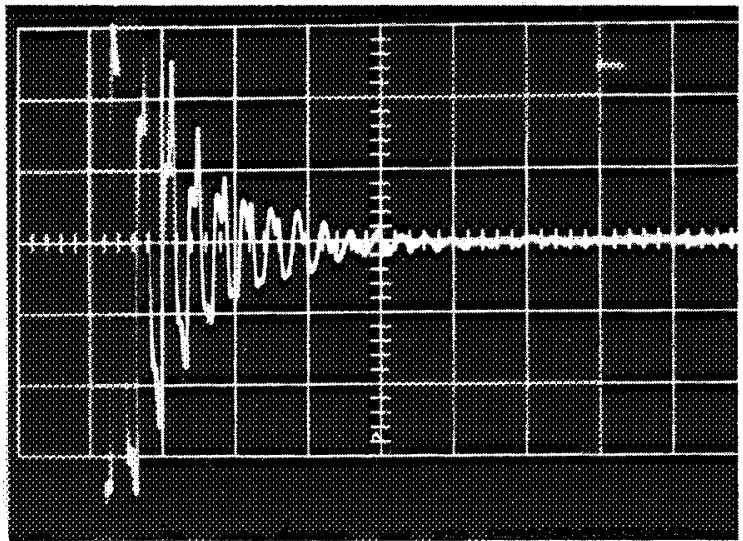

Test 327

$J=.0275$

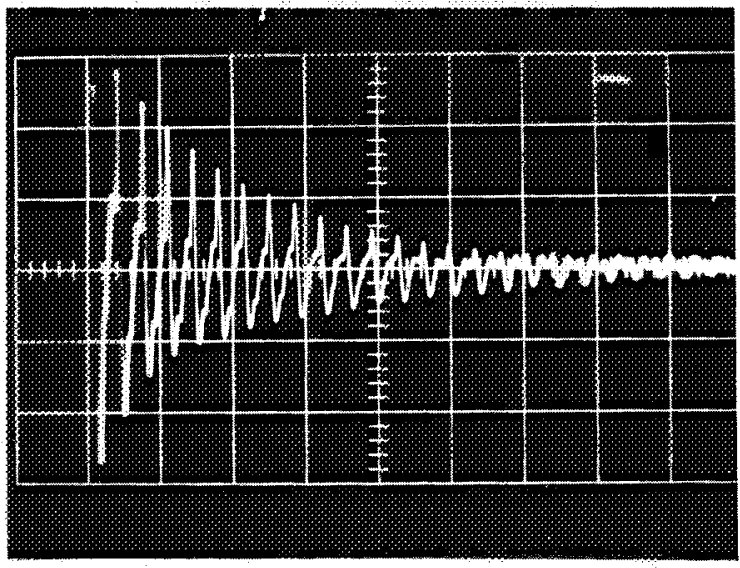

Test $322 \quad J=.0100$

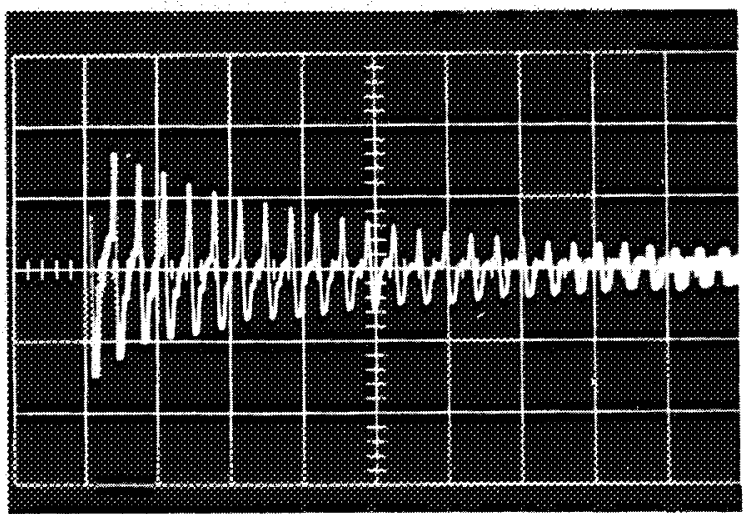

Test 331

FIG. 29. Oscilloscope Records From Burst Diaphragm Tests Using Nozzle No. 4 and Increasing Grain Port Area. Chamber pressure $=20$ psig. Horizontal sweep $=5 \mathrm{milli} \mathrm{sec} / \mathrm{cm}$. 


\section{STEADY-STATE DECAY TESTS}

There were several possible reasons for the higher decay rates observed in the pulse tests. To determine which factors were relevant, however, required greater control of the driver. This was possible using steady-state decay tests.

In this technique, the chamber was driven acoustically through the gun barrel assembly at the head of the chamber by an electro-pneumatic driver (Ling Model EPT-94A) which modulated a small portion of the inflow. The advantage of this device was that, because of its high damping rate, the valve could be cut off within one cycle (unlike the Varidrive system) and the decay of the standing wave in the chamber observed. Since prior to cut-off the valve was tuned to the resonant frequency of the chamber, higher order harmonics (such as appeared in the burst diaphragm tests) were avoided giving the damping constant associated with a particular mode.

The results of these tests are tabulated in Table 8 with oscilloscope records shown in Fig. 30. The upper curve in each of the pictures is for the pressure measured in the motor chamber. The lower curve is for the driving function supplied by the Ling valve. As can be seen, the driver damping is quite rapid. The acoustic attenuation constants obtained from these records agree very closely with those calculated from the steady-state resonance results.

TABLE 8. Steady-State Decay Data, Nozzle No. 3

\begin{tabular}{|c|c|c|c|c|c|}
\hline $\begin{array}{c}\text { Test } \\
\text { number }\end{array}$ & Geometry & $\mathrm{J}$ & $\begin{array}{c}\text { Chamber } \\
\text { pressure, } \\
\text { psig }\end{array}$ & $\begin{array}{l}f_{0}, \\
\text { cps }\end{array}$ & $\sec ^{\alpha}$ \\
\hline $\begin{array}{l}7-20-18 \\
7-20-16 \\
7-20-13 \\
7-20-10 \\
7-20-21 \\
7-20-19\end{array}$ & $\begin{array}{l}1-3 \\
2-3 \\
3-3 \\
4-3 \\
5-3 \\
6-3\end{array}$ & $\begin{array}{l}0.1407 \\
0.0625 \\
0.0351 \\
0.0225 \\
0.0156 \\
0.0115\end{array}$ & $\begin{array}{l}\sim 20 \\
\sim 20 \\
\sim 20 \\
\sim 20 \\
\sim 20 \\
\sim 20\end{array}$ & $\begin{array}{l}\ddot{536} \\
560 \\
561 \\
556 \\
556\end{array}$ & $\begin{array}{r}130.1 \\
91.1 \\
45.1 \\
35.5 \\
19.3\end{array}$ \\
\hline
\end{tabular}

DATA REDUCTION

The data reduction procedure for the transient tests was considerably easier than the procedure used for the oscillograph steady-state tests, but not as convenient as the automated system. A test record such as those shown in Fig. 30 was taped down, a piece of tracing paper 


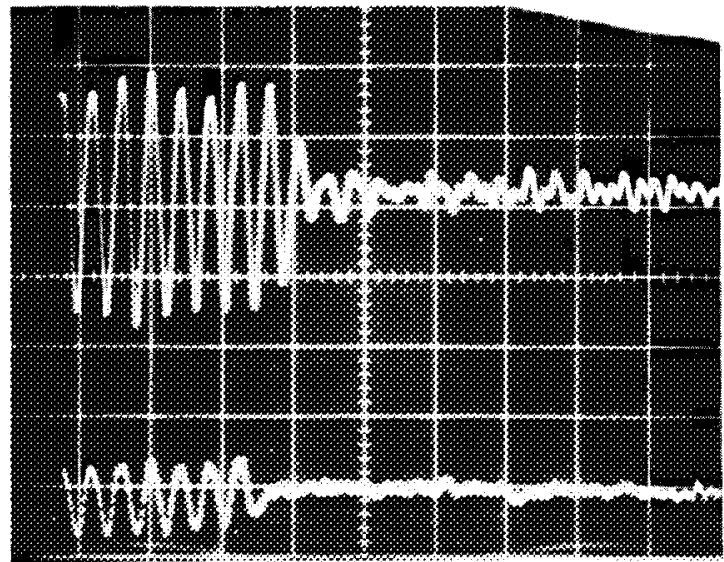

Test $7-20-18 \quad J=.1407$

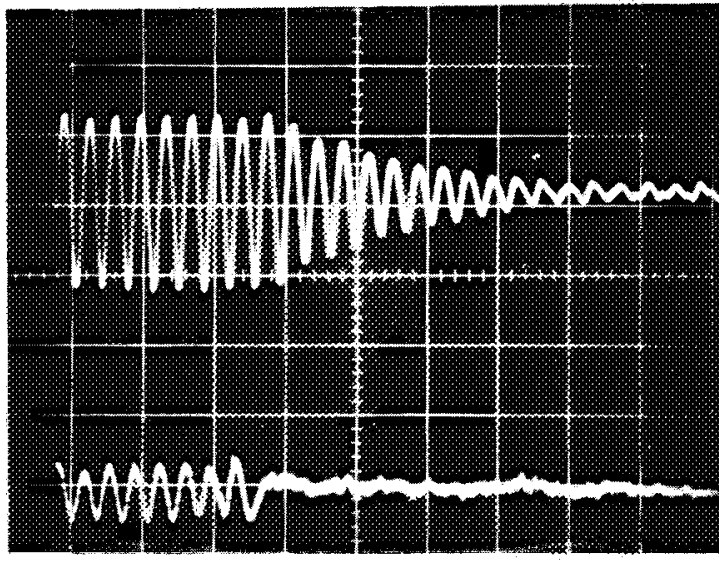

Test $7-20-13 \quad J=.0351$

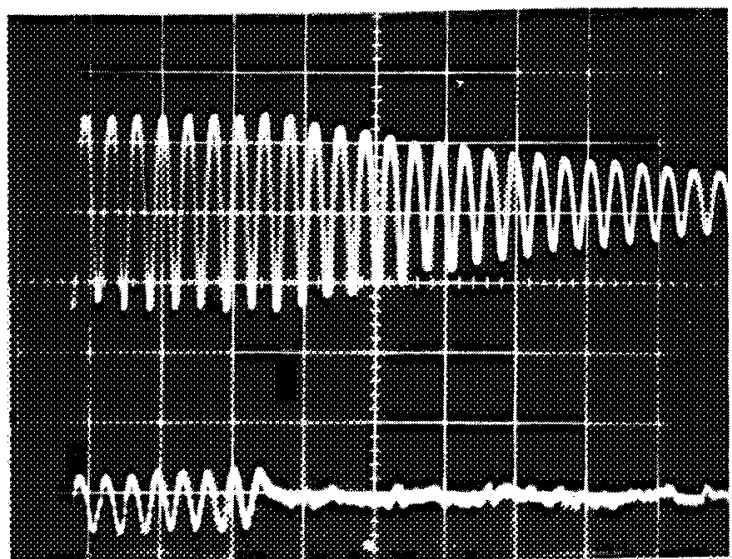

Test $7-20-21 \quad J=.0156$

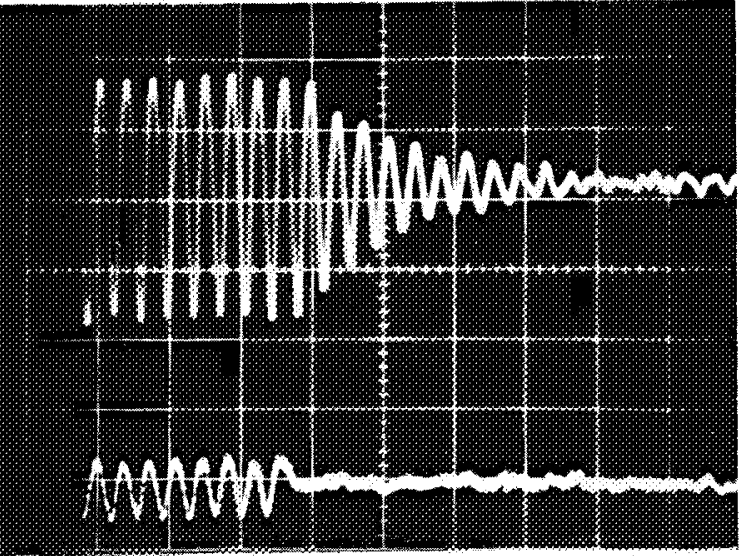

Test $7-20-16 \quad J=.0625$

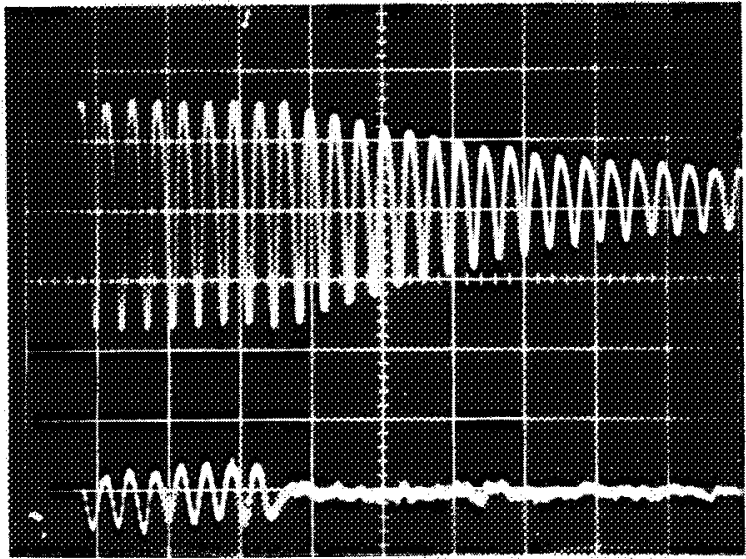

Test $7-20-10 \quad J=.0225$

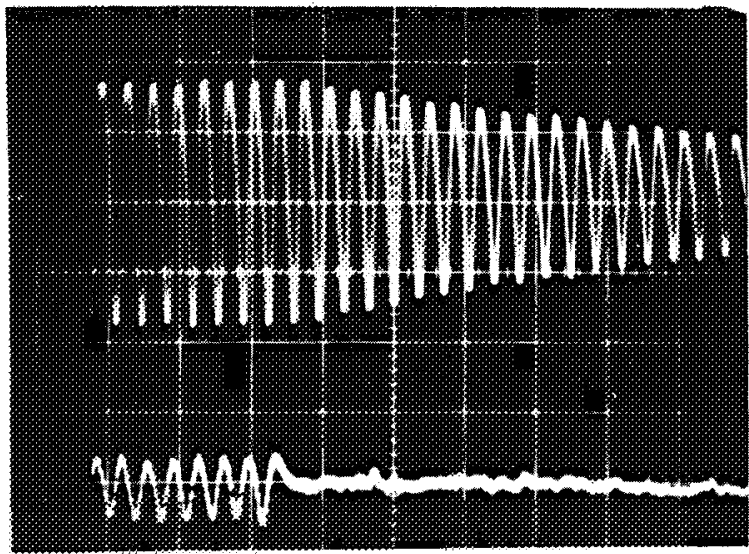

Test $7-20-19 \quad \mathrm{~J}=.0115$

FIG. 30. Oscilloscope Records From Steady-State Decay Tests Using Nozzle No. 3 and Increasing Grain Port Areas. Upper trace is chamber response. Lower trace is driving function. Chamber pressure $=20 \mathrm{psig}$. Horizontal sweep $=5 \mathrm{millisec} / \mathrm{cm}$. 
placed on top, and an envelope for the curve drawn through the peak pressure points. Then, starting with one peak, the width of this envelope was measured at several consecutive decreasing pressure peaks. Knowing the scope sweep rate, the frequency was determined using these same pressure peaks, and thus the time between each peak or the period was known. These results were plotted on semi-log graph paper, a typical graph being shown in Fig. 31. A straight line was drawn through the greatest number of points, since the probable accuracy of the data would not justify further treatment.

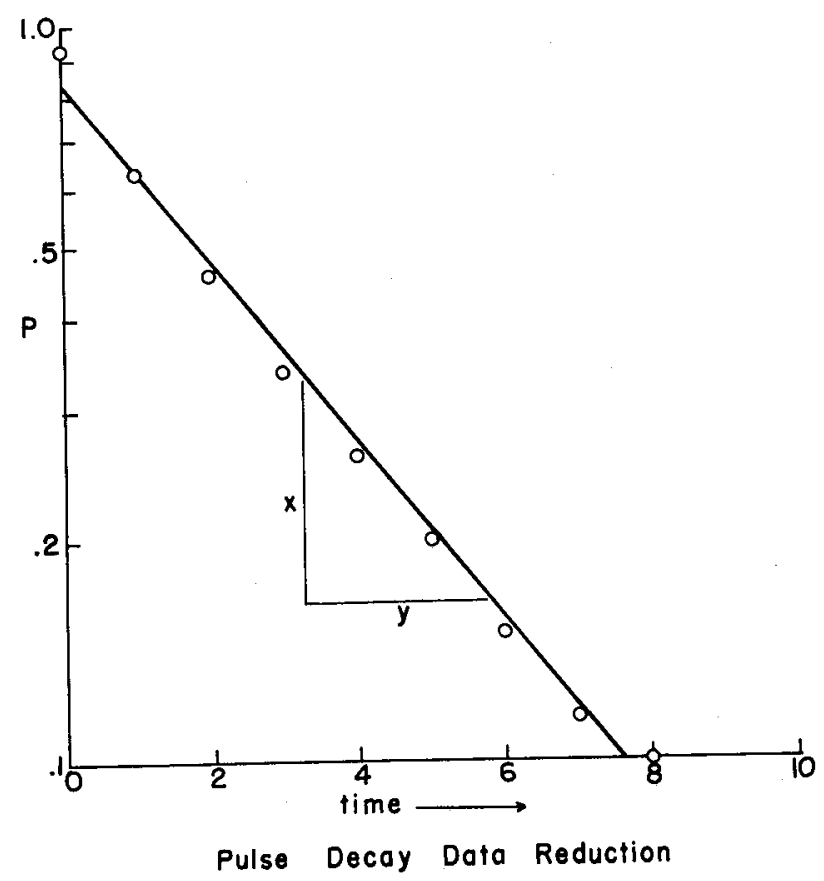

FIG. 31. A Typical Intermediate Graph Used in the Data Reduction to Obtain the Acoustic Attenuation Constant. Each point is for a consecutive pressure peak.

A straight line correlation of the data is equivalent to assuming an exponential decay rate and therefore one may write: 


$$
\begin{aligned}
& p=p_{0} e^{-\alpha t} \\
& \ln p=\ln p_{0}-\alpha t \\
& 2.3 \log p=2.3 \log p_{0}-\alpha t \\
& \log p=\log p_{0}-\frac{\alpha t}{2.3}
\end{aligned}
$$

here $\log p_{0}$ is the intercept with the $y$-axis and $\alpha$ is the slope of the line. This slope can be determined by taking two points and use of Eq. 14.

Thus

$$
\alpha=2.3 \frac{\log p_{2}-\log p_{1}}{t_{1}-t_{2}}
$$

or to account for scale factors of the graph

$$
\alpha=2.3 \frac{(\Delta \log p \text { inches })\left(\frac{\text { cycles }}{\text { inch }}\right)}{(\Delta t \text { inches })\left(\frac{\text { seconds }}{\text { inch }}\right)}
$$

The value of $\alpha$ may thus be determined by direct measurement of the differences between the abscissas and between the ordinates of any two points on the graph. The differences between the abscissas and between the ordinates of two points may now be measured directly with a ruler from the graph paper. In the present work, the points were taken at the extreme left and right when possible so as to measure the largest possible values and thus reduce the error.

\section{TEST RESULTS AND DISCUSSION}

The attenuation constant as a function of $J$ obtained by the above techniques are plotted in Fig. 32. The observed frequency as a function of $J$ for each is plotted in Fig. 33. The attenuation constants obtained from the burst diaphragm tests using Nozzle No. 4 were not plotted with these data but, when compared with other Nozzle No. 4 data, they were between the blank cartridge and steady-state results. The pulse techniques showed 
higher losses than either the steady-state resonance or the steadystate decay tests. Though sufficient tests were not made to definitely establish the reasons for these differences, the following factors are believed to contribute to the increased damping

1. Temperature Effect

2. Condensed Phase Damping

3. Appearance of Higher Modes, resulting in:

a. Increased viscous damping

b. Phase drift of different modes resulting in drift of wave form and apparent change in "decay rate"

The steady-state decay results are essentially the same as those from the steady-state resonance technique. This strongly supports the use of the lumped parameter, half-power bandwidth method for simple geometries since the decay measurements involve no assumptions and are thus a more direct, though somewhat more laborious, method of getting the attenuation constant.

\section{CONCLUSIONS CONCERNING DECAY METHODS}

The following interpretations and summary of results of the decay rate tests can be made:

1. Pulse tests using a blank cartridge are not as simple as originally thought in that they alter the working fluid by changing the gas temperature, the gas composition, and are apt to introduce condensed phase material causing particle damping.

2. Pulse tests using either a blank cartridge or a burst diaphragm showed that there was virtually no control on which acoustic modes of the cavity were driven. Thus, the test records exhibited multiplemode decay which quite possibly resulted in higher attenuation constants.

3. By the steady-state decay technique the characteristics of the working fluid in the chamber were known and it was possible to control the mode frequency to be studied.

4. The steady-state decay technique gave an independent confirmation of the lumped parameter, half-power bandwiath method of determining the attenuation constant. The use of this technique therefore strongly supports the previous steady-state resonance data since the decay measurements involve no assumptions and are thus a more direct method of getting the attenuation constant. 
5. Although the steady-state decay technique is a direct method of determining the attenuation constant, it is limited at present to geometry configurations with small $J$ values. This is due to the extremely rapid damping that occurs at higher J's. Using the steadystate resonance method all geometries could be tested.

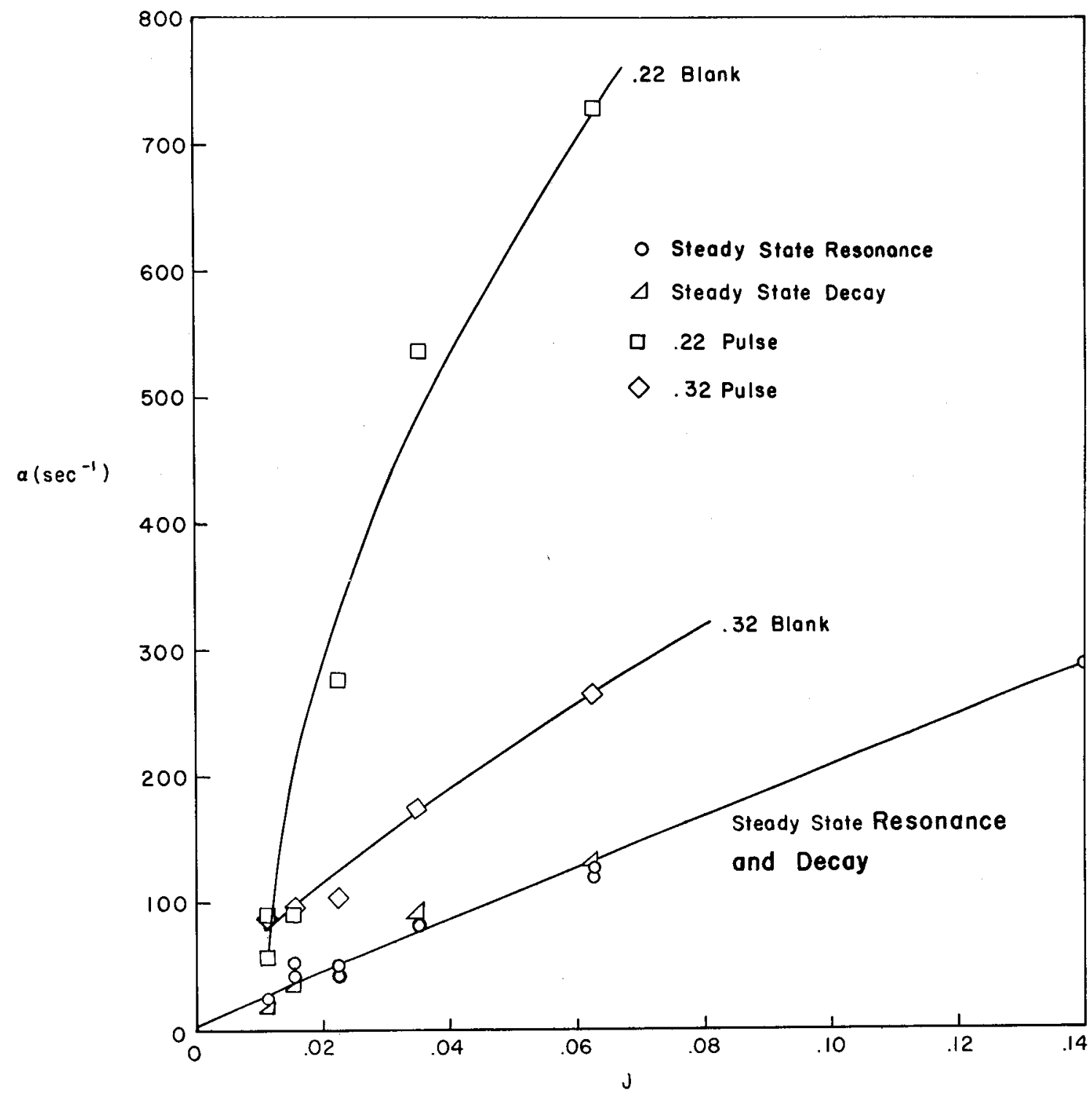

FIG. 32. Comparison of the Attenuation Coefficients Obtained Using Steady-State Resonance Technique With Those From Steady-State Decay and Blank Cartridge Tests. Chamber pressure $=20$ psig. Nozzle No. 3 (throat diameter $=0.375 \mathrm{inch}$ ). 


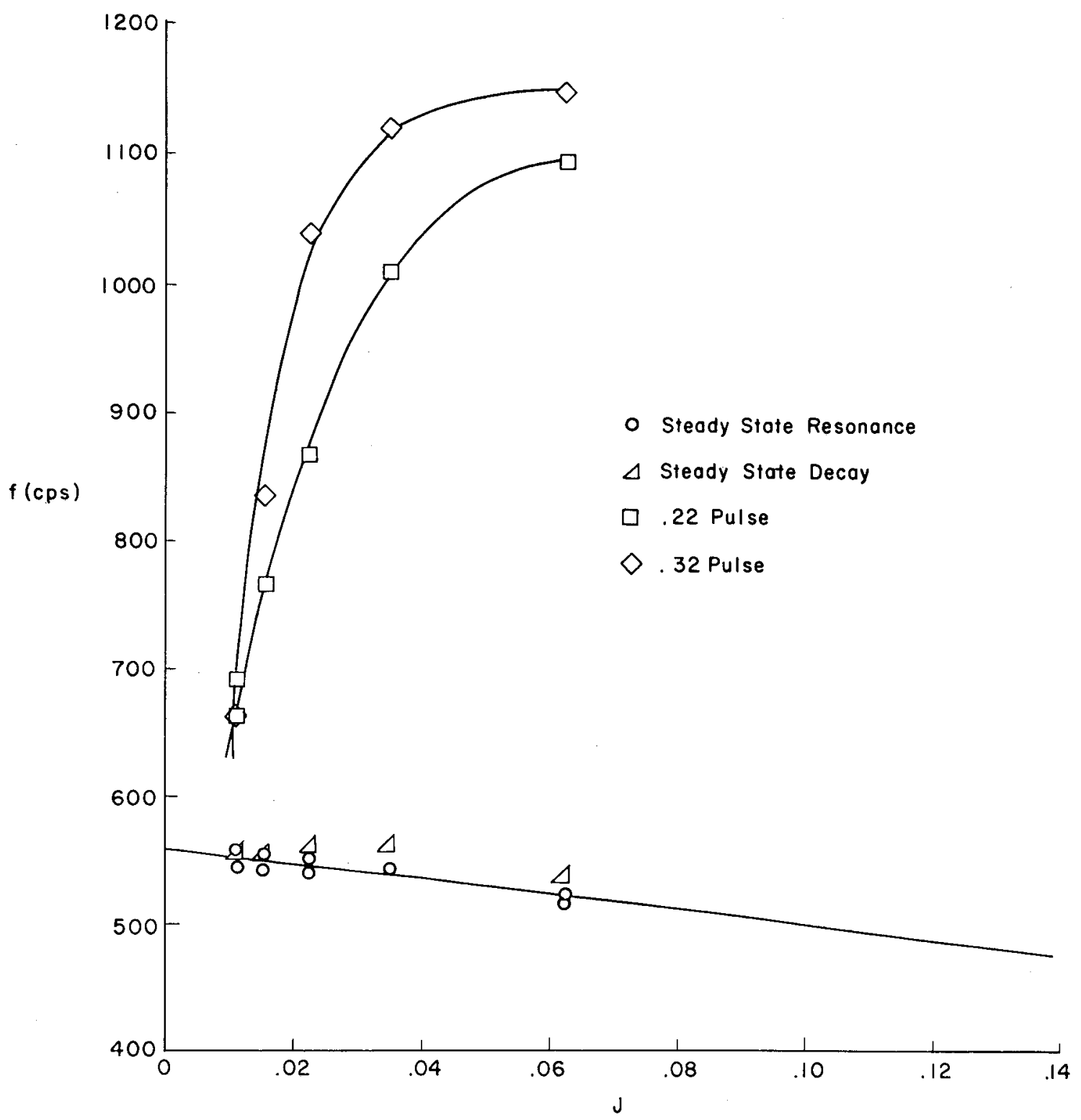

FIG. 33. Comparison of the First Mode Resonance Frequency Obtained Using Different Means of Excitation. Chamber at 20 psig. Nozzle \#3 (throat diameter $=.375$ inch). 


\section{REFERENCES}

1. Price, E. W. "Experimental Solid Rocket Combustion Instability," in Tenth Symposium (International) on Combustion, Pittsburgh, Combustion Institute, 1965, Pp. 1067-82.

2. U. S. Naval Ordnance Test Station. Attenuation of Axial Acoustic Modes in a Model Missile Motor, by F. G. Buffum, H. B. Mathes, R. O. Slates, and E. W. Price. China Lake, Calif., NOTS, July 1965. (NAVWEPS Report 8643, NOTS TP 3684.)

3. Mathes, H. B. "Effect of Geometrical Variables on Losses in Motors as Determined by Cold-Flow Model Testing," Proceedings of the First Interagency Chemical Rocket Propulsion Group Combustion Instability Conference, Chemical Propulsion Information Agency Publication No. 68, Vol. I, January 1965, pp 443-451.

4. Hueter, T. F., and R. H. Bolt. Sonics, New York, Wiley, 1955.

5. Morse, P. M. Vibration and Sound, 2nd ed. New York, McGraw-Hill, 1948.

6. Green, E. I. "The Story of Q," Am Scientist, Vol. 43, No. 4 (October 1955), pp. 584-94.

7. Terman, F. E. Radio Engineering, 3rd ed. New York, McGraw-Hill, 1947.

8. Kinsler, L. E., and A. R. Frey. Fundamentals of Acoustics, 2nd ed. New York, Wiley, 1962.

9. Richardson, E. G., and E. Meyer. Technical Aspects of Sound. Amsterdam-New York, Elsevier, 1962. Chapter 3, "Flow Noise," pp. $123-77$.

10. Cantrell, R. H., F. T. McClure, and R. W. Hart. "Acoustic Damping in Cavities with Mean Velocity and Thermal Boundary Layers," Acous Soc Am, J, Vol. 35, No. 4 (April 1963), pp. 500-9.

11. Hart, R. W., and F. T. McClure. "Theory of Acoustic Instability in Solid-Propellant Rocket Combustion," in Tenth Symposium (International) on Combustion. Pittsburgh, Combustion Institute, 1965. Pp. $1047-65$. 
12. Ingram, J. D. A Survey of Aerodynamic Noise, Air Force Flight Development Lab, Wright-Patterson Air Force Base, Ohio, FDL-TDR64-132, December 1964.

13. Crocco, L., and S. I. Cheng. "Theory of Combustion Instability," in Liquid Propellant Rocket Motors. London, Butterworths Scientific Publications, 1956.

14. Shapiro, A. H. The Dynamics and Thermodynamics of Compressible Fluid Flow. New York, Ronald, 1953.

15. Payman, William, "Explosion waves and shock waves VI. The disturbance produced by bursting diaphragms with compressed air" ROY SOC LONDON, PROC. Ser. A, Vol 186 (1946), pp. 293-321.

16. Crocco, L., R. Mont1, and J. Grey. "Verification of Nozzle Admittance Theory by Direct Measurement of the Admittance Parameter," ARS, J, (June 1961), pp. 771-5.

17. U. S. Naval Ordnance Test Station. Approximate Theory for Acoustic Losses from Model Rocket Chambers with Flow, by R. O. Slates, G. L. Dehority, H. H. Bradley, Jr., F. G. Buffum, and E. W. Price. China Lake, Calif., NOTS. To be published as NAVWEPS Report 9011 , NOTS TP 3993. 
UNCLASSIFIED

Security Classification

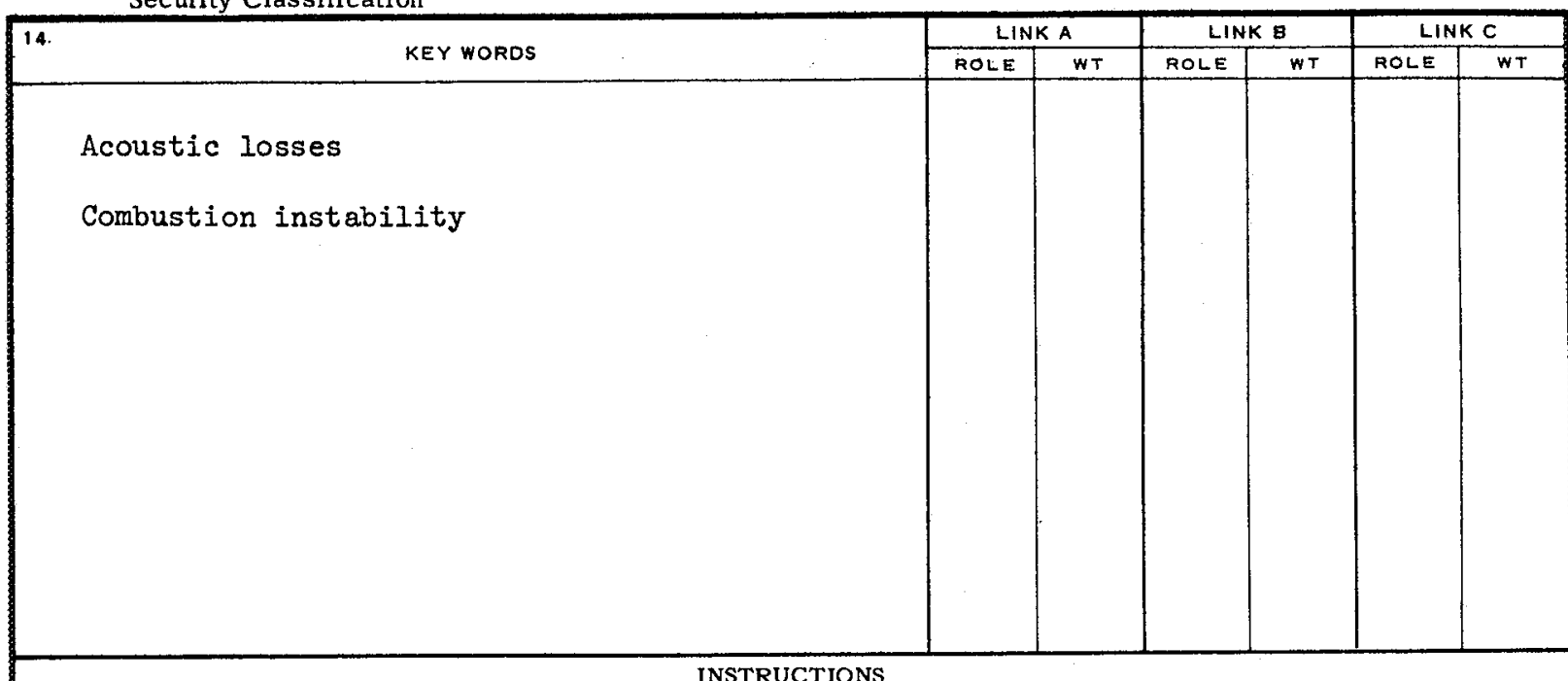

1. ORIGINATING ACTIVITY: Enter the name and address of the contractor, subcontractor, grantee, Department of Defense activity or other organization (corporate author) issuing the report.

2a. REPORT SECURTY CLASSIFICATION: Enter the overall security classification of the report. Indic ate whether "Restricted Data" is included. Marking is to be in accordance with appropriate security regulations.

2b. GROUP: Automatic downgrading is specified in DoD Directive 5200.10 and Armed Forces Industrial Manual. Enter the group number. Also, when applicable, show that optional markings have been us ed for Group 3 and Group 4 as authorized.

3. REPORT TITLE: Enter the complete report title in all capital letters. Titles in all cases should be unclassified.

If a meaningful title cannot be selected without classification, show title classification in all capitals in parenthesis immediately following the title.

4. DESCRIPTIVE NOTES: If appropriate, enter the type of report, e.g., interim, progress, summary, annual, or final. Give the inclusive dates when a specific reporting period is covered.

5. AUTHOR(S): Enter the name(s) of author(s) as shown on or in the report. Enter last name, first name, middle initial. If military, show rank and branch of service. The name of the principal author is an ahsolute minimum requirement.

6. REPORT DATE: Enter the date of the report as day, month, year; or month, year. If more than one date appears on the report, use date of publication.

7a. TOTAL NUMBER OF PAGES: The total page count should follow normal pagination procedures, i.e., enter the number of pages containing information

7b. NUMBER OF REFERENCES: Enter the total number of references cited in the report.

8a. CONTRACT OR GRANT NUMBER: If appropriate, enter the applicable number of the contract or grant under which

the report was written.

8b, 8c, 8 8d. PROJECT NUMBER: Enter the appropriate military department identification, such as project number, subproject number, system numbers, task number, etc.

9a. ORIGINATOR'S REPORT NUMBER(S): Enter the official report number by which the document will be identified and controlled by the originating activity. This number must be unique to this report.

9b. OTHER REPORT NUMBER(S): If the report has been assigned any other report numbers (either by the originato or by the sponsor), also enter this number(s).

10. AVAILABILITY/LIMITATION NOTICES: Enter any limitations on further dissemination of the report, other than those imposed by security classification, using standard statements such as:

(1) "Qualified requesters may obtain copies of this report from DDC."

(2) "Foreign announcement and dissemination of this report by DDC is not authorized."

(3) "U. S. Government agencies may obtain copies of this report directly from DDC. Other qual ified DDC users shall request through

(4) "U. S. military agencies may obtain copies of this report directly from DDC. Other qualified users shall request through

(5) "All distribution of this report is controlled. Qualified DDC users shall request through ."

If the report has been furnished to the Office of Technical Services, Department of Commerce, for sale to the public, indicate this fact and enter the price, if known

11. SUPPLEMENTARY NOTES: Use for additional explanatory notes.

12. SPONSORING MILITARY ACTIVITY: Enter the name of the departmental project office or laboratory sponsoring (paying $f \circ$ ) the research and development. Include address.

13. ABSTRACT: Enter an abstract giving a brief and factual summary of the document indicative of the report, even though it may aiso appear elsewhere in the body of the technical report. If additional space is required, a continuation sheet shall be attached.

It is highly desirable that the abstract of classified reports be unclassified. Each paragraph of the abstract shall end with an indication of the military security classification of the in formation in the paragraph, represented as $(T S),(S),(C)$, or (U).

There is no limitation on the length of the abstract. How. ever, the suggested length is from 150 to 225 words.

14. KEY WORDS: Key words are technically meaningful terms or short phrases that characterize a report and may be used as index entries for cataloging the report. Key words orust be selected so that no security classification is required. Identifiers, such as equipment model designation, trade name, militar project code name, geographic location, may be used as key words but witl be followed by an indication of technical context. The assignment of links, roles, and weights is optional. 


\section{DOCUMENT CONTROL DATA - R\&D}

(Socurity clasalfication of titlo, body of abstract and indexing annotation must be entered when the overall report is classified)

1. ORIGINATING ACTIVITY (Corporato author)
U. S. Naval Ordnance Test Station
China Lake, California 93555

\section{UNCLASSIFIED}

2b. GROUP

None

3. REPORT TITLE

ACOUSTIC IOSSES OF A SUBSCALE, COLD-FLOW ROCKET MOTOR FOR VARIOUS "J" VALUES

4. DESCRIPTIVE NOTES (Type of report and inclusive dates)

Research report

5. AUTHOR(S) (Last name, first name, initial)

Buffum, F. G.; Dehority, G. L.; Slates, R. O.; Price, E. W.

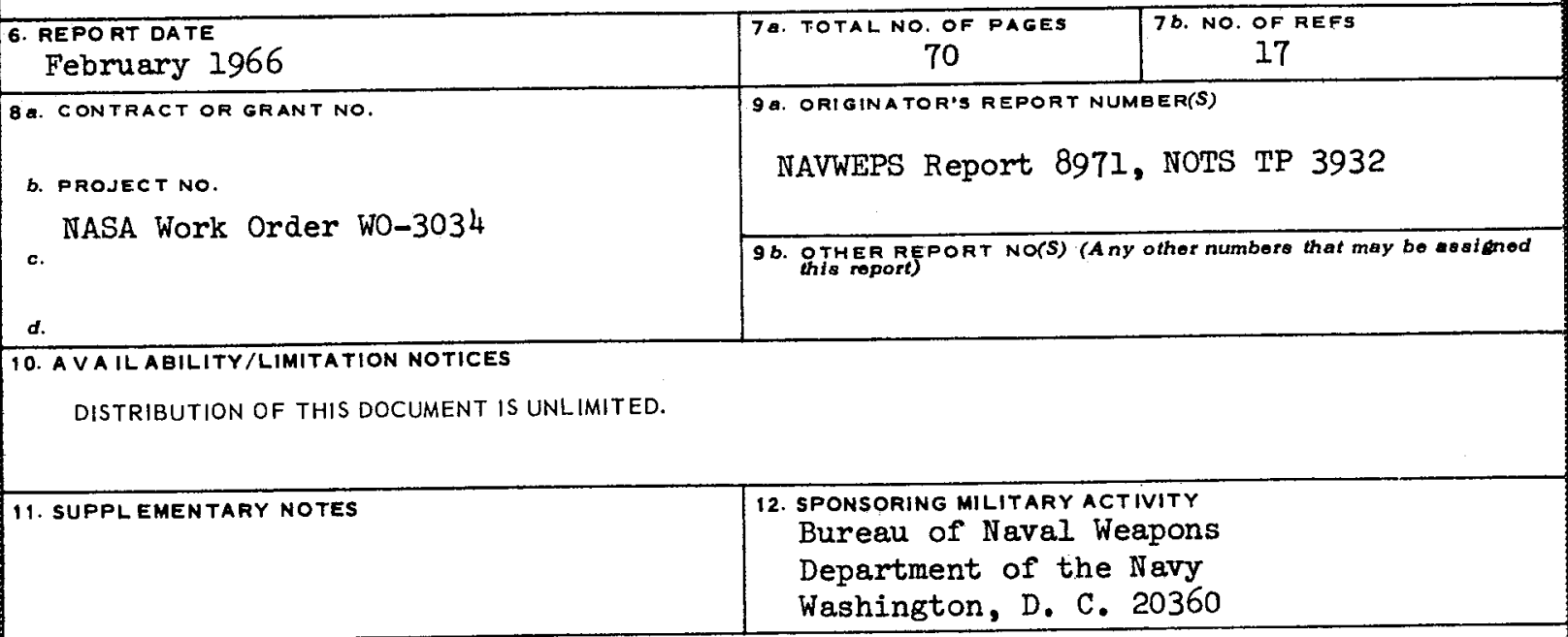

13. ABSTRACT

Acoustic dissipation studies were undertaken using a subscale, cold-flow rocket motor model to determine the effect of purely geometric variables on the acoustic performance leading to axial mode combustion instability. Cold air served as the working fluid to simulate the internal flow and to obtain a critical nozzle throat condition. Using interchangeable metal parts, it was possible to simulate the geometry of a cylindrical-bore grain at various real motor burn times and also to vary the nozzle throat diameter. The results confirmed the speculation that, for practical motor designs, the radiation of acoustic energy through the nozzle is the largest source of loss for the axial mode and increases with the $J$ of the motor. In view of the change in $\mathrm{J}$ with time during burning, this loss can vary conspicuously during the motor burn time. 


\section{NAVWEPS REPORT 8971}

axial mode combustion instability. Cold air served as the working fluid to simulate the internal flow and to obtain a critical nozzle throat condition. Using interchangeable metal parts, it was possible to simulate the geometry of a cylinarical-bore grain at various real motor burn times and also to vary the nozzle throat diameter. The results confirmed the speculation that, for practical motor designs, the radiation of acoustic energy through the nozzle is the largest source of loss for the axial mode and increases with the $J$ of the motor. In view of the change in $J$ with time during burning, this loss can vary conspicuously during the motor burn time.

\section{NAVWEPS REPORT 8971}

axial mode combustion instability. Cold air served as the working fluid to simulate the internal flow and to obtain a critical nozzle throat condition. Using interchangeable metal parts, it was possible to simulate the geometry of a cylindrical-bore grain at various real motor burn times and also to vary the nozzle throat diameter. The results confirmed the speculation that, for practical motor designs, the radiation of acoustic energy through the nozzle is the largest source of loss for the axial mode and increases with the $J$ of the motor. In view of the change in $J$ with time during burning, this loss can vary conspicuously during the motor burn time.
NAVWEPS REPORT 8971

axial mode combustion instability. Cold air served as the working fluid to simulate the internal flow and to obtain a critical nozzle throat condition. Using interchangeable metal parts, it was possible to simulate the geometry of a cylindrical-bore grain at various real motor burn times and also to vary the nozzle throat diameter. The results confirmed the speculation that, for practical motor designs, the radiation of acoustic energy through the nozzle is the largest source of loss for the axial mode and increases with the $J$ of the motor. In view of the change in $J$ with time during burning, this loss can vary conspicuously during the motor burn time.

\section{NAVWEPS REPORT 8971}

axial mode combustion instability. Cold air served as the working fluid to simulate the internal flow and to obtain a critical nozzle throat condition. Using interchangeable metal parts, it was possible to simulate the geometry of a cylindrical-bore grain at various real motor burn times and also to vary the nozzle throat diameter. The results confirmed the speculation that, for practical motor designs, the radiation of acoustic energy through the nozzle is the largest source of loss for the axial mode and increases with the $J$ of the motor. In view of the change in $J$ with time during burning, this loss can vary conspicuously during the motor burn time. 
U. S. Naval Ordnance Test Station Acoustic Losses of a Subscale, Cold-Flow Rocket Motor for Various "J" Values, by F. G. Buffum, G. L. Dehority, R. O. Slates, and E. W. Price. China Lake, Calif., NOTS, February 1966. 70 pp. (NAVWEPS Report 8971, NOTS TP 3932), UNCLASSIFIED.

ABSTRACT. Acoustic dissipation studies were undertaken using a subscale, cold-flow rocket motor model to determine the effect of purely geometric variables on the acoustic performance leading to

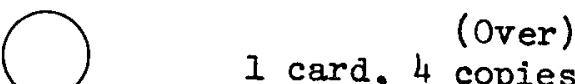

U. S. Naval Ordnance Test Station

Acoustic Losses of a Subscale, Cold-Flow Rocket Motor for Various "J" Values, by F. G. Buffum, G. L. Dehority, R. O. Slates, and E. W. Price. China Lake, Calif., NOTS, February 1966. 70 pp. (NAVWEPS Report 8971, NOTS TP 3932), UNCLASSIFIED.

ABSTRACT. Acoustic dissipation studies were undertaken using a subscale, cold-flow rocket motor model to determine the effect of purely geometric variables on the acoustic performance leading to

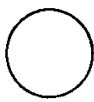

I card, 4 copies
U. S. Naval Ordnance Test Station

Acoustic Losses of a Subscale, Cold-Flow Rocket Motor for Various "J" Values, by F. G. Buffum, G. L Dehority, R. O. Slates, and E. W. Price. China Lake, Calif., NOTS, February 1966. 70 pp. (NAVWEPS Report 8971, NOTS TP 3932), UNCLASSIFIED.

ABSTRACT. Acoustic dissipation studies were undertaken using a subscale, cold-flow rocket motor model to determine the effect of purely geometric variables on the acoustic performance leading to

$$
11 \text { card, } 4 \text { copies }
$$

U. S. Naval Ordnance Test Station

Acoustic Losses of a Subscale, Cold-Flow Rocket Motor for Various "J" Values, by F. G. Buffum, G. L. Dehority, R. O. Slates, and E. W. Price. China Lake, Calif., NOTS, February 1966. 70 pp. (NAVWEPS Report 8971, NOTS TP 3932), UNCLASSIFIED.

ABSTRACT. Acoustic dissipation studies were undertaken using a subscale, cold-flow rocket motor model to determine the effect of purely geometric variables on the acoustic performance leading to 
11 Chief, Bureau of Naval Weapons

DLI-3I (2)

DSC-322 (1)

$\mathrm{RM}-35$ (1)

RMMP (I)

RMMP-II (I)

RMMP-21 (1)

RMMP-4 (1)

RMMP-43 (1)

$\mathrm{RR}$ (1)

RRRE (1)

2 Special Projects Office

Sp-005 (I)

$\mathrm{sp}-273$ (I)

2 Chief of Naval Research

Code 104 (I)

Code 426 (1)

2 Naval Ordnance Laboratory, White Oak (Technical Library)

2 Naval Propellant Plant, Indian Head

2 Naval Weapons Services Office (Code DM)

1 Bureau of Naval Weapons Representative, Sunnyvale (CDR P. S. McManus)

2 Army Ballistics Research Laboratories, Aberdeen Proving Ground

3 Army Missile Command, Redstone Arsenal

ORDXR-OXT, H. Hinrichs (1)

Redstone Scientific Information Center (2)

I Army Research Office, Durham

2 Frankford Arsenal

Pitman-Dunn Laboratory (1)

Technical Library (1)

1 Harry Diamond Laboratories (ORDTL OI2)

1 Picatinny Arsenal (Technical Library)

I White Sands Missile Range (ORDBS-Technical Library)

1 Air Force Office of Scientific Research (SRDL, Lt. Col. P. C. Atkinson)

1 Air Proving Ground Center, Eglin Air Force Base (PGBAP-1)

1 Systems Engineering Group, Deputy for Systems Engineering, WrightPatterson Air Force Base (SEPRR)

1 Director of Defense (R\&E)

I Advanced Research Projects Agency (Director)

1 Armed Services Explosive Safety Board (Technical Office)

20 Defense Documentation Center (TISIA-I)

1 Bureau of Mines, Pittsburgh (Reports Librarian)

8 National Aeronautics \& Space Administration

RPM, William Cohen (1)

RPS, Robert W. Ziem (5)

ATSS-AC, Technical Library (2) 


\section{6,32921}

2 George C. Marshall Space Flight Center

Alton I. Wheeler (I)

Technical Library (1)

I Goddard Space Flight Center (Technical Library)

2 Langley Research Center Robert L. Swain (1)

Technical Library (1)

2 Lewis Research Center

James J. Kramer (1)

Technical Library (1)

1 Manned Spacecraft Center (Technical Library)

1 National Aeronautics and Space Administration, Western Operations, Santa Monica (Eugene F. Wyszpolski)

1 Scientific and Technical Information Facility, Bethesda (NASA Representative, CRT)

1 Aerojet-General Corporation, Sacramento, via BWRR (Librarian)

I Aeronutronic, Newport Beach, Calif. (Division Librarian)

2 Allegany Ballistics Laboratory, Cumberland, Md. T. A. Angelus (I)

2 Applied Physics Laboratory, JHU, Silver Spring Dr. F. T. McClure (I)

1 Atlantic Research Corporation, Alexandria, Va.

52 Chemical Propulsion Information Agency, Applied Physics Laboratory, Silver Spring John Gunn (50)

1 E. I. du Pont de Nemours \& Company, Inc., Eastern Laboratory, Gibbstown, N. J.

1 Hercules Powder Company, Magna, Utah (Librarian)

1 Hercules Powder Company, Research Center, Wilmington (A. M. Ball)

1 Jet Propulsion Laboratory, CIT, Pasadena Chief, Reports Group (1)

1 Lockheed Propulsion Company, Redlands, Calif. (Librarian)

I Lincoln Laboratory, MIT, Lexington

I Princeton University, Forrestal Research Center, Princeton, N. J.

1 Rocketdyne, Canoga Park, Calif. (Dr. R. S. Levine)

1 Rocketdyne, McGregor, Tex. (E. F. Fiock)

I Rohm \& Haas Company, Redstone Arsenal Research Division (H. M. Shuey)

I Thiokol Chemical Corporation, Huntsville Division, Huntsville, Ala. (Technical Library)

I Thiokol Chemical Corporation, Wasatch Division, Brigham City (Technical Director)

I United Technology Center, Sunnyvale, Calif.

I University of Utah, Salt Lake City 